\title{
Report of the Workshop on the Comprehensive Assessment of Right Whales: A Worldwide Comparison
}

The Workshop was held at the Monkey Valley Beach Resort near Cape Town, South Africa from 19-25 March 1998. It was preceded by a two-day Symposium at the Two Oceans Aquarium, Cape Town.

\section{ARRANGEMENTS FOR THE MEETING}

\subsection{Practical details}

Best welcomed the participants to the meeting and took the opportunity to thank MTN Cape Whale Route for their co-sponsorship which had enabled the IWC to increase the number of scientists attending. The list of participants is given as Annex A.

\subsection{Terms of reference}

At its 1982 annual meeting the Commission had agreed to a pause in commercial whaling (the 'moratorium') from 1986. The relevant amendment to the Schedule had included the clause, 'the Commission will undertake a comprehensive assessment of the effects of this decision on whale stocks and consider modification of this provision and the establishment of other catch limits' (IWC, 1999).

The term 'Comprehensive Assessment' had not been defined by the Commission but was eventually defined by the Scientific Committee as an in-depth evaluation of the status of all whale stocks in the light of management objectives and procedures that would include: (1) the examination of current stock size; (2) recent population trends; (3) carrying capacity; and (4) productivity (e.g. see summary in Donovan, 1992).

In 1997 (IWC, 1997b) the Scientific Committee had appointed an intersessional steering group to plan a Workshop to initiate a worldwide comparative assessment of right whales. It noted that right whales have not been considered in any detail by the Committee since its Workshop held in 1983 (IWC, 1986a), since which time considerable new information has accrued. A striking aspect of the present understanding of right whale populations is the recent increase in Southern Hemisphere stocks and a corresponding lack of any detectable increase in Northern Hemisphere stocks. The Committee had agreed that an attempt to explain this contrast should be a major focus of the Comprehensive Assessment of right whales.

Past experience with other species has shown that such an assessment is almost inevitably an iterative procedure. In that context the Workshop noted that an important aim of the meeting was to identify any gaps in knowledge at both the methodological and data collection level, and to recommend ways in which they could be addressed.

\section{ELECTION OF CHAIRMAN}

Bannister was elected Chairman.

\section{APPOINTMENT OF RAPPORTEURS}

Donovan was appointed rapporteur with assistance from Reeves and others. Working Groups appointed their own rapporteurs. Reports of Working Groups are given as Annexes or incorporated into this report under the relevant Agenda Items.

\section{ADOPTION OF AGENDA}

The adopted Agenda is given as Annex B.

\section{REVIEW OF DOCUMENTS AND AVAILABLE MATERIAL}

A list of documents is given as Annex C. In addition, several participants provided relevant material and databases from their own datasets.

\section{SYSTEMATICS}

At the 1983 Workshop (IWC, 1986a), there was considerable discussion over the taxonomy of right whales. Schevill (1986) reviewed the historical development of right whale nomenclature. The 1983 Workshop had agreed to retain the generic distinction between bowhead whales (Balaena) and right whales (Eubalaena). It had also recommended that morphological distinctions between Eubalaena glacialis and Eubalaena australis be further examined.

At present (i.e. at the time of this Workshop), the IWC recognises the following:

E. glacialis $^{1}$ - Northern right whale;

E. australis $^{2}$ - Southern right whale.

However, irrespective of their taxonomic status, North Atlantic and North Pacific right whales are treated separately for the purposes of management and conservation. The Workshop noted that Rice (1998) in his review of the systematics and distribution of marine mammals, considers the Balaenidae to comprise two species: Balaena glacialis the black right whale; and Balaena mysticetus - the bowhead whale ${ }^{3}$.

The Northern and Southern Hemispheres serve as the geographic units for the classification currently recognised by the IWC and, at present, right whales are the only group of large whales for which such taxonomic distinctions are made. The modern classification of E. glacialis and $E$. australis is based upon a single morphological character in the orbital region of the skull (the alisphenoid bone) analysed

\footnotetext{
${ }^{1}$ Balaena glacialis Borowski 1781; Balaena japonica Lacépède 1818; or Balaena sieboldii Gray 1864.

${ }^{2}$ Balaena australis Desmoulins 1822.

${ }^{3}$ See Schaeff and Hamilton (1999) and Bannister et al. (1999). Both disagree with Rice's conclusion, preferring to retain Eubalaena and the two species glacialis and australis on the basis of recent usage, the result of the 1983 Workshop (IWC, 1986a) and this Workshop, genetic information and pending further investigation.
} 
in limited specimens from each hemisphere (Muller, 1954). However, this character appears to be ontogenetic, as it is variable in developmental stages between Northern and Southern Hemisphere specimens (B. Rommel, J. Mead, pers. comm.).

No study to date has examined other sources of character information (morphological or molecular) to assess the validity of the earlier classification based on traditional morphology (Desmoulins, 1822; Muller, 1954). Moreover, representative taxon or population sampling throughout the two species' range has not occurred. Specifically, there has been little or no reproducible information on North Pacific $E$. glacialis, and previous genetic results from $E$. australis have generally been based on one or two populations or geographic regions (Schaeff et al., 1991).

Historically, there has been conflicting taxonomic classification for North Pacific right whales. At various stages, the North Pacific right whale has either been classified as a sub-species of its North Atlantic counterpart (e.g. E. glacialis sieboldii) or elevated to full species status (E. sieboldii or E. japonica). Based primarily on morphometrics, the North Pacific right whale was considered closely related to North Atlantic E. glacialis, and both were considered taxonomically distinct from Southern Hemisphere right whales (Ivanova, 1961a; b).

To re-examine the systematics and classification of Eubalaena, SC/M98/RW23 examined mitochondrial DNA control region sequences from the three ocean basin forms of right whales (North Atlantic $(\mathrm{NA})=269$; North Pacific $(\mathrm{NP})=8$; Southern Oceans $(\mathrm{SO})=55)$. Population Aggregation Analysis (PAA) revealed that each of the three forms is characterised by a small number of diagnostic nucleotide positions $(\mathrm{NA}=3 ; \quad \mathrm{NP}=3 ; \quad \mathrm{SO}=4) . \quad \mathrm{A}$ phylogenetic analysis confirmed the grouping of mitochondrial lineages into three monophyletic clades concordant with the three forms. Furthermore, the phylogenetic analysis indicated that North Pacific right whales are more closely related to Southern Ocean right whales than they are to North Atlantic right whales, which appear ancestral in this phylogeny. The results are inconsistent with the current taxonomy and support an independent taxonomic status for each of the three. The conclusions should be tested further with additional samples from all three ocean areas. Further analysis should include the addition of South Pacific samples $(n=45$, SC/M98/RW22) as well as historic and current samples from North Pacific animals.

The Workshop recognised that questions of nomenclature are subject to the International Code of Zoological Nomenclature (e.g. see comment in Schevill, 1986). From the perspective of assessing the status of right whales, the Workshop agreed that its discussions under stock identity would provide sufficient basis for progress, irrespective of taxonomic status. It noted that the IWC Scientific Committee only considers questions of changing taxonomic status on the basis of published papers. It recommends that the further analyses outlined above are undertaken and that the Scientific Committee revisits the question of the taxonomic status of right whales after the results are published. ${ }^{4}$

\footnotetext{
${ }^{4}$ Editor's note: After a thorough review at the 2000 meeting, the IWC Scientific Committee agreed to retain the generic name Eubalaena for right whales, and to recognise three species: E. glacialis, the North Atlantic right whale; E. australis, the southern right whale; and $E$. japonica, the North Pacific right whale. The Workshop Report published here has been modified to reflect these changes.
}

\section{STOCK IDENTITY: DISTRIBUTION AND POPULATION SEPARATION}

There has been considerable discussion in recent years within the IWC regarding the concept of 'stock identity' (e.g. see IWC, 1990a; Donovan, 1991). In summary, from a management perspective, what must be initially determined is the 'unit' that is to be conserved. Such a unit is generally termed a 'management stock' and in ideal circumstances would normally be based on a true biological population, although it may be based on smaller 'groupings' (e.g. feeding aggregations which show strong site fidelity). What comprises a useful management stock cannot be viewed in isolation from the purpose for which it is being defined (e.g. see discussions with respect to the development of the RMP and AWMP, as well as discussion under Item 10.3). The Workshop agreed that it was not appropriate at this meeting to undertake a detailed philosophical review of the 'stock' concept, which in IWC terms has been closely linked to the question of the regulation of whaling operations.

From the perspective of right whales it was agreed that there was value in attempting to:

(1) identify present and past breeding (i.e. mating) and calving grounds as the basic 'management unit' (where possible the identity of true biological populations); and

(2) identify associated feeding areas.

The power and applicability of genetic techniques to identify separate populations has increased dramatically since the previous Workshop (e.g. see IWC, 1991; Dizon et al., 1997). Such information, combined with more 'traditional' approaches to examining stock identity within the IWC Scientific Committee, is discussed below.

The Workshop considered the available genetic information on population structure within each ocean basin according to three habitat classifications: calving grounds, summer feeding grounds and breeding grounds.

\subsection{North Atlantic}

At the 1983 Workshop (IWC, 1986a), three hypotheses concerning stock identity were considered (essentially an eastern, a central and a western stock). Little direct evidence had been available to support or refute these and that Workshop 'provisionally agreed to divide the North Atlantic, for statistical purposes, into eastern and western sectors and to treat the $60-62^{\circ} \mathrm{N}, 33-35^{\circ} \mathrm{W}$ area separately' (Fig. 1).

\subsubsection{Seasonal distribution}

\subsubsection{WESTERN NORTH ATLANTIC}

A combination of survey and some opportunistic data yields a partial description of the seasonal distribution of right whales in the western North Atlantic. A summary of relative abundance by month can be found in Annex D, table 1 . SC/M98/RW2 revealed significant gaps in the data, with little survey effort in June, November and December. On average, the catalogue database can only account for about $25 \%$ of the total catalogue in any month other than August or September. Furthermore, there is considerable variability between years in areas such as the Great South Channel and the Roseway Basin, where in several years, no whales were observed despite some survey effort (SC/M98/RW30).

From December to March, right whale cows, their newborn calves and some juveniles, are found in the coastal waters of the southeastern USA (i.e. off Georgia/Florida, $c a$ 


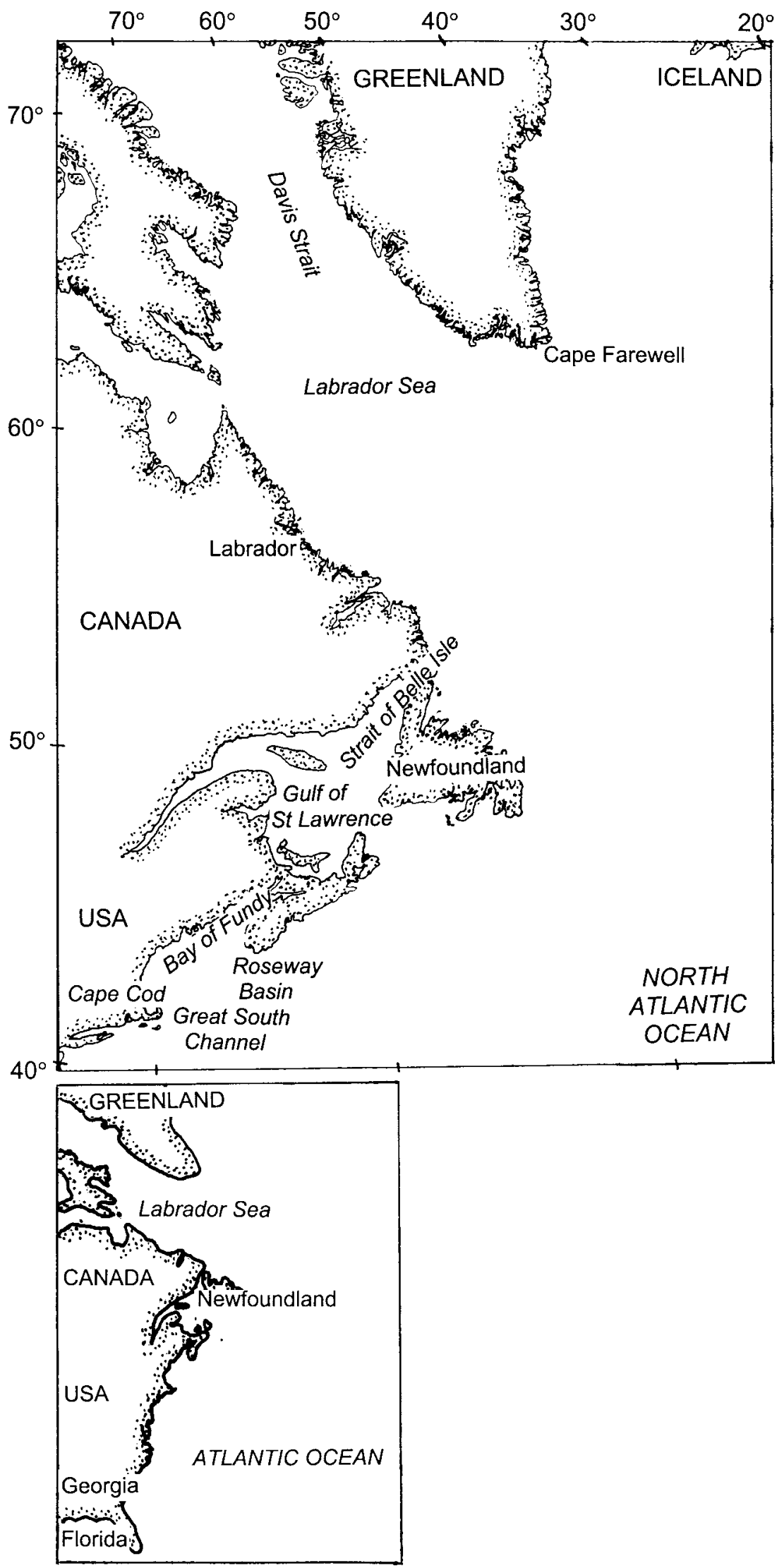

Fig. 1. Western North Atlantic.

$27-32^{\circ} \mathrm{N}$ ), the only known calving ground in the North Atlantic. Non-calving adult whales are rarely seen in the area. Calving apparently peaks in January.

In Cape Cod Bay $\left(\mathrm{ca} 42^{\circ} \mathrm{N}\right)$, right whales appear in low numbers in January, abundance peaks in March, April and May, and in most years tails off in June. Some cows with calves pass through the area in April and May. Other adults and juveniles are also represented in the area. In the Great South Channel $\left(\mathrm{ca} 42^{\circ} \mathrm{N}\right)$, right whales are observed from April-July, with a peak in abundance in May and June. Cow-calf pairs are rarely seen in the area, but all other classes are represented. 
In the Bay of Fundy $\left(\mathrm{ca} 45^{\circ} \mathrm{N}\right)$, right whales are present from June-November, with a peak in abundance in August, September and early October. Approximately $60 \%$ of all known cows bring calves to the Bay of Fundy (SC/M98/RW41). In Roseway Basin $\left(c a 42^{\circ} \mathrm{N}\right)$, whaling records show that right whales were formerly present from July to November (Reeves and Mitchell, 1986a), with a peak in abundance in August and September. Cow-calf pairs have only been seen here on five occasions during the past 18 years. Adult females are also present in low numbers, as this is predominantly an adult and juvenile male habitat. Since 1992, there has been a significant drop in abundance of right whales in the Roseway Basin area and a concurrent increase in the numbers of whales in the Bay of Fundy.

\subsection{GULF OF ST LAWRENCE, GASPÉ, NEWFOUNDLAND}

In recent years, a small number of animals have been seen in these areas, including three cows, one of which brought its calf to the Gaspé area in the summer (Lien et al., 1989; Knowlton et al., 1992; SC/M98/RW2).

\subsection{GREENLAND/ICELAND/LABRADOR BASIN}

There have been three records of right whales in this area in the last 11 years, including one cow-calf pair from the southeastern USA, one single adult previously seen in Roseway Basin and one unidentified whale.

\subsection{MID-ATLANTIC MIGRATORY CORRIDOR}

Scattered opportunistic sightings, satellite tagging tracks and historic catch records all support the view that the coastal waters of the USA between South Carolina $\left(\mathrm{ca} \mathrm{32}-34^{\circ} \mathrm{N}\right)$ and Rhode Island $\left(\mathrm{ca} 42^{\circ} \mathrm{N}\right)$ represent a springtime northward migratory corridor from the calving ground to the habitats in the Gulf of Maine $\left(\mathrm{ca} 43^{\circ} \mathrm{N}\right)$ (Knowlton, 1997; Slay and Kraus, 1997; SC/M98/RW4).

\subsubsection{Movements of identified whales}

Photographic re-identifications since the 1980s have supported the hypothesis that the right whales observed in all five of the well-defined habitats along the east coast of North America (i.e. southeast USA, Cape Cod, Great South Channel, Bay of Fundy and Roseway Basin) comprise a single stock. Supplementary satellite tagging work has confirmed the movements between the calving ground and northeastern summering grounds (Slay and Kraus, 1997). Opportunistic observations have led to non-cow photographic matches between: Newfoundland and the Great South Channel; the Labrador Basin and the Bay of Fundy; and the Gulf of St Lawrence and the Gulf of Maine. Schaeff et al. (1993) showed that female philopatry occurs in North Atlantic right whales, possibly resulting in summering feeding subgroups within the population. The fact that calving has only been confirmed in the southeastern USA, and cow-calf pairs observed there have been observed summering in the Bay of Fundy, the Gulf of St Lawrence, the Labrador Basin and near Greenland (Knowlton et al., 1992; also supports the hypothesis that western North Atlantic animals probably comprise a single breeding stock. Apparent courtship activity is observed almost year-round but the location of the breeding (i.e. mating) grounds remains unknown.

\subsubsection{Historic catches}

No new information is available beyond that given at the 1983 Workshop (IWC, 1986a, pp.2-3) and summarised below.
A summer fishery existed in the Strait of Belle Isle (Newfoundland) region, but there are problems with distinguishing between bowheads and right whales in the records. The same applies to records from the Labrador coast, north to the mouth of Davis Strait, also a summer fishery. There was catching east of the Grand Bank and possibly in a mid-ocean area (Maury, 1853). Further summer fisheries occurred east of Cape Farewell (Greenland) centred at $60-62^{\circ} \mathrm{N}, 33-35^{\circ} \mathrm{E}$, around Iceland, off North Cape (Norway) and off the British Isles.

The Bay of Biscay was an important winter ground, and catching occurred off the northwest African coast, centred on Cintra Bay $\left(23^{\circ} \mathrm{N}, 16^{\circ} 15^{\prime} \mathrm{E}\right)$.

\subsubsection{Genetic information}

\subsubsection{WESTERN NORTH ATLANTIC}

7.1.4.1.1 CALVING GROUNDS (DECEMBER-MARCH)

It is clear that the primary calving grounds of the animals found in the western North Atlantic are off the southeast USA, (i.e. the Georgia/Florida coast, $c a 27-32^{\circ} \mathrm{N}$ ). In the absence of any evidence for other extant calving grounds in the North Atlantic, genetic analysis is unlikely to provide additional information for defining this habitat. However, Brown noted that nearly $33 \%$ of known reproductively active females remain unsampled genetically due to lack of effort on the calving grounds. This limits interpretation of apparent segregation of maternal lineages on the feeding grounds as discussed below.

\subsection{SUMMER FEEDING GROUNDS (JULY-OCTOBER)}

The frequency of mtDNA lineages (i.e. haplotypes) has been analysed for heterogeneity based on the pattern of sightings in the Bay of Fundy, the primary summer and autumn study area in the western North Atlantic (Schaeff et al., 1993). For this analysis, females were classified into one of three groups according to their pattern of habitat use in their calving year: (1) always sighted in the Bay of Fundy - 'Fundy-all'; (2) never sighted in the Bay of Fundy - 'Fundy-none'; and (3) sometimes sighted in the Bay of Fundy - 'Fundy-some'. Based on RFLP (Restriction Fragmental Length Polymorphisms) ( $n=96$; Schaeff et al., 1993) and, more recently, control region sequence and Single Stranded Confirmation Polymorphism (SSCP) analyses $(n=180$, including the 96 used for the RFLP; Malik et al., 1999), significant differences in haplotype frequencies were found among these three groups of females. Thus, the presence of females with calves in known feeding habitats is non-random with respect to mtDNA haplotype. This suggests that certain females with their calves always return to the same feeding area.

7.1.4.1.3 BREEDING GROUNDS (MONTHS UNCERTAIN)

The location of breeding (mating) grounds is unknown. Given that only a single calving ground is known, it is likely that there is only one breeding stock in the western North Atlantic. However, the possibility that two breeding stocks use the single calving ground could be tested by looking for deviation from Hardy-Weinberg equilibrium (i.e. a Wahlund effect) among calves in the southeast US. Further evidence for stock habitat definitions could come from paternity (or parentage) analysis of individuals observed in sexually active groups.

\subsubsection{EASTERN AND CENTRAL NORTH ATLANTIC}

Rosenbaum et al. (2000) reported on three historic samples (from the late $19^{\text {th }}$ and early $20^{\text {th }}$ centuries) analysed from the central and eastern region: one from Iceland and two 
from Scotland. All three match the most common haplotype found in the western North Atlantic. Although this number of samples is too small for statistical interpretation of stock structure, it demonstrates the potential for using further historical samples for that purpose.

\subsubsection{Synthesis}

The Workshop agreed that only animals found in the western North Atlantic can be considered a functioning extant unit based on current sightings information. Thus, a practical management approach is to consider the animals in the western North Atlantic (largely off the eastern seaboard of the USA and Canada) as a single 'management unit' - the genetic information suggests that this probably corresponds to a 'true' biological population (e.g. see Donovan, 1991; IWC, 1994). The animals found in the eastern North Atlantic may be considered as a 'relict' population or populations.

\subsubsection{Research recommendations}

The Workshop recommends that:

(1) to reduce known bias from regional sampling of July-October feeding habitats and to complete the DNA archive of the western North Atlantic, directed genetic sampling should be undertaken, especially of females on the calving ground and any unsampled animals in Massachusetts Bay (January-May) and the Great South Channel (April-June);

(2) available information on mtDNA haplotypes of individual whales should be examined further to test for heterogeneity in regional resighting probabilities, scarring patterns and reproductive success; the latter could provide some information on differential habitat quality, if local habitat use is influenced by maternal fidelity;

(3) genetic sampling of the 'Fundy-none' females be undertaken - this is particularly important if differential reproductive success is demonstrated by 'Fundy-all' and 'Fundy-none females';

(4) further historical samples from the central and eastern North Atlantic, preferably from prior to the $19^{\text {th }}$ century, should be obtained to test the hypothesis that more than one stock division existed within this ocean.

\subsection{North Pacific}

At the 1983 Workshop (IWC, 1986a), most discussions concerning stock identity had centred on the historical whaling records. It had been noted that the continuous distributions revealed by the Maury (1853) charts called into question the concept of traditional stock separation. Attention had been drawn to the surprising absence of evidence for coastal calving grounds. That Workshop had agreed to consider the right whales on the eastern and western sides as separate for statistical purposes, noting that the lack of biological evidence precluded conclusions concerning biological populations.

\subsubsection{Distribution (see Annex D, table 2) \\ 7.2.1.1 FEEDING GROUNDS}

The Okhotsk Sea and the adjacent waters along the Kuril Islands and Kamchatka coast represent a major feeding ground for the species (Fig. 2; SC/M98/RW10, SC/M98/RW11). Historical concentrations of sightings in

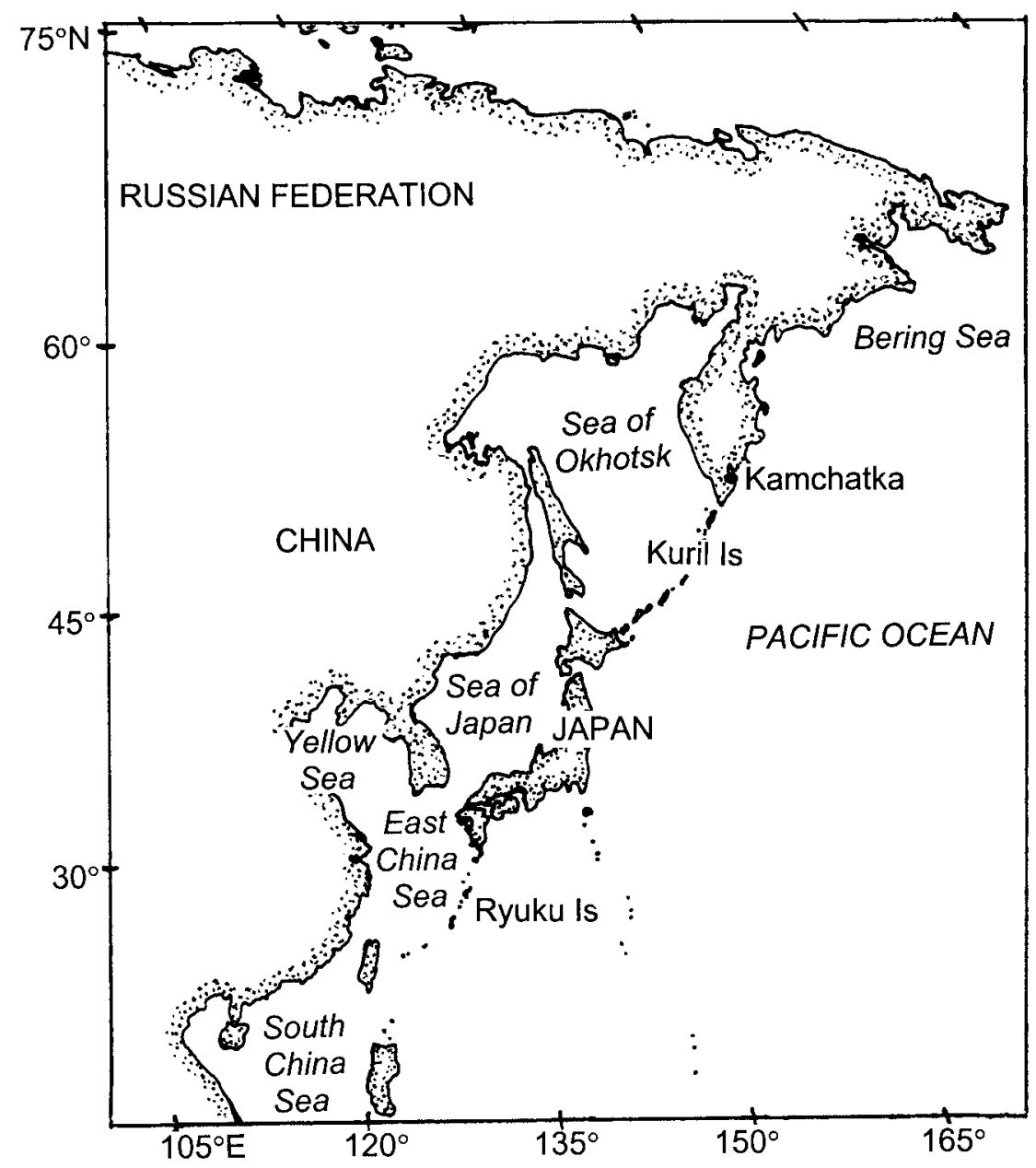

Fig. 2. Western North Pacific showing place names mentioned in the text. 
the Bering Sea, together with some recent sightings, suggest that this region was an important summer habitat for eastern North Pacific right whales. Historical evidence also indicates major feeding grounds in the northern Gulf of Alaska (Muller, 1954).

\subsubsection{BREEDING AND CALVING GROUNDS}

In the western North Pacific, various areas have been proposed as breeding and calving grounds, including the Ryukyu Islands, the Yellow Sea, the Sea of Japan and offshore areas (Fig. 2). Overall, mid-winter sightings and seasonal movements in spring and autumn give various degrees of support to all of these suggestions, but the general paucity of winter records makes a definitive assessment impossible.

There is very little information on the winter distribution of right whales in the eastern North Pacific. There are two opinions on the locations of the breeding and calving grounds there: in mid-ocean waters far offshore, or in embayments. If the latter were true it is perhaps surprising that they have not been identified - it seems unlikely that they would have been overlooked on either side of the Pacific, unless perhaps in some remote part of southeastern Asia. One school of thought is that since the biological advantages of coastal calving are not clear, there is no reason to suppose that right whales cannot give birth and perhaps mate far from land. By contrast, it is possible to argue that since right whales in all other ocean areas appear to calve inshore, it would be surprising if those in the North Pacific did not also do so (IWC, 1986a).

\subsubsection{Movements}

In general, there appears to have been a northward movement to high latitudes in spring, and a similar southward trend in autumn. However, right whales were found across a broad latitudinal range during both seasons, suggesting a non-synchronous migration (Scarff, 1986).

\subsubsection{Genetic information}

Genetic analysis to date has included sequencing of the mtDNA control region of eight samples (SC/M98/RW43): six $^{5}$ collected by biopsy sampling from the southeastern Bering Sea; one historical sample from the Sea of Japan; and another historical one from California (both $19^{\text {th }}$ century baleen). The six biopsy samples included two haplotypes and the two historical samples were each a unique haplotype. All four haplotypes were closely related. The distribution and number of samples collected to date are insufficient for an analysis of population structure.

\subsubsection{FEEDING GROUNDS}

Sampling of animals on feeding grounds has been limited to the southeastern Bering Sea. Since there is little evidence to support the hypothesis of a central stock, the animals found there provide the only likely source of samples from any putative 'eastern' stock.

\subsubsection{CALVING AND BREEDING GROUNDS}

There is no genetic information from such areas for any stock.

${ }^{5}$ Until the relevant analysis has been completed, it is not possible to state that these represent six different animals.

\subsubsection{Synthesis}

The question of whether two or more stocks of right whales exist in the North Pacific remains open. However, the Workshop agreed that only the animals found in the western area can be considered a functioning extant unit based on current sightings information (SC/M98/RW10 and RW11). The fact that right whales in the eastern and western North Pacific appear to have different catch and recovery histories supports the hypothesis that once there were at least two stocks, at least with regard to feeding ground divisions.

It has been proposed (Omura, 1986) that the right whales which summer in the Okhotsk Sea represent a discrete population that winters in the Sea of Japan and perhaps the East China Sea. Although it seems unlikely that animals found in such close proximity (notably in the Kuril Islands and Okhotsk Sea) would belong to separate stocks, insufficient data exist to confirm or deny the possibility.

\subsubsection{Research recommendations}

The Workshop recommends that additional analysis of historical samples available in Japan should be undertaken to characterise the western stock. However, there are few known historical samples from the eastern North Pacific and future comparisons are likely to be limited to samples from the Bering Sea. Further biopsy samples should be collected when possible in all regions. Analysis of nuclear DNA using current and historical samples from eastern and western regions could provide some evidence to test the possibility that more than one breeding stock exists or existed in the North Pacific.

\subsection{South Atlantic and Indian Ocean coast of Africa}

At the 1983 Workshop (IWC, 1986a), most of the discussion on stock identity had centred on the interpretation of historical distribution concentrations from whaling records, and whether these can be used to infer biological stocks. Little agreement on the latter was reached. That Workshop had agreed that the South African and Argentinian animals probably represented separate stocks but the other divisions it had used, such as dividing catches at $20^{\circ} \mathrm{E}$ (either side of Cape Agulhas), were largely for statistical purposes.

\subsubsection{Distribution and seasonality (see Annex D, table 3)} 7.3.1.1 CALVING GROUNDS

The following six winter calving grounds can be identified (Fig. 3), based principally on the distribution of current or historical sightings/catches:

(1) Brazil $\left(8-32^{\circ} \mathrm{S}\right)$ - surface-active groups extending south to $32^{\circ} \mathrm{S}$, and contemporary sightings at the Abrolhos Banks ( ca $\left.18^{\circ} \mathrm{S}\right)$;

(2) Argentina $\left(42-43^{\circ} \mathrm{S}\right)$ - biggest concentration around Peninsula Valdes $\left(42^{\circ} \mathrm{S}\right)$, but with stragglers occurring both to the north and south;

(3) Tristan da Cunha (mid-Atlantic, ca $38^{\circ} \mathrm{S}, 12^{\circ} \mathrm{E}$ ) possibly including Gough Island;

(4) Three regions of historical catches on the Namibian/Angolan coast ( $\mathrm{ca} 16-27^{\circ} \mathrm{S}$ : southern Angola - Baia dos Tigres; Walvis Bay; Lüderitz) whose separation might simply reflect the logistic difficulties of operating in the areas between them;

(5) South Africa - the coast south of $32^{\circ} \mathrm{S}$, between St Helena Bay on the west coast and Port Elizabeth on the east coast;

(6) Mozambique/Natal $20^{\circ} \mathrm{S}$ - the waters surrounding Maputo Bay ( ca $26^{\circ} \mathrm{S}$ : historically known as Delagoa Bay), and including a possible migratory corridor on the Natal coast. 


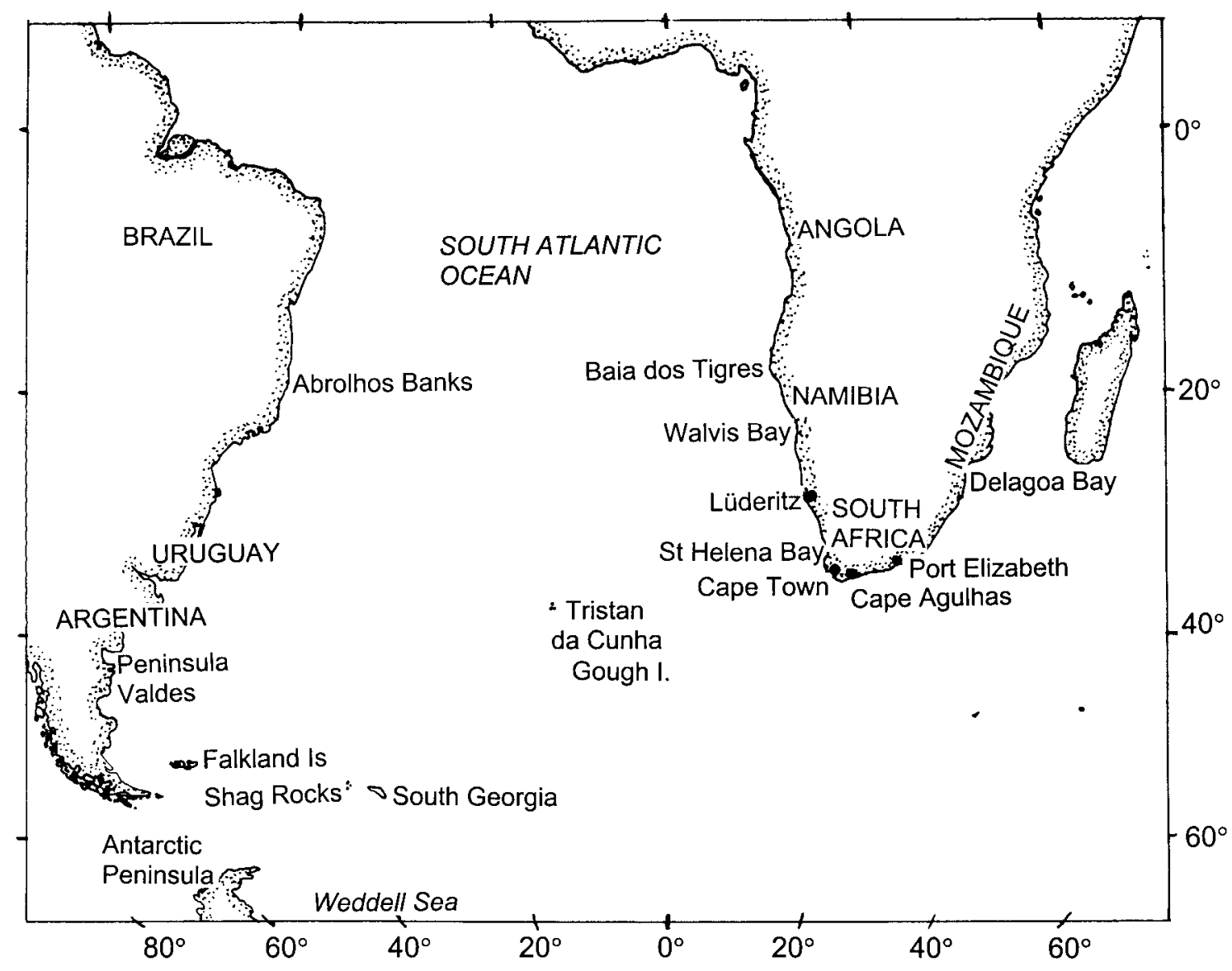

Fig. 3. South Atlantic and Indian Ocean coast of Africa.

\subsubsection{FEEDING GROUNDS}

The following seven summer feeding grounds can be identified (Fig. 3), mainly based on the distribution of catch positions of right whales in $19^{\text {th }}$ century Yankee (Townsend, 1935 ) or $20^{\text {th }}$ century Soviet whaling (Tormosov et al., 1998):

(1) Brazil/False Banks/Falkland Islands - offshore from southern Brazil, Uruguay and Argentina, between $30^{\circ}$ and $55^{\circ} \mathrm{S}$, and west of $40^{\circ} \mathrm{W}$ : seasonality ranging from October-January in the north, to February-May in the south. Soviet catch seasonality was from November-December in the north and March in the south;

(2) South Georgia/Shag Rocks $\left(c a 53^{\circ} \mathrm{S}\right)$ - an area mainly to the north of South Georgia in which catches were made by modern whalers in the early years of this century, and by Soviet whalers in the 1960s, and where there have been recent sightings (SC/M98/RW26);

(3) Pigeon-Tristan Ground - a concentration of $19^{\text {th }}$ century catches surrounding Tristan da Cunha and extending to the east, from October-January (Soviet catches in the 1960s, mostly in November, indicate that at least the Tristan ground was then still inhabited);

(4) Cape-Tristan - a band of $19^{\text {th }}$ century catches extending from Tristan da Cunha towards Cape Town $\left(30-40^{\circ} \mathrm{S}\right)$ from October-January (some Soviet catches were taken in November-December in the 1960s);

(5) South of $50^{\circ} \mathrm{S}$ - a diffuse area of Soviet catches extending from $50^{\circ} \mathrm{S}$ to the ice edge and from $10^{\circ} \mathrm{W}$ to $30^{\circ} \mathrm{E}$, seasonality peaked in March but extended from December-April (Townsend, 1935), data showed catches from February-May;
(6) Antarctic Peninsula $\left(\mathrm{ca} 65^{\circ} \mathrm{S}, 60-70^{\circ} \mathrm{W}\right)$ - an area of recent sightings through opportunistic and directed efforts.

In delineating these grounds, the Workshop noted the following caveats:

(a) the catch distributions in time and space may be affected by logistic considerations of the whaling fleets; only for South Georgia were there opportunistic observations for periods outside the southern summer;

(b) the Townsend (1935) plots may exaggerate the size of these grounds because of the author's desire not to overlay positions in areas of dense catching so that inter alia the colour coding for each month's catches could be discerned;

(c) the Townsend (1935) data as published are known to contain some errors of position, species identification and number of days on which whales were caught.

\subsubsection{Movements}

Movements of right whales between calving grounds, or between calving and feeding grounds in the South Atlantic, are known for nine photographically identified individuals (Best et al., 1993, fig. 1; SC/M98/RW26), and Best and Findlay (pers. comm.). These indicate between-year movements from Argentina to Brazil ( 3 adult females), from Argentina to Tristan da Cunha (1 adult male), from Argentina to South Georgia (1 adult female, 2 adults of unknown sex), from Gough Island to South Africa (1 adult female), and from South Africa to 'south of $50^{\circ} \mathrm{S}$ ' and back (1 adult female). 
A comparison of average stable isotopes from seven baleen plates from Argentina with seven plates from South Africa indicated that three of the Argentinian whales had higher nitrogen and carbon values than any of the South African whales (Best and Schell, 1996; SC/M98/RW13). This indicated that they had probably fed in a different region (or at a different trophic level) from whales from South Africa. The other four whales had similar isotope ratios to the seven South African whales and so might have been feeding in the same area (or at the same trophic level in another area) as the South African whales.

\subsubsection{Morphology}

Comparisons of the incidence of various callosity patterns and dorsal pigmentation types have revealed statistical differences between calving grounds in Argentina and South Africa (Payne et al., 1983; Best, 1990). So far, no such comparisons have been made between right whales off Brazil with those in Argentina or South Africa, although suitable photographs do exist.

Depigmented lesions caused by gull attacks, which persist for up to four years, have so far only been seen in right whales from Argentina, where they are now found on up to one third of the population (Rowntree et al., 1998). No such lesions have been seen on 63 whales examined in Brazilian waters, or in 484 adult females examined in South African waters (Palazzo, Flores, Best, pers. comm.). As such, they might be considered a potential indicator of stock identity.

\subsubsection{Parasites}

The barnacle Tubicinella is universally present in the callosities of right whales over 12 months of age in South African waters (Best, pers. comm.), but has not been recognised on right whales from Argentina (Rowntree, pers. comm.). The presence of barnacles in the callosities of a right whale from South Georgia (Matthews, 1938) might therefore indicate that the animal came from a population other than that wintering off Argentina. Cyamids have not been identified to species in all areas of the South Atlantic. There are apparently higher infestation rates of the orange species Cyamus erraticus (which is found on the body surface away from the callosities) in Antarctic waters, than in either Argentina or South Africa (Roussel de Vauzeme, 1834).

\subsubsection{Genetic information}

\subsubsection{CALVING GROUNDS}

Samples were available for genetic analysis from biopsy samples of whales off South Africa $\left(34^{\circ} \mathrm{S} ; n=21\right)$ and from stranded or beachcast calves in Peninsula Valdes, Argentina $\left(42^{\circ} \mathrm{S} ; n=20\right)$. The analysis of mtDNA variation reported in SC/M98/RW23, based on sequencing of the control region, showed significant differentiation between the two calving grounds at both the haplotype and nucleotide level. Estimates of long-term maternal gene flow (2-5 females per generation) were low by demographic standards, often used for management purposes (Donovan, 1991). These results support the historical assumption of stock divisions between these two calving grounds.

\subsubsection{FEEDING GROUNDS}

A sample of eight whales from South Georgia was compared with those from the two calving grounds (SC/M98/RW23). The sample size was considered too small for a statistical test of heterogeneity but included two haplotypes common to both calving grounds, two shared only with Argentina, two shared only with South Africa and two not found on either calving ground. This is consistent with, but not strong evidence for, some mixing of the two stocks during the feeding season.

\subsubsection{BREEDING GROUNDS}

Specific breeding grounds are not known but mating is commonly observed on both calving grounds (SC/M98/RW21). Analysis of nuclear DNA markers (microsatellites) is currently underway (Schaeff, 2001) and will allow a test of the hypothesis of reproductive isolation (i.e. male and female gene flow) between calving grounds.

\subsubsection{Synthesis}

There are (or were) up to six different calving grounds in the South Atlantic. Currently, three of these are recognised as being substantially populated: Brazil, Argentina and South Africa (see Item 10). In light of the genetic and morphological (and possibly parasite) data, the Workshop agreed that the calving grounds off Argentina and South Africa should be considered as separate management units. Although the gull damage data are indicative of a degree of separation between Argentina and Brazil, the three incidences of photo-identified whales moving from Argentina to Brazil suggest that this separation is not absolute. No comparison of any kind has yet been made between whales from Brazil and South Africa. Photo-identification links have been established between only two of the five suggested feeding grounds and breeding/calving grounds further north, i.e. between South Georgia/Shag Rocks and Argentina, and between 'south of $50^{\circ} \mathrm{S}$ ' and South Africa.

\subsection{Australia/New Zealand and Indian Ocean excluding East Africa (SC/M98/RW22)}

At the 1983 Workshop (IWC, 1986a), Dawbin had considered that two populations existed in the New Zealand area: a New Zealand-Kermadecs population and a Campbell and Auckland islands population (see Fig. 4), largely based on the different catch histories. Although it had been agreed that there was no discontinuity in the catch records, the 1983 Workshop had divided eastern and western Australian catches (at $135^{\circ} \mathrm{W}$ ) for statistical purposes.

\subsubsection{Seasonal distribution (see Annex D, table 4) 7.4.1.1 AUSTRALIA - SOUTHWEST}

Animals are present from April-November. Cows with calves first appear in June, and are most abundant in August-September, with numbers tailing off into November. There are no records of cows with calves in December. 'Unaccompanied' animals (i.e. not cows and their accompanying calves) - either single or in surface active groups - are also present from April-November, but they peak earlier, with high abundance in July and August (Bannister, 1990).

\subsubsection{AUSTRALIA - SOUTH CENTRAL}

Seasonal abundance of cow-calf pairs and 'unaccompanied' animals is as for the southwestern region, above. Information is available for individual categories within the latter group: juveniles peak in July/August; adult males and non-calving females in July, tailing off through August/September (Burnell and Bryden, 1997). 


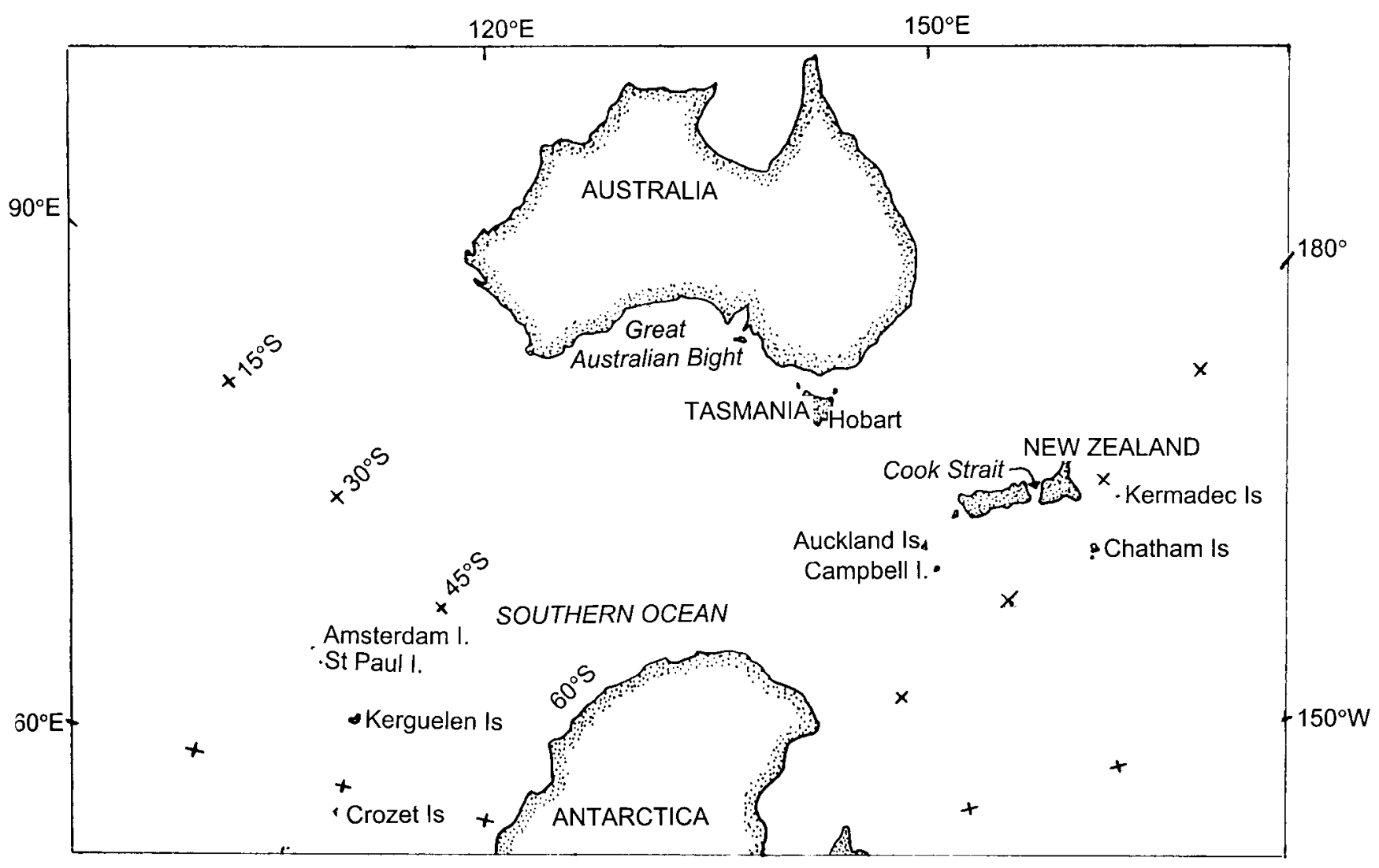

Fig. 4. Australia/New Zealand and Indian Ocean excluding East Africa.

\subsubsection{AUSTRALIA - SOUTHEAST}

Cow-calf pairs have been seen mainly in June-November (but there is one record for January) with a peak in August, but 'unaccompanied' animals are present from March to September, peaking in July (Burnell, 1997).

\subsubsection{SOUTHERN OCEAN $\left(90\right.$ - $150^{\circ}$ E) EXCLUDING ANTARCTIC} A large concentration of 75 'unaccompanied' animals was seen at $41-44^{\circ} \mathrm{S}$ in January (Ohsumi and Kasamatsu, 1986) and another 35 animals in the same area - including two cow-calf pairs - in December (Bannister et al., 1997). Marking information exists for two animals around $46^{\circ} \mathrm{S}$ in summer (November-March). A total of 78 animals was taken south of Tasmania in Soviet operations in March-April (Tormosov et al., 1998).

\subsubsection{ANTARCTIC $\left(90-150^{\circ} \mathrm{E}\right)$}

Two 'unaccompanied' animals were seen at ca $64^{\circ} \mathrm{S}$ (SC/M98/RW18) in February and a further 23 were taken in Soviet operations between $61^{\circ}$ and $65^{\circ} \mathrm{S}$ from January-March, but mainly in the latter month (Tormosov et al., 1998).

\subsubsection{MAINLAND NEW ZEALAND (NORTH AND SOUTH ISLANDS)}

Current information on the seasonal distribution of southern right whales around the main islands of New Zealand is based exclusively on opportunistic sightings. The movements of right whales facilitate their observation near the coastline, but even so, the reported number of sightings off the mainland is very low - rarely more than two or three reported sightings of individuals or cow-calf pairs per annum (SC/M98/RW20).

Most reports are from the Cook Strait area or from the northeast coast of the North Island, mainly between July and
October. The number of whales frequenting the coastline of the North and South Islands is probably fewer than ten each year.

\subsubsection{SUB-ANTARCTIC ISLANDS (CAMPBELL AND AUCKLAND} ISLANDS)

Based on Townsend's (1935) charts, whales were found near the sub-Antarctic islands in December, March, April, May and June.

Since systematic research work began in 1995, survey effort in the sub-Antarctic has been concentrated in the winter months (June-August). Opportunistic surveys were also conducted in winter 1983 (Campbell Island, June-September) and in spring 1996 (Auckland Islands, September).

Right whales are thought to appear there in May, with a peak in abundance reported in late July/early August. During winter months, all segments of the population are represented on these calving grounds, including cow-calf pairs and surface active groups (SC/M98/RW20; SC/M98/RW33). There have been opportunistic sightings of right whales in small numbers in the Auckland Islands during the summer months. Soviet whaling records reveal large numbers of whales caught in the vicinity of the Auckland Islands during autumn months (March-April; Tormosov et al., 1998). These included males, females and some lactating females.

\subsubsection{Movements of identified whales 7.4.2.1 SOUTHERN AUSTRALIA}

Historical evidence (Townsend's 1935 charts) and anecdotes suggest movement from the south towards Tasmania early in the season, i.e. April, followed by westwards movement across the Australian Bight. The bulk of whales were thought to move south from Western Australia in late spring/early 
summer (October-December) with some evidence of an eastward trend around $40^{\circ} \mathrm{S}$. Recent photo-identification records indicate a link between probable feeding grounds at ca $42^{\circ} \mathrm{S}$ and $64^{\circ} \mathrm{S}$ and calving grounds on the southern Australian coast (summarised in SC/M98/RW18). Records of easterly movement from two recovered marks (Tormosov et al., 1998) are not inconsistent with earlier views but the Antarctic records represent a considerable extension southwards in distribution, by comparison at least with Townsend's (1935) data which showed no catches taken south of $50^{\circ} \mathrm{S}$. An additional 108 movements greater than $200 \mathrm{~km}$ were made by individually identified whales between areas on the southern Australian coast. The large number of movements detected between the three continental Australian regions suggests that the animals found in these areas comprise a single stock. The directions of movement within- and between-years and to offshore locations suggest a generalised westerly movement of whales along the southern Australian coast and an easterly trend on the feeding grounds in summer months (SC/M98/RW18; SC/M98/RW19).

\subsubsection{NEW ZEALAND SUB-ANTARCTIC ISLANDS}

Photographic comparison shows within- and between-year movements of whales between the two New Zealand sub-Antarctic concentrations, at Campbell Island and the Auckland Islands (SC/M98/RW34). There is insufficient information to conclude if there is age- or sex-class sub-division between the two areas. Although the high latitude of the Auckland Islands is more consistent with known right whale feeding grounds in other parts of the world, it appears that this sub-Antarctic region is currently the primary wintering habitat for southern right whales in New Zealand waters.

\subsubsection{Historical data}

Information is available from coastal and pelagic whaling records; the latter is from American whale ship logbooks per Townsend's (1935) charts and subject to the usual sailing vessel logistic limitations from the effects of wind, weather and currents.

\subsubsection{AUSTRALIA - SOUTH WEST}

Little seasonal information is readily available on local bay whaling operations, but pelagic bay whaling operated from June-October - mainly July-September (Bannister, 1986b) and pelagic offshore whaling from 'late spring to summer' with a peak in November-December. Offshore operations show a latitudinal shift southwards by month, from $\mathrm{ca} 35^{\circ} \mathrm{S}$ in September to $c a 45^{\circ} \mathrm{S}$ in December (SC/M98/RW18).

\subsubsection{AUSTRALIA - SOUTH CENTRAL}

A pelagic bay whaling record (Bannister, 1986a) details a total catch of 33 animals over 79 days in June-August. Offshore records show catching at $\mathrm{ca} 45-50^{\circ} \mathrm{S}$ in February-March.

\subsubsection{AUSTRALIA - SOUTH EAST}

Dawbin (1986) details substantial catches in the area, particularly in the $1830 \mathrm{~s}-40 \mathrm{~s}$, but without seasonal information. Right whales were apparently seen in numbers in the Derwent River, Hobart, Tasmania, between May and November (Dakin, 1963). Pelagic catches show a seasonal distribution off the Australian east coast similar to that off the west coast (SC/M98/RW18), i.e. from $c a 30^{\circ} \mathrm{S}$ in September to $c a 45^{\circ} \mathrm{S}$ in December. There are records of catch positions yet further south, in February, at $c a 50^{\circ} \mathrm{S}$, in the central Tasman Sea, but it is not clear whether they are referable to animals from the Australian or New Zealand sub-Antarctic (SC/M98/RW18 and Item 7.4.1.7).

Information on the Southern Ocean is included in the above. There is no information on historical catches, if any, south of $50^{\circ} \mathrm{S}$ (SC/M98/RW18).

\subsubsection{INDIAN OCEAN (EXCLUDING THE AFRICAN COAST)}

On Townsend's (1935) charts, two major catching areas are represented between $40^{\circ} \mathrm{S}$ and $50^{\circ} \mathrm{S}$, the 'Desolation' Ground (Kerguelen Island) at $\mathrm{ca} 70^{\circ} \mathrm{E}$, and the 'Crozettes' Ground (Crozet Island) at $c a 50^{\circ} \mathrm{E}$. To the north of the former, including and to the east of St Paul/Amsterdam Island, is an extended area of catching at $c a \quad 60-80^{\circ} \mathrm{E}$, $30-40^{\circ} \mathrm{S}$. Catching was recorded at the Crozettes Ground in December-May, with most apparently in February-March. North of the Desolation Ground, most catching was in October-November, but with some, around St Paul Island, in September.

\subsubsection{MAINLAND NEW ZEALAND (NORTH AND SOUTH ISLANDS) AND KERMADEC ISLANDS}

Based on Townsend's (1935) charts, whales appeared to exhibit a general northward migration along the South Island from January-March, that peaked in Cook Strait from May-September then went further northeast to the Kermadec Islands from August-November. The Workshop noted, however, that there may be some doubt over the identity of the Kermadec Islands catches (SC/M98/RW37). Whales were found further south near the Chatham Islands in January and September and off the Chatham Rise in December-January.

\subsubsection{NEW ZEALAND SUB-ANTARCTIC ISLANDS}

Historically, right whales were widely distributed within New Zealand waters. Based on Townsend's (1935) charts, wintering grounds were found mainly east of the Kermadec Islands (but see 7.4.3.5 above), off the Chatham Islands, in Cook Strait and to a lesser extent near the Auckland Islands. Current wintering grounds are limited to the Auckland Islands and Campbell Island.

\subsubsection{Genetic information}

\subsubsection{CALVING GROUNDS}

Samples were available for genetic analysis from biopsy samples of whales off southwestern Australia $\left(34^{\circ} \mathrm{S} ; n=20\right)$ and near the Auckland Islands $\left(51^{\circ} \mathrm{S} ; n=20\right)$ (SC/M98/RW23). As in the South Atlantic, the analysis of mtDNA variation, based on sequencing of the control region, showed significant differentiation between the two calving grounds at both the haplotype and nucleotide level (SC/M98/RW23). Estimates of long-term maternal gene flow (3-5 females per generation) were low by demographic standards. There was no evidence of a strong sex-bias in the haplotype frequencies. These results support the historical assumption of stock separation between these two calving grounds.

\subsubsection{FEEDING GROUNDS}

A sample of five whales from feeding grounds south of Australia $\left(41-44^{\circ} \mathrm{S}\right)$ was compared to those from the two calving grounds (SC/M98/RW23). The sample size was too small for a statistical test of heterogeneity but included 
haplotypes common to both calving grounds. This is consistent with, but not strong evidence for, some mixing of the two stocks during the feeding season.

\subsubsection{BREEDING GROUNDS}

As for the South Atlantic, specific breeding grounds are not known but mating is commonly observed on both calving grounds. Analysis of nuclear DNA markers (nuclear introns and microsatellites) is planned and will allow a test of the hypothesis of reproductive isolation between calving grounds.

\subsubsection{Synthesis}

The Workshop agreed that the animals found on the Australian coast in winter should be considered as a single management unit and that this probably comprises a true biological population. The offshore sightings and catches as far as $65^{\circ} \mathrm{S}$ indicate more extensive movements into colder waters than previously believed.

The animals found around the Auckland Islands and to a lesser extent Campbell Island represent the great majority of animals in New Zealand waters. The Workshop recommends that the management unit for southern right whales in this region previously described as the Campbell Island population (IWC, 1986a) be referred to as the New Zealand sub-Antarctic population. This is separate from what can be termed the New Zealand-Kermadec management unit and the Australian unit.

Based on Townsend's (1935) charts, major areas of catching in the central Indian Ocean around and to the east of St Paul/Amsterdam Island in September, October and November, and around Kerguelen ('Desolation Ground') in January-May, could indicate a separate Central Indian Ocean management unit. An even more extensive fishery near the Crozet Islands ('Crozettes Ground'), in December-May, could indicate another management unit further east, possibly linked to a small area to its northwest, where catching occurred in September-November. Little information exists on the present occurrence of right whales in those areas (Ohsumi and Kasamatsu, 1986).

\subsubsection{Recommendations}

Additional genetic samples are needed from existing or suspected feeding and calving areas to improve characterisation of population structure in the Australia/New Zealand region and the central Indian Ocean (see Table 1). In particular, the Workshop recognised that the Auckland Islands and Campbell Island represent the only known current calving grounds in the New Zealand area. It recommends that the current research programmes continue and that the relationship between animals found at the Auckland Islands and Campbell Island be further investigated (e.g. by collecting biopsy samples at the latter).

\subsection{Southern Hemisphere stocks - general}

The Workshop recognised that there are many regions of the Southern Hemisphere from which information is currently unavailable but which are known, from historical records, to have once been occupied by right whales. It was agreed that genetic information would be of considerable value in determining stock separation and migratory interchange among these regions.

Additional genetic sampling is needed to characterise the relationships of whales in regions throughout the Southern Hemisphere, particularly the calving grounds. Samples from feeding grounds are required for more reliable allocation of
Table 1

Calving or feeding areas of right whales in the Southern Hemisphere where, based on current abundance, it is considered possible to collect biopsy samples from a minimum of 20 individuals (counting cow/calf pairs as a single individual for purposes of mtDNA analysis).

\begin{tabular}{lccl}
\hline Region & $\begin{array}{c}\text { Samples } \\
\text { available? }\end{array}$ & $\begin{array}{c}\text { More } \\
\text { needed? }\end{array}$ & Comment \\
\hline Calving* & Yes & Yes & \\
Argentina & $?$ & $?$ & \\
Tierra del Fuego & $?$ & Yes & Latitudinal component \\
Brazil & No & Yes & with Argentina \\
Tristan de Cunha & Yes & $?$ & \\
South Africa & Yes & Yes & \\
Western and South & & & \\
Australia (three areas) & No & Yes & \\
East Australia/Tasmania & Yes & Yes & \\
Auckland/Campbel & Auckland) & (Campbell) \\
Island & $?$ & Yes & \\
Chile/Peru & & & \\
Feeding & Yes & Yes & \\
South Georgia & Yes & Yes \\
Antaretic Peninsula & Yes & Yes \\
\hline >40 off Australia &
\end{tabular}

* Note that in calving areas sampling should be repeated in at least each of three consecutive years.

historical catches to calving grounds (see Item 10). In addition to longitudinal divisions, right whale calving grounds along some continental coasts are distributed over latitudes from approximately $15^{\circ} \mathrm{S}$ to $50^{\circ} \mathrm{S}$. It is important to analyse latitudinal as well as longitudinal components of population structure. To this end, the Workshop recommends that the Scientific Committee requests that, where possible, collection of biopsy samples is undertaken from vessels involved in suitable programmes such as: CCAMLR, SO-GLOBEC and BAS krill surveys. It noted that such work is already given priority on IWC SOWER cruises. When possible, biopsy samples should be preserved for multi-disciplinary studies. For molecular genetic analysis, this can be in a salt/DMSO solution or $70 \%$ ethanol (Dizon et al., 1997). For in situ molecular assays reflecting hormonal and pollutant states (e.g. SC/M98/RW24), a thin, midline section of skin and blubber should be fixed in $10 \%$ buffered formalin. Tissues wrapped in solvent-rinsed metal foil and stored at $-70^{\circ} \mathrm{C}$ are also suitable for most purposes.

The Workshop also noted that stable isotope analysis of baleen plates might provide evidence of the use of differing feeding grounds by right whales from different calving grounds (see SC/M98/RW13) and recommends that where possible, such studies be carried out.

\subsubsection{Geographic sampling}

Following the recommendations for sample sizes for initial descriptions of stock divisions using mtDNA (IWC, 1991), the Workshop recommends that priority be given to areas where it should be possible to collect samples from a minimum of 20-50 individuals (Table 1). In calving areas, this sampling should be repeated in at least each of three consecutive years, assuming three calving female cohorts (i.e. 60-150 individuals per area).

However, the Workshop stressed that the minimum recommended sample size of 20 individuals per sub-population is sufficient only for an initial description of population structure when the effect size (i.e. genetic isolation) between sub-populations is large. For detecting dispersal rates of interest for demographic management 
purposes, simulation studies have shown that sample sizes of 80 individuals per sub-population (excluding duplicate samples) are needed to provide unbiased estimates of relevant genetic parameters. This total sample could be accumulated over years and could be chosen to represent the habitat range of the putative population unit of interest. Such sample sizes are also sufficient for multi-disciplinary studies recommended elsewhere in this report (and see SC/M98/RW24).

The Workshop also recommends the timely analysis of both extant and future samples, including the large sample (660) from South Africa, which could provide valuable information on breeding habitats, degree of polygyny (estimation of effective population size), female use of calving areas (influence of female-directed philopatry) and estimates of genetic variability and male- and female-directed gene flow. This is not only important for an understanding of South African right whales but also for comparison with the North Atlantic population.

Additional historic specimens from some areas of the Southern Hemisphere (as well as the eastern North Atlantic and North Pacific - see above) could be used to test putative population designations where current abundance is so low that obtaining representative biopsy samples is not practical. In certain situations, such as specimens obtained from bone huts in Namibia, historic material may provide sample sizes (i.e. 20-50) adequate for an initial examination of population structure.

\subsection{General recommendations}

\subsubsection{Population structure}

The Workshop recommends that an analysis of callosity patterns and dorsal pigmentation types (c.f. Payne et al., 1983; Best, 1990; Schaeff et al., 1999) be carried out comparing the various Southern Hemisphere populations. It also recommends that special attention be paid to the question of whether barnacles are present in the callosities of animals in any other populations beside South Africa.

It reaffirms that additional genetic samples are needed from other known or suspected feeding and calving areas to improve understanding of population structure/division in the Southern Hemisphere (see 7.4.1 above and Table 1).

\subsubsection{Choice of genetic markers and molecular methods}

The Workshop noted that the choice of the 5' end of the mtDNA control region has become a standard for studies of population variation and structure for most marine mammals (Dizon et al., 1997). To date, studies of right and other whales have focused on the first 300 base-pairs of the control region (SC/M98/RW21 and SC/M98/RW22). The Workshop recommends that this level of resolution should be considered the minimum for future comparable studies. Direct sequencing of samples, although expensive, provides the greatest flexibility for data exchange and comparison.

For studies of nuclear variation, the Workshop recommends that microsatellites be considered the markers of choice for individual identification (i.e. DNA profiling), paternity or parentage analysis and estimation of kinship. For analysis of population structure, there is some concern over the problem of distinguishing between identity in size and identity in descent (i.e. homology of alleles). This could positively bias estimation of gene flow (Rosenbaum and Deinard, 1998). Nuclear intron alleles (i.e. non-coding sequences), although less variable than microsatellites, are more likely to be homologous and may prove more useful for systematic studies as well as for some population analyses (Palumbi and Baker, 1994).

\subsubsection{Data analysis and reporting}

For mtDNA sequences, the Workshop recommends that nucleotide and haplotype diversity and their standard errors (with specified equations) be estimated and reported. For these to be meaningful, they must be based on comparable lengths of homologous sequences (i.e. the first 300 base-pairs of the control region). If longer sequences are used, the estimates should also be reported for the comparable minimum or consensus lengths. Statistical analyses of population structure should include both haplotype and nucleotide correlations (e.g. $F_{\text {st }}$ and $\emptyset_{\text {ST }}$ or their analogues) and tested with a permutation procedure.

As yet, there appears to be no general agreement on standard methods for statistical analyses of microsatellites. The Workshop recommends that, at a minimum, the frequencies of alleles should be reported by length and the samples should be tested for deviation from Hardy-Weinberg equilibrium.

\section{HISTORICAL AND MODERN CATCHES}

\subsection{Historical (pre-modern)}

Most data from pre-modern whaling are in the form of production statistics (oil or baleen) rather than whales caught. As a result, the numbers of whales killed are estimated rather than known. Different authors have used different yield or catch-per-voyage values, derived from different assumptions and procedures. The same can be said of adjustments for hunting loss, ranging from 1.2-1.5 times the landed catch, depending on the fishery (e.g. IWC, 1986a, p.31).

In the review below, based on a compilation at the Workshop by Reeves, no attempt has been made to standardise estimation methods. Annex L summarises data available for southern right whales.

\subsubsection{North Atlantic}

The North Atlantic stocks of right whales had already been severely reduced by Basque pelagic whaling and shore whaling prior to the beginning of 'Yankee' pelagic whaling in the mid $18^{\text {th }}$ century (IWC, 1986a). At least dozens of right whales were taken each year in the Bay of Biscay between 1059 and 1650 (Aguilar, 1986; IWC, 1986a). Aguilar (1986) reviewed catch and production data from Basque whaling elsewhere in the North Atlantic, concluding, for example, that some 25,000-40,000 right whales were taken off Labrador between 1530 and 1610. French (and probably other) whalers continued to kill right whales at least opportunistically through the mid- $18^{\text {th }}$ century (Du Pasquier, 1986). Shore whaling along the US east coast began in the mid $17^{\text {th }}$ century, with peak catches of right whales from approximately 1680-1730 (Reeves et al., 1999). Estimates of the number of right whales taken off the northeastern USA between 1696 and 1734 range from about 2,000 (based on baleen exported) to 3,800 (based on oil exported). Shore whaling continued, with variable amounts of effort, along portions of the US coast until 1924, with total known catches only in the hundreds for this 190 -year period. Catches by pre-modern shore whalers in the $20^{\text {th }}$ century include about ten animals (including struck/lost) off Long Island, New York (Reeves and Mitchell, 1986b); five off North Carolina (Allen, 1977; Allen and Kirkwood, 1977); and one in southeastern Canada (Mitchell et al., 1986). Modern whalers at Iceland and the Faroes took 24 right whales between 1889 and 1898 (Brown, 1986). 
The estimated catch of right whales by American pelagic whalers in the North Atlantic between 1855 and 1897 is about 186 (Best, 1987).

\subsubsection{North Pacific}

Right whales were exploited by net fisheries off Japan beginning in the late $17^{\text {th }}$ century. Omura (1986) estimated that no more than about 50 right whales per year were taken in each of two areas (the Sea of Japan and the Pacific coast of Japan) in the years before about 1850. Thereafter, catches by net whalers declined, presumably because of stock depletion due to pelagic whaling.

Few right whales were taken by shore whalers along the coast of North America. Scarff (1986) found evidence of only 10 catches (and 13 additional sightings) between 1856 and 1886.

Pelagic whaling for right whales began in the Sea of Japan in the 1820s (Omura, 1986), on the 'Northwest' or Kodiak grounds in the central and eastern North Pacific in 1835 (Kugler, 1986), and in the Okhotsk Sea in 1845 (Kugler, 1986). Best (1987) estimated a total catch of about 14,500 right whales by American pelagic whalers in the North Pacific (including the Okhotsk Sea) between 1835 and 1904, of which more than $90 \%$ were taken in 1840-59. These cannot be allocated to grounds.

The catches summarised above make no allowance for hunting loss, and they do not include catches by British, French and other European whalers.

\subsubsection{Southern Hemisphere}

Shore-based catches in the Southern Hemisphere can be allocated to management units, based primarily on locations of winter calving grounds. Pelagic catches, however, have often been compiled in a coarser manner and therefore cannot readily be allocated to particular units. In the Tables and text below, the Southern Hemisphere catch data are presented in mixed format, with catches by shore whalers grouped by coastal wintering area, catches by offshore whalers assigned to coastal wintering areas when possible ('bay whaling'), and the rest only to ocean basin.

\subsubsection{SOUTH PACIFIC}

Best (1987) estimated that American whalers took about 14,700 right whales in the South Pacific between 1815 and 1909. He made no attempt to allocate these catches to specific grounds, but Dawbin $(1953 ; 1988)$ used the same data (from Starbuck, 1878) to estimate American catches off New Zealand totalling 4,487 in 1832-1901 (all but four before 1850). Although shore whaling began in Australia as early as 1805 , catch records are available only beginning in 1827. Shore-based catches peaked in the 1830s and 1840s, with a total of 10,148 from 1827-53 for South Australia, Victoria, New South Wales and Tasmania, combined. New Zealand shore whaling began in 1829 and peaked in the 1840s. The shore whalers based in New Zealand took 2,715 right whales from 1830-1930. In addition, whalers from Australia took at least 2,638 right whales in New Zealand waters from 1833-68 (Dawbin, 1986). French whalers took an estimated 3,871 near southern Australia, Tasmania and New Zealand in 1835-41 (Du Pasquier, 1986).

Pre-modern catches of right whales along the west coast of South America have not been well documented. It is known that French whalers took about 2,372 on the Coast of Chile ground in 1817-37 (Du Pasquier, 1986) and some of the catches attributed by Best (1987) to the South Pacific would have been off South America.
None of the above estimates includes allowance for hunting loss. Nor are returns from British and German whaling in the South Pacific fully taken into account.

\subsubsection{SOUTH ATLANTIC}

The estimated total catch of right whales by American whalers in the South Atlantic from 1805 to 1914 is 28,532 (Best, 1987). Best and Ross (1986) estimated a total catch of 1,580 by shore whalers in southern Africa between 1792 and 1912. Estimates of catches by French whalers can be apportioned to different grounds (Du Pasquier, 1986): 1,252 off southern Africa, 1785-1837; 382 at Tristan da Cunha, 1830-37; 2,369 on the Brazil Banks/Falkland Islands, 1785-1837; and 624 on unspecified grounds (summarised here from IWC, 1986a, p.29).

Richards (1993) attempted a comprehensive compilation of catches on the Brazil Banks/Falklands grounds by pelagic whalers from France, Britain, the USA and Spain between 1765 and 1812, and summarised the literature of Brazilian shore whaling. Shore whaling, which targeted mainly females and calves, began in 1603. By 1678, and for a century following, 4-6 (or more) shore stations took 20-30 whales each year. After 1770, total annual catches were as high as 1,000 but soon declined, averaging only 190 per year in 1793-96. By the 1820s only a few tens of whales were being taken per year, and the shore operations ceased.

Richards (1993) estimated a combined total catch, including that of the shore whalers in Brazil and that of the multinational fishery on the Brazil Banks/Falklands grounds offshore, at about 29,500 right whales between 1772 and 1814. This estimate partially overlaps those of Best (1987) for the American whalers and Du Pasquier (1986) for the French.

None of the above estimates allows for hunting loss.

\subsubsection{INDIAN OCEAN}

Comparatively little pre-modern whaling for right whales has been documented for the Indian Ocean. Shore whaling in Madagascar began in the mid-1750s, and French whalers hunted right whales in Delagoa Bay, Mozambique, beginning in 1789 (IWC, 1986a). Du Pasquier (in IWC, 1986b, p.30) indicated that at least 103 were taken there in 1789-91 and that substantial whaling effort continued until at least 1803. Catches from Delagoa Bay between 1785 and 1805 by a multinational fleet are included in Richards and Du Pasquier (1989).

American pelagic whalers hunted right whales intensively on the Coast of New Holland Ground, offshore western Australia, in 1838-49 (Bannister, 1986a). Bannister (1986a) also estimated that at least 266 (possibly 311 ) right whales were taken by local bay whalers in SW Australia in 1836-66. Major whaling grounds were at St Paul/Amsterdam Island and Kerguelen Island (Desolation Ground). Another important right whale ground was at the Crozet Islands, where American whaling began in the early 1830s and ended by about 1848 when the ground was fished out (Richards, 1990). At least 1,080 right whales were taken by the American whalers at 'the Crozettes' in 1841-45 (Richards, 1990). Best (1987) estimated a total catch of about 12,500 in the Indian Ocean by American whalers between 1830 and 1909. Of this total, more than three-quarters were taken in the period 1835-44. It is important to note that the estimate by Richards (1990) is subsumed in the ocean-wide estimate by Best (1987).

None of the above estimates allows for hunting loss. 


\subsection{Modern}

8.2.1 North Atlantic, 1900-1967

About 140 right whales were taken in the eastern North Atlantic between 1902 and 1967, including about 100 killed off the Shetlands, Hebrides and Ireland in the years 1906-1910 (Brown, 1986). This intense episode of whaling seems to have had a catastrophic effect on the right whale population in the eastern North Atlantic.

Two right whales were killed by shore whalers in Newfoundland: one in 1937 and one in 1951 (Mitchell et al., 1986).

\subsubsection{North Pacific, 1900-1970}

Catch data for the North Pacific since 1900 were summarised in SC/M98/RW10. Between 1911 and 1946, Japanese whalers took 160 right whales in the western North Pacific (Omura, 1986), and an additional 18 animals were taken between 1915 and 1946 (SC/M98/RW10). In the 1950s, 10 whales were taken for scientific research by Soviet whalers off the Kurils, and two for scientific research by Japanese whalers off eastern Japan. Two were taken for scientific research by Japan in the Okhotsk Sea in 1968, two by China in the Yellow Sea before 1978, and one by Korea in the Sea of Japan in 1974 (SC/M98/RW10).

In the eastern North Pacific, about 28 right whales were taken in the Gulf of Alaska, Bering Sea and British Columbia waters between 1911 and 1938 (SC/M98/RW10). One animal was taken off California in 1924, one off British Columbia in 1951, and ten in the Gulf of Alaska and Bering Sea in the 1960s (SC/M98/RW10). All but one of the latter were taken for scientific research by Japan.

Of special importance is the discovery that large illegal catches were made by Soviet whalers between 1958 and 1964. Two factory ships built specifically for the North Pacific, the Vladivostok and the Dalnij Vostok, began operations in 1963 and killed close to 200 right whales in the eastern North Pacific in 1964 (SC/M98/RW10). There is also evidence that 'hundreds' of right whales, including bowheads (SC/M98/RW10), were taken in the Okhotsk Sea in the 1960s and that additional unreported catches were made from shore stations in the Kuril Islands between 1948 and 1970 (Yablokov, 1994; SC/M98/RW10).

\subsubsection{Southern Hemisphere}

Relatively few right whales were officially reported as taken by modern whaling in the Southern Hemisphere. Catches of 63 at Campbell Island in 1909-13 (Dawbin, 1986), 38 in New Zealand between 1915 and 1959 (IWC, 1986b, p.30, citing Cawthorn, unpubl.; Dawbin, 1986), and occasionally in New South Wales through 1930 (Dawbin, 1986) were apparently made by open-boat shore whalers. At least 105 were taken in southern Africa, in the period 1908-75 (Best and Ross, 1986), 649 at South Georgia, the South Shetlands and Kerguelen, in 1900-1920 (Tønnessen and Johnsen, 1982), and 309 off Chile, in 1900-20 (Tønnessen and Johnsen, 1982). Catches from shore stations in Brazil occurred from at least 1950 to 1973, totalling approx. 350 (Palazzo and Carter, 1983).

Of particular significance are the previously unreported illegal Soviet catches during the period 1951/52-1971/72, totalling at least 3,349 (Tormosov et al., 1998). The largest documented catch was 1,335 whales off Patagonia in 1961/62. Large catches were also made in the southeast Atlantic (total 704, 1961/62-1967/68), the southwest Pacific (372, 1963/64-1969/70) and the southwest Indian Ocean near Crozet Island (309, 1962/63-1967/68).

\section{BIOLOGICAL PARAMETERS}

\subsection{Data collection: field and analysis techniques}

The Workshop agreed that it was important to try to standardise data collection and data fields to allow for comparisons among and between datasets on specific research questions. It reviewed the nature of the datasets maintained by some participants, and recognised that most studies maintained comparable datasets. It was agreed that as long as the data can be searched in a comprehensive manner, it is unnecessary to standardise all data fields. The Workshop did not attempt a comprehensive assessment of methodology and techniques of all data collection, but rather addressed specific categories of particular importance, i.e. photo-identification, biopsy and necropsy.

\subsubsection{Photo-identification data}

The focus of discussion on photo-identification data was the coding of the quality/detail of photographed sightings for comparison of matches within and among catalogues quantitatively, either to help to establish the level of confidence in a given match or to quantify the risk of missing a match. This is important when trying to obtain unbiased estimates of biological parameters or abundance (e.g. see Hammond, 1986). Currently there are no accepted standard methods for quantifying such risks but any that are developed will be more reliable if they are based on measures of quality for each sighting. The Workshop recognised that such estimates will be easier to derive for automated matching systems. It particularly encourages those groups anticipating future automation of their catalogues to initiate or expand the recording of quality measures.

Hiby demonstrated an automated system for matching aerial photographs of callosity patterns, as described in SC/M98/RW38. The system, developed with joint funding from IFAW and IWC, is being used to automate the catalogue of photographs from Argentina and the programs were provided to participants from South Africa and Australia at the Workshop.

\subsubsection{CODING OF PHOTOGRAPHED SIGHTINGS}

To quantify the quality of photographs (i.e. one or more photographs), five assessment categories with associated numerical codings (in parentheses) were agreed:

(A) Head obscured by water and/or glare: Quality: good (1), medium (2), poor (3), unmatchable (4).

(B) Focus/image size: Quality: good (1), medium (2), poor (3), unmatchable (4).

(C) Angle/foreshortening: Quality: good (1), medium (2), poor (3), unmatchable (4).

(D) Viewpoint: Left side only (1), right side only (2), topside/both sides (3).

(E) Distinctiveness of individual: Good (1): even with poor quality photographs, animal is distinctive enough to match.

Average (2): with average quality photograph, animal is distinctive enough to match.

Poor (3): generic/indistinct animal. Even with high quality photos, confirming match is difficult.

Because each study area uses different image types, it was agreed that rather than try to develop a standard assessment for these criteria, each research group should decide what 
photographs typify each of these categories. Ten or so example photographs should be printed by each group to ensure consistency in photograph coding over time and between individual researchers.

The Workshop recognised the value of long-term photo-identification studies (IWC, 1990b) in providing essential data for assessing and monitoring the status of right whale populations. It recommends the continuance of existing programmes and the establishment of new programmes where appropriate.

Given the value of the historical information contained in the various photo-identification catalogues, it also recommends that the images in catalogues be digitised and archived in a secure way (see IWC, 1990b, pp.9-10 for details).

\subsubsection{Biopsy data}

The Workshop discussed a range of topics pertinent to the collection of skin and blubber biopsy samples from right whales for both genetic and organo-chemical and biochemical analyses. The type and efficacy of various sampling systems were discussed along with other variables potentially affecting sample collection (e.g. angle and range of shot, class of animal, type of vessel).

A brief review of the methodology used and the number and location of samples currently available from different geographic areas is given in Annex E.

\subsubsection{STERILISATION OF BIOPSY TIPS}

The importance of sterilisation of biopsy tips was noted both for the whale (issues of infection) and for meaningful analyses (cross contamination). For DNA (skin) samples it was noted that either ethanol rinse and flaming and/or bleach would suffice. However, for organo-chemical (blubber) analyses it is important to clean the tip with solvent after flaming (see SC/M98/RW24)

Wherever possible, enough tips should be taken into the field to sample for the entire day, allowing tips to be used on only one animal before undergoing thorough sterilisation overnight or onshore.

\subsubsection{REACTION OF RIGHT WHALES TO BIOPSY}

All research groups have noted a range of apparently short-term reactions to biopsy darting. The frequency and extent of reaction is highly variable and is influenced by group size, activity of whale and possibly sex of whale. It was noted that females with calves show more reaction than do their calves.

Importantly, it was highlighted that the reaction to the vessel from which biopsy is being undertaken often exceeds the reaction to the biopsy darting itself.

The possibility and potential of alternative sampling methods is discussed below.

(a) Sloughed skin. Some difficulty was reported with accurately identifying the individual whale from which the sample comes. The quality and quantity of DNA in such samples is low (Whitehead et al., 1990) and may potentially limit analysis.

(b) Scrub scrapes. A system of using sterile nylon scrub pads to collect skin was described. Such a system has been successfully used on dusky and Hector's dolphins in New Zealand (Patenaude, pers. comm.) and on sperm whales (Whitehead et al., 1990). It was suggested that such 'non-penetrative' techniques may be useful for demographic studies where multiple sampling of individuals may be required. (c) Hand scrapes. It was suggested that peeling skin can be collected by hand from whales alongside boats. The method's feasibility for large whales is unknown, and there is the risk of sample contamination from the collector.

It was noted that none of these alternative techniques would provide blubber samples and that the small size of the samples may be restrictive for some types of DNA analysis.

\subsubsection{PERMITS AND REGULATIONS}

The Workshop highlighted the fact that calves typically show less reaction to biopsy darting than the mother and agreed that there is considerable scientific merit in obtaining samples from calves. Such samples can provide valuable data not otherwise available (e.g. sex ratio at birth, paternity analyses) and the Workshop recommends that, where possible, such samples should be obtained.

Permits for the acquisition and export or import of biopsy samples are subject to the requirements of domestic legislation, sometimes requiring public advertisement and comment. Researchers should therefore ensure that in planning research trips or distribution of samples, adequate time is allocated for fulfilling the requirements of the permitting process.

The Workshop recommends that IWC member nations should be asked to facilitate the transfer of skin/blubber biopsy samples between research institutions in different countries to assist collaborative analyses, and that the IWC Secretariat approaches the CITES Secretariat to determine the best way to facilitate the exchange of such material.

\subsubsection{Necropsy data}

The Workshop recommends that, where possible, necropsies should be conducted to determine the cause of death (SC/M98/RW8; SC/M98/RW25) and to collect biological samples relevant to studies of the recovery of right whale populations. Detailed necropsies should follow protocols described by Blaylock et al. (1996). At a minimum, collections should include: standard morphometric measurements; skin (or other tissue if skin is not present) in salt-saturated DMSO; skin/blubber interface in formalin; internal organ tissue in $10 \%$ neutral, buffered formalin; parasites in 70\% alcohol; and dried baleen (for genetic and isotope analysis).

In addition, there are a number of important ongoing studies that could be further addressed through necropsy data. A brief description of these, the sampling technique to be used and the researcher to contact for further information is given in Annex F.

\subsection{Methodology and estimates}

The Workshop first examined data and methodologies in the context of the assumptions underlying the models used and their likely reliability.

\subsubsection{Data types}

A number of points were noted that were applicable to all of the analyses used at the Workshop.

(1) Biological parameters for all populations were estimated on the basis of repeated photo-identification of individual whales usually from aerial, shore-based, or ship-based surveys.

(2) In the Southern Hemisphere, analyses were generally confined to cow-calf pair data; however, in the North Atlantic and all areas in the Southern Hemisphere apart 
from South Africa, individuals of all ages and both sexes are photographed.

(3) There is a potential lack of comparability among areas in observed calving events, because the relative timing and duration of surveys differ, as do the observation platforms.

(4) Assessing the quality of photo-identification catalogues and the extent of whale approachability will lead to improved population parameter estimates by enabling questions of heterogeneity in recapture probability to be better addressed (e.g. Hammond, 1986; IWC, 1990b). The question of photograph quality is discussed under Item 9.1. It was suggested that measuring the time necessary to photograph an individual could provide an index of approachability. Inter-individual differences will introduce heterogeneity which may lead to biased estimates as discussed below.

Two further issues pertinent to the estimation of age at first parturition were identified.

(1) All analyses use observations of mothers first identified as calves, taking into account the possibility that a first calf may have been missed and that insufficient time may have passed for some animals to have yet had their first calf.

(2) For Argentinian and South African whales, a subset of animals was used, because these were easier to re-identify. It is assumed that this subset is representative of the whole group of maturing females.

\subsubsection{Parameter estimation methodology}

The following papers containing estimates of biological parameters were presented.

SC/M98/RW12 uses a model that is an extension of one used in an earlier paper for animals off Argentina (Payne et al., 1990). It uses a maximum likelihood approach. The total population is forced to follow an exponential rate of increase, while allowing each yearly calving group to be of different sizes. This allows more flexibility for fitting the model and providing estimates of inter-calf interval, population rate of increase and mortality rate for calving females. Tests for time trends in mortality rate and in population rate of increase are also made. The model is extended to estimate age at first parturition, by requiring that a maximum value for that age be specified.

SC/M98/RW16 applies the method of Payne et al. (1990) to animals off South Africa, to estimate inter-calf interval, population rates of increase and survival rates, and is extended to estimate age at first parturition for females. The authors then use the balance equation to explore the likelihood of different possible values of population rate of increase on the assumption that juvenile survival should not exceed that of adults.

SC/M98/RW3 also uses a maximum likelihood approach, somewhat comparable to that of Payne et al. (1990). Sighting histories of all categories of individuals (i.e. juveniles, mature males, calving and non-calving females) in the western North Atlantic population are used. The model estimates annual survival probability, given different hypothesised patterns of sighting probability: constant; variable over time; or depending on an index of 'offshore' habitat use. Tests for time trends in survival rate are made.

SC/M98/RW15 uses a Bayesian approach to estimate the size of the mature female population off South Africa and the population rate of increase. The estimation method requires a prior distribution for the starting population size and a 'first guess' for initial rate of increase. Survival rate values for each three-year interval are obtained from the mark-recapture program SURGE, which uses a maximum-likelihood approach similar to that in the three papers above, and is based on the assumption of a fixed three-year calving cycle.

SC/M98/RW1 presented estimates for certain biological parameters (e.g. mortality rate) for the western North Atlantic based on a six-year running total of catalogued animals (i.e. animals seen during the period, excluding known deaths). Two problems identified with this straightforward approach are that: (a) some animals that are alive may not be seen during the six-year period; and (b) changes in geographical coverage over the period will affect the likelihood of sighting animals.

Best and Kishino (1998) use a regression approach to obtain estimates of mortality rate for calving females off South Africa. It was noted that the methods used, although robust, are subject to bias of known direction but of unknown magnitude.

Underlying assumptions of the estimation methods presented, their biological significance and the effects of their violation, are given in Table 2; assumptions shared by all estimation methods are listed first, followed by the particular assumptions of each model. The importance of the effects of violations of these assumptions can be tested using the different methodologies on synthetic datasets.

\subsubsection{RECOMMENDATIONS AND CONCLUSIONS}

The Workshop agreed that of all the potential biases arising from possible violation of the assumptions listed in Table 2, those related to probable differences in parameter values by sex and age in the analysis presented in SC/M98/RW3 potentially introduced the most serious bias into results. It recommends that the authors continue to develop their methodology to allow for these factors (and see Item 9.2.2 below).

\section{It also recommends that:}

(1) the effects of problems in re-identification from catalogue photographs on estimates of sighting probability be tested (e.g. if the catalogue admits photographs showing only part of the callosity pattern, a new partial pattern will not be accepted as a new whale because it will not be comparable to the entire catalogue, but may be accepted if it matches an existing partial pattern);

(2) the effects of differential approachability of individuals on their inclusion in the dataset be examined;

(3) the effects of dependence between successive calving cycle lengths on the estimation methods of SC/M98/RW12 be examined;

(4) the different models presented be used to examine the same datasets (and vice-versa) in order to understand better their differences and similarities - any inconsistencies between results should be thoroughly investigated (e.g. see Item 10).

\subsubsection{AGE AND GROWTH}

Maximum lengths of males and females, and ranges in calf size are given in Table 3.

\subsection{NORTH ATLANTIC}

There is limited information available on longevity based on photo-identification records (Hamilton et al., 1998). Only seven catalogued animals were first identified over 20 years ago. One animal fortuitously identified from a photograph 
Table 2

Assumptions used in the papers addressing biological parameters (see text).

Assumptions

Assumption biologically appropriate? Relevant data

General/all methods

Calving (= potential sighting) intervals independent of

each other for the same individual

No heterogeneity in sightings probability among individuals

'Mortality' includes death, emigration and reproductive senescence

\section{'Mortality' excludes immigration}

\section{SC/M98/RW12 - Argentina}

Constant trend in population rate of increase over time

used in estimating other parameter estimates

\section{SC/M98/RW15 - South Africa}

Bayesian; uses a prior distribution on population size beginning of time series + first guess at initial rate of increase and survival rate

Three-year cycle in sighting availability of calving females

\section{Best and Kishino, 1998 - South Africa}

Constant sightings probability over time

If individual not resighted within nine years after firs sighting, it is assumed dead

\section{SC/M98/RW3 - North Atlantic}

Survival rate equal in a given year irrespective of sex, age and breeding status (i.e. calving or not)

\section{Same assumption for sightability}

Effect of spatial distribution assumed to be adequately modelled by offshore index

May be incorrect if calves are lost and not observed

Australia: observation that certain females are seen to calve at more regular intervals than others.

The effects of violations of this assumption have not been checked.

Incorrect if a shift in geographical distribution is undetected.

Potential problem of recognition of photographed individuals from catalogue.

Some individuals are less approachable, so less likely to be photographed.

Some individuals may be photographed more due to clear markings, thus are more likely to be 'resighted' and re-identified, especially if observed in large groups.

North Atlantic: use of all members of the population regardless of age or sex can lead to erroneous parameter values; heterogeneity in sightings probability between cow/calf pairs and females in their non-calving years. Violation of this assumption may affect estimation of absolute population size and mortality rate; possibly low effect on inter-birth interval estimate; population trend estimate likely unbiased unless heterogeneity levels change with time.

No evidence of senescence in Argentinian population.

North Atlantic: 1 female with 29 years of reproductive history.

Russian data: lower \% pregnant in the largest females, but low sample size (not statistically significant count at $5 \%$ level).

In general, observation periods are not long enough to detect signs of senescence.

In bowhead whale catch data, anatomical signs of senescence.

Immigration of individuals would not bias mortality rate estimate downward from true value, but would bias the population rate of increase upwards.

Probable heterogeneity in sighting probability between cow/calf pairs.

In SC/M98/RW16 evidence for a three-year cycle in estimated number of calves/year, contrary to assumption of constant trend in increase over time; unlikely to cause bias in survival and rate of increase estimates, but may affect precision.

Posterior distributions not very sensitive to choice of first guesses of rate of increase and survival rate in South African case.

Probably little effect if a small deviation from this cycle.

In both Argentina and South Africa lower effort now than at start of the study has lowered sighting probability over time.

Argentina: about $50 \%$ sighting probability/year/individual, resulting in a $12 \%$ chance of no sighting over nine years if still alive.

S. Africa: $\sim 75 \%$ sightings probability giving a $2 \%$ chance of no sighting if still alive.

Assumption critical, and survival probability is very sensitive to it; however the bias produced is in a known direction (mortality biased upward).

From other mammal species, survival not constant over age; early year(s) likely to have lower survivorship.

Effect of breeding status on survival estimate unknown.

Some neonatal mortality will happen before sighting.

Calving and non-calving females have different sightability.

In North Atlantic mature females have different sightability from males and juveniles.

Offshore index takes into account shift in sightings effort over time, but not potential shifts in population structure.

Observed shifts in geographical distribution on feeding grounds in the 1990s and influx of newly mature females violate this assumption.

Differentials in distribution of different age classes at different distances offshore could cause the estimated changes in demographic parameters over time. 
Table 3

Summary of maximum length data for right whales.

\begin{tabular}{lccc}
\hline Species & Males & Females & Calves (mean length at birth) \\
\hline North Atlantic & $12.9 \mathrm{~m}$ (Allen, 1916) & $59 \mathrm{ft}(18 \mathrm{~m})$ Thompson $(1928)$ & $c a 4 \mathrm{~m}$ \\
North Pacific & $17.1 \mathrm{~m}$ (Klumov, 1962) & $18.3 \mathrm{~m}$ (Klumov, 1962) & $6 \mathrm{~m}($ Ohsumi, 1981) \\
Southern Hemisphere & $>16 \mathrm{~m}$ (Tormosovet al., 1998) & $53.7 \mathrm{ft}(16.5 \mathrm{~m})($ Best and Ross, 1986) & $6.1 \mathrm{~m}($ Best, 1994) \\
\hline
\end{tabular}

taken in 1935 was re-photographed over 60 years later. A female photographed with a calf in 1967 was also seen with a calf 29 years later, in 1996.

Hamilton et al. (1998) also presented information on the age-structure of the population in 1996, both with and without presumed mortalities being taken into account. Juveniles and calves accounted for $26-31 \%$ of the population, considerably less than the estimate of $56-58 \%$ given for the Bering-Chukchi-Beaufort Seas stock of bowhead whales by Zeh et al. (1993).

\subsection{NORTH PACIFIC}

Little information exists for North Pacific animals, other than that for maximum lengths given in Table 3.

\subsection{ARGENTINA}

An age-length key for animals aged up to 10 years (albeit with wide confidence intervals) was published by Whitehead and Payne (1981). The longest active reproductive span from the photo-identification catalogue is 26 years.

\subsection{SOUTH AFRICA}

Best and Rüther (1992) measured 72 cow-calf pairs photogrammetrically in 1988 and 1989. Adult females ranged from about $12.4-15.5 \mathrm{~m}$. Presumed primiparous females were smaller on average than those believed to have had at least two calves (13.5m versus $14.3 \mathrm{~m}$ ). Primiparous females also appeared to give birth to smaller calves $(5.4 \mathrm{~m}$ versus $5.9 \mathrm{~m}$ ). Calf growth rates were of the order of $2.8 \mathrm{~cm}$ per day $( \pm 0.7 \mathrm{~cm})$ and calves grew to about half their mother's length by mid-October.

From stable isotope analysis of baleen plates, Best and Schell (1996) concluded that growth in body length slowed markedly after weaning. Best speculated that the presence of distinct modes in the length composition at $9-12 \mathrm{~m}$ (SC/M98/RW25 and Tormosov et al., 1998) suggested that a spurt in growth preceded sexual maturity.

\subsection{AUSTRALIA}

The longest active reproductive span identified thus far is 25 years (Burnell, pers. comm.).

\subsection{WESTERN NORTH ATLANTIC}

SC/M98/RW1 reported a mean mortality rate of about 0.031 $(\mathrm{SD}=0.017)$ for the period 1986-97. Methodological concerns regarding the approach used are given above and under Item 10.

Additional methodological work is recommended under Item 9.2 with respect to the technique for estimating survivorship given in SC/M98/RW3. The Workshop recommends that the results of this work be presented to the IWC Scientific Committee as soon as possible, given the possibility raised in the preliminary analysis that survival rates may have declined in recent years.

\subsection{ARGENTINA}

SC/M98/RW12 estimates adult female annual mortality as $0.020(\mathrm{SE}=0.005)$ for the period 1971-90. The authors had found no evidence for any trend over the time period. From a balance equation, an estimate of $0.92(\mathrm{SE}=0.11)$ was derived for survival of females from birth to first parturition.

\subsection{SOUTH AFRICA}

SC/M98/RW16 provides an estimate of adult female survivorship of $0.99(95 \%$ CI $0.975,1.005)$ for the period 1979-96, using similar methodology to that given in SC/M98/RW12.

SC/M98/RW15 provides an alternative estimate of survivorship based on a duck hunting mark-recapture approach. Annual adult female mortality was estimated as 0.978 (95\% CI 0.969, 0.985). SC/M98/RW16 also provides an estimate of juvenile survivorship. Although the point estimate (1.02) is biologically not feasible, the 95\% CI $(0.504,4.59)$ is wide; the authors also noted that some $75 \%$ of neonatal mortality occurred before the survey period, which would naturally have led to a higher estimate of juvenile survival.

\subsubsection{REPRODUCTIVE PARAMETERS}

9.2.2.3.1 AGE AT SEXUAL MATURITY

Western North Atlantic

Based on resightings information $(n=19)$, Hamilton et al. (1998) estimated the median age at first parturition to be 9.5 years. Observed ages ranged from 5-14 years. The authors also investigated the question of missed calvings.

\section{Argentina}

SC/M98/RW12 estimated mean age at parturition as 9.0 years $(\mathrm{SE}=0.3)$. The modal age at first calving was also nine years, with about $50 \%$ of first calvings occurring at this age. Observed ages ranged from seven to an inferred maximum of 11 years.

\section{South Africa}

SC/M98/RW16 estimated 9.1 years as the age at which 50\% of first calvings occur $(95 \%$ CI 7.3, 31.4). Observed ages ranged from 6-13 years $(n=123)$. Further analyses taking into account the proportion of marked animals at each age that had not reached parturition age would reduce the upper confidence limit.

\section{Australia}

The only available information is from two females observed with their presumed first calves, giving ages at first conception of eight years and nine years (Bannister, pers. comm.).

\subsection{PREGNANCY RATE AND CALF PRODUCTION}

North Atlantic

SC/M98/RW1 reported a mean gross annual reproductive rate $(\mathrm{GARR})$ of $0.0423(\mathrm{SD}=0.0186)$ for the period 1986-1997. 


\section{Argentina}

SC/M98/RW12 estimated a pregnancy rate of 0.339 $(\mathrm{SE}=0.006)$.

\section{Southern Ocean}

Aggregated data from Soviet catches (Tormosov et al., 1998) obtained from three factory ships in 1960/61-1967/68 gave increasing pregnancy rates for a series of size classes from $12-12.4$ to $15.5-15.9 \mathrm{~m}$ of $4.0-39.0 \%$. For the largest females, $>16 \mathrm{~m}$, the rate was $16.7 \%$, but this estimate was based on a small sample, and not statistically significantly different from the rates reported for immediately smaller animals. Some of the low rates in the smaller size intervals above $12.5 \mathrm{~m}$ probably reflect the presence of some immature animals in the sample.

\section{Auckland Islands}

The percentage of calves observed over three years averaged $11.8 \%$ (range $9.4-13.8 \%$ ) of the total number of animals observed (SC/M98/RW20).

\subsection{REPRODUCTIVE CYCLE/SEASONALITY \\ North Atlantic}

For the western North Atlantic, Knowlton et al. (1994) gave a mean interval of 3.67 ( $\mathrm{SE}=0.11, n=86$, range 2-7) years. The Workshop noted that there had been an increase over time in recent years (SC/M98/RW1). The rates were variable but for 1985-1997 there was a significant increase $(p<0.001)$ from 3.33-5.36 years. The variable intervals had been shown not to be affected statistically by sampling.

SC/M98/RW29 reported that changes in calving rate could be correlated statistically with the Southern Oscillation Index (SOI), with low calving years one year after minima in the SOI, which indicate El Niño years. With an intense El Niño in 1998, a low calving rate would be expected in 1999.

\section{South Atlantic}

For Argentina, there was no detectable time trend in calving interval (SC/M98/RW12). The mean interval was 3.35 years $(\mathrm{SE}=0.05)$. The mean calving interval estimated using the same model for South Africa (SC/M98/RW16) was 3.12 years $(95 \%$ CI $3.05,3.17)$. The probability distribution of calving intervals differed from that for right whales off Argentina in that it contained more three-year intervals $(0.85$ vs 0.692) and fewer five-year intervals (0.03 vs 0.131). Payne et al. (1990) suggested that the high probability for a five-year interval off Argentina reflected animals losing their calves soon after birth (and before being sighted), and then changing from a three- to a two-year cycle. However, the Workshop could offer no explanation of why the South African situation should differ.

\section{Australia}

Observations at Head of the Bight, South Australia (SC/M98/RW19), gave an interval of 3.3 years $(\mathrm{SE}=0.1$, $n=57)$. A larger sample, including animals from a wider area of the Australian southern coast, gave an estimate of 3.64 years $(\mathrm{SE}=0.13, n=117)$. The Workshop noted that the estimates were not directly comparable with those derived using a modelling approach as in SC/M98/RW12.

\section{ESTIMATES OF ABUNDANCE AND TRENDS}

In presenting estimates of abundance and population trends for the southern right whale, the Workshop agreed to divide the Southern Hemisphere into 11 management units based on the breeding stocks given under Item 7: sub-Antarctic New Zealand, Australia, Central Indian Ocean, Mozambique, South Africa, Namibia, Tristan da Cunha, Brazil, Argentina, Chile/Peru and mainland New Zealand/Kermadec. Current best estimates of certain demographic parameters and population sizes for each of these regions are summarised in Table 4.

\subsection{Population trends}

\subsubsection{Increase rates - Southern Hemisphere}

10.1.1.1 AUSTRALIA

SC/M98/RW18 provides aerial survey data at the peak of the season (mid-August to mid-September) for three sections of the southern coast of Australia: (A), (B) and (C) in increasing extent along the coast from east to west (SC/M98/RW18, fig. 2 ). The areas were selected to cover the main areas of whale concentration, initially off the southern Western Australian coast (Areas (A), (B)) and later extended eastwards to South Australia to embrace the major area of coastline along which coastwise movements had been detected (Area (C)). For each dataset, information is provided for three classes of whale: (a) all animals; (b) 'unaccompanied' animals; (c) cow-calf pairs. Data for areas (A) and (B) are provided for the 15-year period 1983-97, excluding two years in (A) and four years in (B) (ibid table 1) and for the five-year period 1993-97 for (C). Regressions of the natural logarithms of

Table 4

Summary of estimates of certain demographic parameters and current abundance levels for different breeding stock population units used for the modelling exercise described in Item 10.3. A dash indicates no information.

\begin{tabular}{|c|c|c|c|c|c|c|}
\hline Breeding unit & $\begin{array}{l}\text { Growth } \\
\text { rate } r\end{array}$ & $\begin{array}{l}\text { Annual } \\
\text { survival } S\end{array}$ & $\begin{array}{l}\text { Age at first } \\
\text { parturition } t m\end{array}$ & $\begin{array}{l}\text { Most recent population } \\
\text { estimate of mature females }\end{array}$ & $\begin{array}{l}\text { '1997' estimate of mature } \\
\text { females used in model }{ }^{1}\end{array}$ & $\begin{array}{l}\text { ' } 1997 \text { ' total population (i.e. all } \\
\text { animals) estimate used in model }\end{array}$ \\
\hline New Zealand & - & - & - & 69 (1997) & 70 & 330 \\
\hline Australia & 0.0825 & - & - & $220(1995)$ & 254 & 1,197 \\
\hline Central Indian Ocean & - & - & - & - & 0 & 0 \\
\hline Mozambique & - & - & - & $<10$ & 0 & 0 \\
\hline South Africa & 0.072 & $0.98-0.99$ & 9.1 & $613(1996)$ & 659 & 3,104 \\
\hline Namibia & - & - & - & $<10$ & 0 & 0 \\
\hline Tristan da Cunha & - & - & - & $20(1985)^{2}$ & 48 & 226 \\
\hline Brazil & - & - & - & $25(1995)$ & 29 & 137 \\
\hline Argentina & 0.071 & 0.98 & 9.0 & $330(1990)$ & $547^{3}$ & 2,577 \\
\hline Chile/Peru & - & - & - & $<10$ & 0 & 0 \\
\hline NZ/Kermadec & - & - & - & - & 0 & 0 \\
\hline Total & & & & & 1,607 & 7,571 \\
\hline
\end{tabular}

${ }^{1}$ Estimates calculated assuming a growth rate of 0.075 for all areas. ${ }^{2}$ Upon review later in the meeting, it was felt that this number was probably too high.

${ }^{3}$ This is entirely extrapolation-based, as data are available only to 1990. 
maximum counts of cow-calf pairs for all three areas are significantly different from zero $(p=0.0001-0.025)$ for the data for the two (smaller) areas (A) and (B), but not for the larger area (C) (ibid table 3 (c)).

The Workshop agreed that the increase rate for Area (A)(c) was the best available at this time for the following reasons:

(1) the final two years, 1996 and 1997, of all the datasets are likely to be less comparable with the remainder because of a change in pilot and observer following the death of the pilot employed for all flights until 1995; the effect is relatively greater for the short five-year dataset (C) than for the others (there is also concern that the 1997 results include some undercounting because of bad weather); and

(2) although Area (B) traverses somewhat more of the coastline than (A), the probability level for the regression is lower ( $p=0.025 \mathrm{cf}$. 0.0001) and the 95\% confidence interval much wider $(0.128-0.1297)$ than for Area (A), despite the lower estimated increase rate, of $7.12 \%$.

The Workshop agreed that the current best estimate of the rate of increase for this population was 0.0825 (95\% CI $0.510-0.1140$ ) for the period 1983-97.

\subsubsection{SOUTH AFRICA}

SC/M98/RW15 estimated an annual increase rate of 0.0733 $(\mathrm{SE}=0.41 \%)$ per annum for right whales off South Africa, based on a regression analysis of numbers of cow-calf pairs seen during annual aerial surveys off the southern coast of South Africa from 1969-1996. This estimate would be negatively biased if survey efficiency declined with time. Two alternative estimates are available. Based on the model of Payne et al. (1990) for estimating a trend in the number of calvings produced, SC/M98/RW16 estimated an annual rate of increase from 1982-1996 as 0.081 (95\% CI 0.06, 0.97). However, this estimate is thought to be biased upwards because it is clearly sensitive to the last data point (for 1996) which reflects a stronger cohort in the breeding group. SC/M98/RW15 also uses a Bayesian approach to estimate values which yield values for current population growth rate in the range 0.071-0.073. The Workshop agreed that an increase rate of 0.072 represented the best estimated annual increase for this population.

\subsubsection{ARGENTINA}

The annual rate of increase for the breeding female component of the Argentinian concentration was estimated at $0.071(\mathrm{SE}=0.8 \%)$ in $\mathrm{SC} / \mathrm{M} 98 / \mathrm{RW} 12$ for the period 1971-1990. This is a maximum likelihood estimate based on resightings of females with calves only, and the Workshop agreed that it represented the best estimate of increase rate for this population.

\subsubsection{OTHER REGIONS}

There was no information available for other areas.

The Workshop recommends that two additional datasets should be investigated in the future: (1) the sightings data collected by Japanese scouting vessels (JSV) in the Antarctic during the years 1965/66-1981/82, some of which has been analysed by Ohsumi and Kasamatsu (1986); and (2) the data from the Japanese Antarctic Research Programme which began in $1987 / 88$.

\subsubsection{Increase rates - Northern Hemisphere}

\subsubsection{WESTERN NORTH ATLANTIC}

Best commented that population simulations of the Western North Atlantic right whales suggest that some recovery must have taken place following protection in 1935, and that this slow recovery seemed to have continued at least until the 1980s (Reeves et al., 1992).

SC/M98/RW1 provided population size estimates based on a six-year running total of catalogued animals (see Item 9.2). The values were used to obtain an annual rate of increase (range -0.039 to +0.031 ) for each of the years 1987-1996. A regression estimate obtained using all the data is probably negatively biased $(0.01, \mathrm{SE}=0.0232$ although the SE needs to be adjusted to account for the fact that the data are correlated) because of reduced sampling effort in recent years.

Annex G summarises three alternative methods used to obtain estimates of the rate of increase for this population. The first provides an estimate of 0.0159 (CI -0.0246 , 0.0564) with the caveat that the result is likely to underestimate the rate of increase for the 1980s because the calving interval has increased significantly in recent years. The second looks only at parous females and shows an increase between 1985 and 1997 (0.035, 95\% CL 0.024-0.045) but with an apparent long-term oscillation in recruitment. The third (based on the approach outlined in SC/M98/RW3) suggests that 0.043 is an upper bound to the population growth rate. Although actual growth rates are likely to be considerably less than that, the figure serves to illustrate that the growth rate of the North Atlantic right whale is both low and substantially less than that of southern right whale populations.

In view of the methodological concerns expressed under Item 9.2, the Workshop did not believe it was in a position to reach any firm conclusions as regards recent population trends.

Given concerns expressed about the status of this population (see Item 11) the Workshop recommends that as a matter of urgency further work is carried out to provide quantitative information on population trends. For example, more complex models (which allow for parameters such as calving rate to vary with time) should be explored to test for any possible changes in trend. In addition, the use of stochastic models should be explored: stochasticity is particularly important when considering small populations. The Workshop also noted that there are indications of a decrease in growth rates in recent years, as suggested by a statistically significant increase in the calving interval and three years of poor calf production (SC/M98/RW1). Further concerns were related to a major change in the feeding grounds that is thought to have occurred, as well as to an increase in reported ship strikes and potentially fatal entanglements in recent years.

\subsubsection{NORTH PACIFIC}

No information on trends is available. Given the concerns expressed under Item 11 about the status of right whales in the North Pacific, the Workshop recommends that studies designed to assess population trends be implemented as a matter of urgency.

\subsection{Estimates of current abundance}

The estimates reported below refer to adult females where no direct estimates of total population size had been carried out. For modelling purposes (see Item 10.3) 'best' annual estimates of the number of females have in some cases been multiplied by a factor of three under the assumption that 
there is a fixed three-year calving cycle and hence three separate cohorts. Item 10.3 indicates how the estimates may be converted for certain cases to total population numbers for use in simulations.

The estimates of abundance given below and in Table 4 have different levels of reliability. They can be divided into four categories:

(1) based on regular research surveys over an extended period: Australia, South Africa, Argentina;

(2) based on limited research: New Zealand sub-Antarctic, Brazil, Tristan da Cunha;

(3) based upon opportunistic sightings: Mozambique, Namibia, Chile/Peru, Mainland New Zealand/ Kermadecs;

(4) no recent information: Central Indian Ocean.

\subsubsection{Southern Hemisphere}

\subsubsection{SUB-ANTARCTIC NEW ZEALAND}

No surveys aimed at estimating absolute population size have been carried out. A crude estimate of 23 females per year can be obtained from the average maximum count of females obtained during directed research in the Auckland Islands in 1996 and 1997 (SC/M98/RW20). This is probably a minimum estimate because of uncertainty as to the timing of the peak season in this area and the presence of an unsurveyed area.

\subsubsection{AUSTRALIA}

SC/M98/RW18 provides estimates of the number of cow-calf pairs observed during aerial surveys of Southern Australia, between Cape Leeuwin, Western Australia and Ceduna, South Australia during 1993-97. As noted under Item 10.1, estimates for 1996 and 1997 are likely to be biased downwards. However, during the earlier period and within the area surveyed, the counts are likely to represent only a slight undercount of the absolute number of adult reproductive females visiting the coast each year because: (1) the cow-calf pairs are relatively sedentary and easily visible; (2) surveys are conducted during the period of peak abundance; and (3) aspects of the survey methodology were changed as little as possible over the years (see SC/M98/RW18). In 1995, 65 cow-calf pairs were counted in the survey area. Based on an incidental flight network for photo-identification off southeastern Australia, the estimated minimum number of cow-calf pairs sighted in coastal waters between Sydney and Coffin Bay (South Australia) in 1995 was six (Burnell, 1997). Furthermore, an additional two cow-calf pairs were sighted off the west coast of Western Australia in 1995 (Bannister, pers. comm.), yielding a 'best' population estimate of 73 reproductive females for 1995.

\subsubsection{CENTRAL INDIAN OCEAN}

There was no information available for this area.

\subsubsection{MOZAMBIQUE}

No right whales were seen during a winter survey of the coastal waters of southern and central Mozambique in 1991 (Findlay et al., 1994). The absence of any current sightings of cow-calf pairs in the area suggests that the current population size is zero. However, a few individual right whales were sighted moving up the Natal coast during several months of intensive humpback whale surveys during 1990 (K. Findlay, pers. comm.) and it is possible that the area may be restocked in the future from the South African population.

\subsubsection{SOUTH AFRICA}

Aerial surveys for cow-calf pairs have been carried out since 1969. SC/M98/RW15 provides an estimate, based on a Bayesian approach, of 613 (95\% CI 583-646) adult females in the South African population in 1996. Results presented in SC/M98/RW16 can be used to derive a rough 1996 population size estimate of 453 , based on summing estimates of the number of adult females present for each of the previous three years. Although the Workshop agreed that the former estimate was based on a more thorough analysis, it expressed some concern at the extent of the difference between the two approaches and recommends further investigation (see also Item 9.2).

\subsubsection{NAMIBIA}

No surveys have been carried out. There have been 1-2 incidental sightings per year of cow-calf pairs there (Best, pers. comm.). However, the Namibian coast is generally very isolated and the actual number of whales present may be greater. For simulation purposes only, an estimate of $<10$ cow-calf pairs was adopted.

\subsubsection{TRISTAN DA CUNHA}

No surveys designed to estimate absolute population size have been carried out. The only available information is derived from aerial surveys conducted on a single day in each of the years 1985-89. Although the daily surveys were fairly comprehensive in terms of their coverage of the three islands, they were subject to factors such as poor weather conditions. The maximum number of cow-calf pairs seen on any of the days surveyed was two, suggesting that the total number of reproductive females in this population over this period was very low.

\subsubsection{BRAZII}

No surveys designed to estimate absolute population size have been carried out. Fixed-wing surveys were undertaken off southern Brazil in 1987 and 1988, producing counts of 29 adults and 6 calves, and 12 adults and 8 calves, respectively (Best et al., 1993). Aerial surveys of right whales off southern Brazil in 1993, 1994 and 1997 (Palazzo and Flores, pers. comm.) yielded counts of cow-calf pairs of 6,10 and 9 (Table 5).

Table 5

Summarised information on aerial surveys of right whales off southern Brazil, 1993-94 (Palazzo and Flores, unpublished data).

\begin{tabular}{llcccc}
\hline Year & Month & $\begin{array}{c}\text { No. } \\
\text { flights }\end{array}$ & $\begin{array}{c}\text { Distance surveyed } \\
(\mathrm{N} \leftrightarrow \mathrm{S})\end{array}$ & $\begin{array}{c}\text { No. whales } \\
\text { sighted }\end{array}$ & $\begin{array}{c}\text { No. cow/calf } \\
\text { pairs }\end{array}$ \\
\hline 1993 & Late Aug. & 01 & $400 \mathrm{~km}$ & 17 & 6 \\
1994 & Late Aug. & 01 & $400 \mathrm{~km}$ & 27 & 10 \\
1997 & Late Sep. & 01 & $400 \mathrm{~km}$ & 24 & 9 \\
\hline
\end{tabular}

\subsubsection{ARGENTINA}

Aerial surveys have been carried out in the Peninsula Valdés region since 1971. SC/M98/RW12 provides an estimate of 330 (95\% CI 274-386) for the size of the breeding female component in 1990. This is a maximum-likelihood estimate based on resightings of females with calves only.

\subsubsection{CHILE/PERU}

No surveys designed to estimate absolute population size have been carried out. Sightings of right whales off the coasts of Chile and Peru appear limited to approximately 10 
sightings since 1984 (Aguayo and Torres N, 1986; Van Waerebeek et al., 1992). Three or four of these were of cow-calf pairs.

\subsubsection{MAINLAND NEW ZEALAND/KERMADECS}

One or two opportunistic sightings of cow-calf pairs in the past ten years suggest that this population is very small.

\subsubsection{Northern Hemisphere}

\subsubsection{WESTERN NORTH ATLANTIC}

From SC/M98/RW1, a total population estimate of 300 can be derived for 1993 (the year midway through the last six years) based on all animals seen that year plus the previous five years, but excluding all those known to have died over the period (see Item 9.2). Two sources of negative bias are associated with this estimate: (a) some animals might not have been seen in the six-year period; and (b) some areas were not surveyed in the later years and hence a portion of the population might not have been seen. The adult female component was estimated at 74 in 1997. Greater confidence can be attached to the estimate of the number of adult females because the surveys (which maintained a constant level of effort) provided complete coverage of the inshore areas in which the females occur. With respect to (a), so-called 'suburban whales' may comprise a small component of the North Atlantic population. Because they occur only intermittently in the areas surveyed, the estimates above may be biased downwards (SC/M98/RW2).

\subsubsection{EASTERN NORTH ATLANTIC}

There have been only sporadic sightings in this area (Brownell, 1986).

\subsubsection{WESTERN NORTH PACIFIC}

Data from Japanese sightings cruises conducted during 1989, 1990 and 1992 provide estimates of abundance of right whales in the Okhotsk Sea (SC/M98/RW11). A total of 2,688 n.miles of track lines uniformly covered the research area $\left(50^{\circ}-56^{\circ} \mathrm{N}, 143^{\circ} \mathrm{E}\right.$, Kamchatka Peninsula). The surveys had been designed to estimate minke whale, not right whale abundance (Buckland et al., 1992; Miyashita and Shimada, 1994). The hazard rate model was applied for sixteen primary right whale sightings within a perpendicular distance of 1.5 n.miles and the effective search half-width was estimated at 0.940 n.miles $(\mathrm{CV}=0.217)$. The mean school size corrected for size-bias was $1.75(\mathrm{CV}=0.169)$. Abundance in the research area was estimated at 922 $(\mathrm{CV}=0.433 ; 95 \% \mathrm{CI} 404,2,108)$. This estimate is biased downward because: (a) the Russian territorial waters (12 n.miles zone), where right whales are known to occur, were not surveyed; (b) the probability of detection on the track line $(g(0))$ was assumed equal to one; and (c) the survey was conducted in closing mode. One factor was noted as possibly positively biasing the estimate: sightings in the eastern area were conducted in August whereas those in the western area were conducted more in September, so that there was a possibility of double countings if there was westward migration over this period.

The Workshop notes the wide confidence intervals associated with the above estimate of abundance. It believed it was important to clarify the status of this population which had been thought to be at very low levels. It therefore recommends that a further sightings survey be undertaken following the guidelines for surveys adopted by the Scientific Committee (IWC, 1997c). It recommends that the Committee requests the Commission to urge relevant member nations to cooperate in this exercise and in particular that the Russian Federation is urged to grant permission for vessels to survey within 12 n.miles of the Okhotsk Sea coast.

\subsubsection{EASTERN NORTH PACIFIC}

Recent sightings of small groups of right whales in the eastern North Pacific are encouraging, but no confirmed sightings of calves have been recorded this century.

\subsection{Estimates of initial abundance}

The Workshop agreed that there was some merit in attempting to obtain an estimate of the initial population size for southern right whales by extrapolating backwards from estimates of current abundance using a modelling approach similar to that previously used by the Scientific Committee. Previously published estimates of initial population size are given in Table 6.

Table 6

Published (and other available) estimates of initial population size for right whale populations

\begin{tabular}{lcll}
\hline Area & No. whales & Time & Reference \\
\hline S. Atlantic & At least 17,000 & 1830 & IWC (1986:9) \\
New Zealand & 10,000 & ca. 1829 & Dawbin in RW37 \\
Australia & 15,000 & $?$ & Dawbin in RW37 \\
NW Atlantic & $12,000-15,000$ & 1530 & Gaskin (1991) \\
NW Atlantic (US) & $>1,000$ & $1680 \mathrm{~s}$ & RW4 \\
\hline
\end{tabular}

The population simulation approach adopted requires:

(1) agreement on a population model and required population parameters;

(2) estimates of current abundance;

(3) an agreed catch history.

The Workshop agreed that it was only possible to attempt the above analysis for the entire Southern Hemisphere combined. Although in principle it could also be attempted for specific breeding populations within the Southern Hemisphere, that would necessitate historical catches being assigned to these different populations. Discussions under Item 7 revealed that assigning catches made outside the breeding grounds would be extremely difficult and was certainly not a task that could be achieved at this meeting.

\subsubsection{The model}

To obtain an estimate of the initial pre-exploitation size $K$ of a population, the following difference equation was used to describe the dynamics of a whale stock:

$$
P_{t+1}=P_{t}+r P_{t}\left(1-\left(\frac{P_{t}}{K}\right)^{\mu}\right)-C_{t}
$$

where:

$P_{t}$ is the total population size in year $t$;

$r$ is the intrinsic growth rate (the maximum the population can achieve, when its size is very low);

$\mu$ is 2.39 (this sets the $M S Y$ level, $M S Y L=0.6 K$ as conventionally assumed for such analyses by the IWC Scientific Committee); and

$C_{t}$ the total catch (in terms of number of animals) in year $t$. 
Assuming $P_{0}=K$, and given values for the parameter $r$ as well as a catch history series, equation (1) can be used to generate population size estimates $P_{t}$ corresponding to a particular value of $K$ for each of years $t=0, \ldots t_{\text {current }}$ where year 0 corresponds to the pre-exploitation period and $t_{\text {current }}=1997$. Given a population size estimate $P_{t^{*}}^{o b s}$ for a recent year $t^{*}$, where $t^{*} \leq t_{\text {current }}$, a 'best' estimate for $K$ can be found by successively substituting different values for $K$ until the difference between the model estimate $\hat{P}_{t^{*}}^{\text {obs }}$ and observed population size estimate $P_{t^{*}}^{o b s}$ is sufficiently small.

Equation 1 is the population model used in the Catch Limit Algorithm of the Revised Management Procedure (IWC, 1993). This provides a good approximation to the sex-and-age structured model 'BALEEN II' (de la Mare, 1989) conventionally used by the Scientific Committee for stock assessment computations. The approach described above is an example of what is described as 'Hitting with fixed MSYR' in such exercises.

Since it was not possible to carry out the analyses by management unit, an average of the growth rate estimates in Table 4 of $r=0.075$ was assumed. For comparative purposes, computations were also performed using $r=0$ and $r=0.04$. The scenario using $r=0$ is equivalent to a method for estimating $K$ by simply summing all historical catches plus the current population size estimate, i.e. assuming zero surplus production. Performing computations over a range of $r$ values therefore effectively provides a means of assessing to what extent the surplus production characteristics of the resource were able to compensate for population decreases as a result of whaling.

\subsubsection{Current population size}

$t^{*}$ current was set at 1997 and, where necessary, female population size estimates were adjusted to a ' 1997 ' estimate by assuming an annual growth rate of 0.075 . An estimate of the total number of adult females in the Southern Hemisphere in 1997 was obtained by combining the population estimates for the different breeding stocks (Table 4). The estimate obtained (1,607 adult females) is negatively biased because: (a) it excludes contributions from areas about which no information on current abundance is available; and (b) the population size in areas with recent population estimates of $<10$ adult females was set at zero. However, it may also be larger than appropriate because: (a) the value used for the relatively large Argentinian population involves an extrapolation over a seven year period; (b) the higher of two estimates for the relatively large South African population was adopted; and (c) the value used for Tristan da Cunha may be too high (see footnote in Table 4).

Current population size estimates for the various breeding stocks in the Southern Hemisphere are all expressed in terms of the number of reproductive females (and therefore exclude the number of males and immature females).

Let $N_{0}$ be the number of newborn whales, $N_{1}$ be the number of one year old whales, $N_{2}$ the number of two year old whales in a particular year and so on. Given the survival rate $s$ and the growth rate $r, N_{\mathrm{i}}$ can be represented in terms of $N_{0}$ as follows:

$$
\begin{aligned}
& N_{1}=N_{0} s e^{-\mathrm{r}} \\
& N_{2}=N_{1} s e^{-\mathrm{r}}=N_{0} s e^{-\mathrm{r}} s e^{-\mathrm{r}} \\
& N_{3}=N_{2} s e^{-\mathrm{r}}=N_{0} s e^{-\mathrm{r}} s e^{-\mathrm{r}} s e^{-\mathrm{r}}, \text { and so on. }
\end{aligned}
$$

An annual average estimate of $s=0.98$ (see Table 4) was assumed for simulation purposes. Furthermore, an average estimate of the age of first parturition of $t_{m}=9$ years (Table 4) was also assumed.
Using the above estimate of $t_{m}$, the number of juveniles in the population is calculated as the sum of $N_{0}, N_{1}, \ldots N_{8}$, yielding $N_{0} x$, where $x$ is given by:

$$
x=1+R+R^{2}+\ldots+R^{8}
$$

and $R=s e^{-\mathrm{r}}$.

The number of adults in the population is calculated as the sum of $N_{9}, N_{10}, \ldots . N_{\infty}$, yielding $N_{0} y$, where $y$ is given by:

$$
y=R^{9}(1 / 1-R) .
$$

The ratio $x /(x+y)$ then gives the proportion of females which are juvenile or calves.

Let $N_{i}^{T}$ denote the total number of whales in the population in year $i$. This is obtained from the number of adult females in the population using the relation:

$$
N_{i}^{T}=2 N_{i}^{F}(x+y) / y,
$$

where $N_{i}^{F}$ denotes the number of females in the population in year $i$. The conversion equation above assumes a 50:50 sex ratio and a constant survival rate after birth.

In this case, the ratio of juveniles and calves to adults is estimated to be about $1.4: 1$. It is important to note, however, that this relatively high ratio is a consequence of the relatively high population growth rate. In the North Atlantic, juveniles and calves account for only $26-31 \%$ of the population (see Item 9.2.1).

The estimates of total population size obtained for each of the breeding stock areas included in the analysis are presented in Table 4. Together they provide an estimate for $P_{1997}^{o b s}$ of 7,571 whales in the Southern Hemisphere for use in the population model. However, noting the coarseness of many of the assumptions used to arrive at this figure, the Workshop emphasised that the current best estimate of the total number of right whales in the Southern Hemisphere is preferably expressed as 'about 7,000'.

\subsubsection{Historical catches}

Catch data for the Southern Hemisphere were considered under Item 8 . These data have been revised (because some of the catches indicated to have occurred in a particular area are subsumed within estimates given for another area) to obtain estimates of the total Southern Hemisphere catch by decade (Table 6). Catch data were modified further by adjusting for struck and lost (and presumed dead) rates, which ranged from 1.2-1.5 times the landed catch, depending on the fishery (IWC, 1986a, p.31). A base-case catch history series was obtained by assuming an average loss rate of 1.35 (Table 7). Where there was ambiguity as to whether or not catches were duplicated in the various series available, the base-case catch history assumed the average of the two extremes of assuming no duplication at all and of assuming duplication for every instance that this was suspected. 'High' and 'low' series of catches were also developed based on these two extremes (of possible duplication) together with extreme values of the range for struck and lost. In all instances the catch data per decade were converted to annual estimates by assuming an even distribution of catches over each ten-year period.

It is important to note the following caveats:

(1) the available catch data do not include substantial British catches whose total magnitude is unknown - in some cases, e.g. off Brazil and South Africa, where they were large, they have been included whereas in others, e.g. off Australia and New Zealand, they have not, and might have comprised around one tenth of the total, i.e. around 10,000; 
(2) the composition of the catches was assumed to comprise equal proportions of males and females. Because female whales constituted a larger proportion of many of the catches (particularly those taken by shore whalers) and because their selective removal would have had a greater impact on a population's rate of growth, by ignoring a sex disaggregation of catches the analysis above gives a likely lower bound for $K$;

Table 7

Grand totals for Southern Hemisphere catches by decade (see Item 8)Base-case, High case and Low case.

\begin{tabular}{lrrr}
\hline & \multicolumn{3}{c}{ Estimated removals $^{1}$} \\
\cline { 2 - 4 } Decade & Base-case & High case & Low case \\
\hline $1770 \mathrm{~s}$ & 8,197 & 8,197 & 8,197 \\
$1780 \mathrm{~s}$ & 11,390 & 11,990 & 11,390 \\
$1790 \mathrm{~s}$ & 12,893 & 14,173 & 12,839 \\
$1800 \mathrm{~s}$ & 10,559 & 12,739 & 9,312 \\
$1810 \mathrm{~s}$ & 3,837 & 4,336 & 3,436 \\
$1820 \mathrm{~s}$ & 14,069 & 15,689 & 12,273 \\
$1830 \mathrm{~s}$ & 53,091 & 59,821 & 48,230 \\
$1840 \mathrm{~s}$ & 21,488 & 24,380 & 19,730 \\
$1850 \mathrm{~s}$ & 4,901 & 5,528 & 4,458 \\
$1860 \mathrm{~s}$ & 2,639 & 2,965 & 2,387 \\
$1870 \mathrm{~s}$ & 1,029 & 1,158 & 931 \\
$1880 \mathrm{~s}$ & 1,012 & 1,138 & 916 \\
$1890 \mathrm{~s}$ & 290 & 338 & 276 \\
$1900 \mathrm{~s}$ & 753 & 798 & 718 \\
$1910 \mathrm{~s}$ & 677 & 686 & 675 \\
$1920 \mathrm{~s}$ & 104 & 110 & 104 \\
$1930 \mathrm{~s}$ & 122 & 123 & 122 \\
$1940 \mathrm{~s}$ & 2 & 2 & 2 \\
$1950 \mathrm{~s}$ & 163 & 164 & 163 \\
$1960 \mathrm{~s}$ & 3,099 & 3,099 & 3,099 \\
$1970 \mathrm{~s}$ & 60 & 60 & 60 \\
\hline 1105 & 2 & 3 & \\
\hline
\end{tabular}

1 Large catches in some areas by British (and possibly other European) whalers in the late $18^{\text {th }}$ and $19^{\text {th }}$ centuries are not fully taken into account.
(3) catches were assumed to have been taken in proportion to the different components of the population (including calves), which therefore ignores any disaggregation of catches on the basis of age.

\subsubsection{Results}

Fig. 5 shows the results of this population modelling exercise for the base-case catch series and for various values of $r$. The assumption of no historical surplus production suggests an initial total population size of about 160,000 , but this drops to about 60,000 if the level of surplus production suggested by current growth rates $(r=0.075)$ is taken into account. This points to the importance of incorporating surplus production considerations into estimates of initial abundance.

Fig. 6 shows trajectories for the case $r=0.075$ for each of the base, high and low historic catch scenarios. Only the early part of the estimated population trajectory changes to any marked extent, suggesting that the uncertainties in catch history considered translate into a possible range for initial total population size of 55,000-70,000 whales.

Fig. 7 shows the $r=0.075$ trajectory for the base-case catch series on an expanded scale over the period from 1880 . Overall this trajectory illustrates: (i) the rapid depletion of the stock following the substantial catches of the early-mid 1800s; (ii) the almost complete lack of any sign of a recovery after 1850 , for almost 100 years, followed by a gradual recovery after protection in 1935; and (iii) the effects of the illegal Soviet catches of the 1960s in delaying further recovery by about 20 years.

The trajectory also indicates that the entire Southern Hemisphere population reached a low point of about 300 animals in 1920, corresponding to an adult female population of about 60 individuals only. Intuitively, this

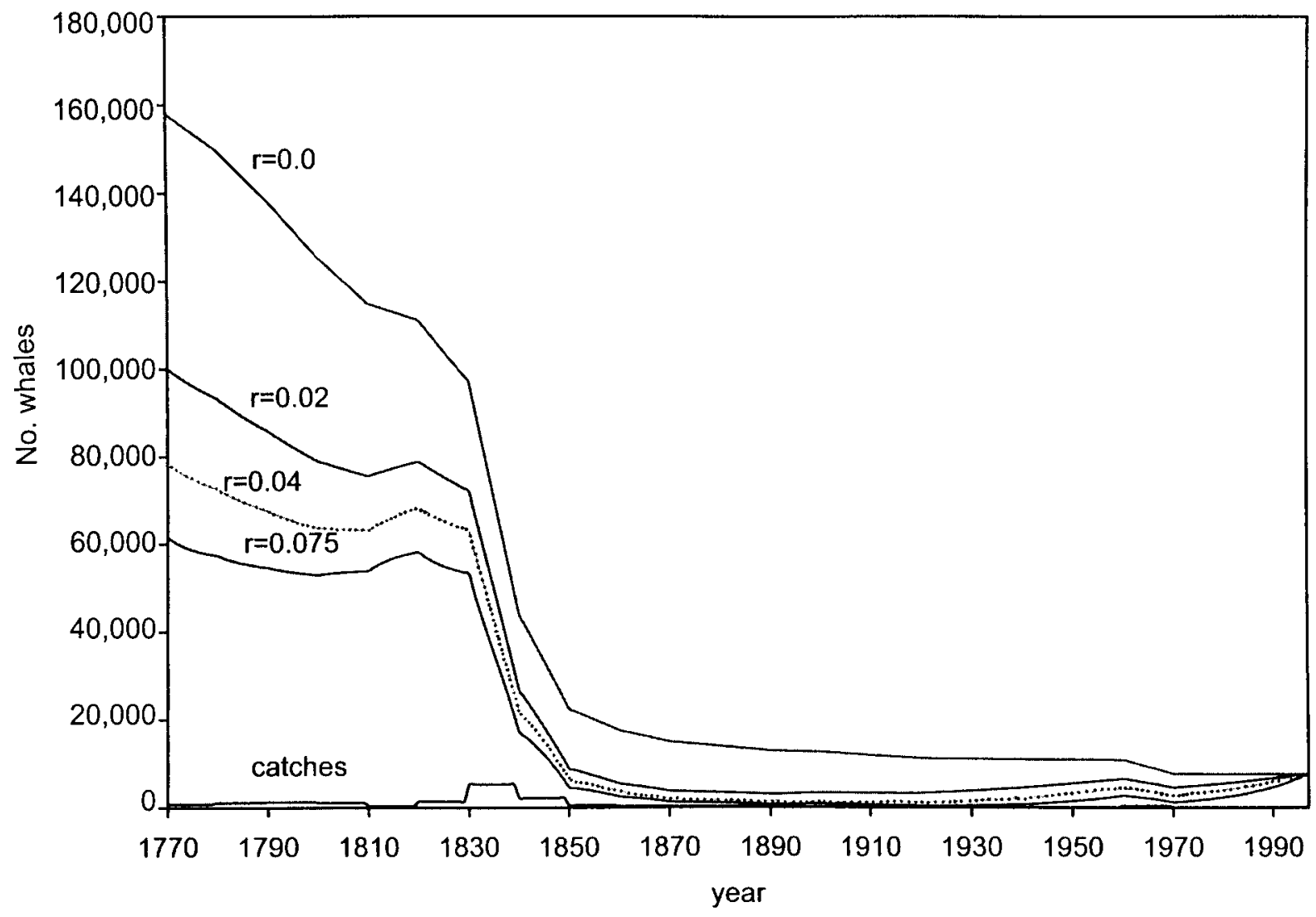

Fig. 5. Total population size and catches (all Southern Hemisphere combined). 


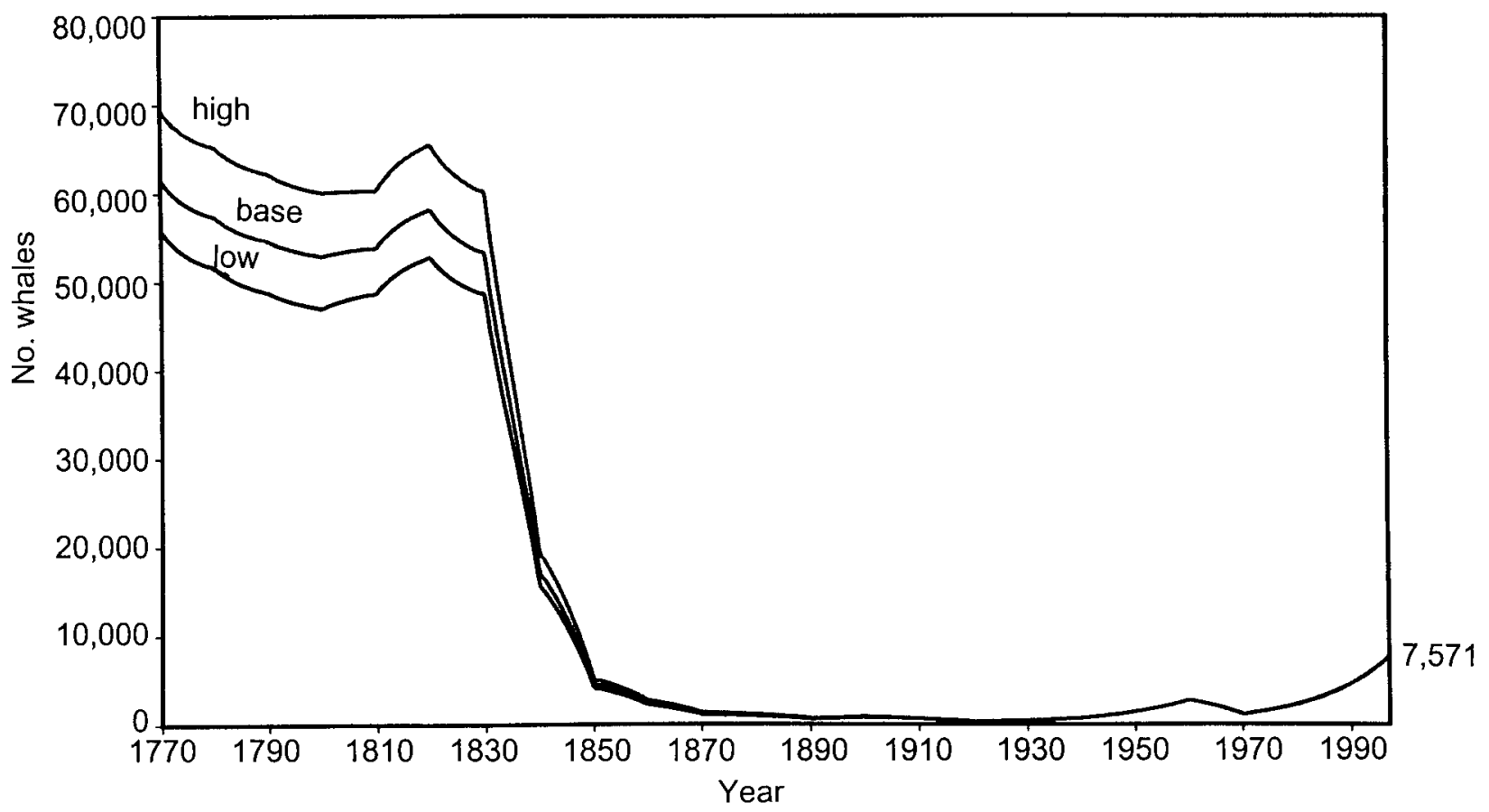

Fig. 6. Total population size (all Southern Hemisphere combined).

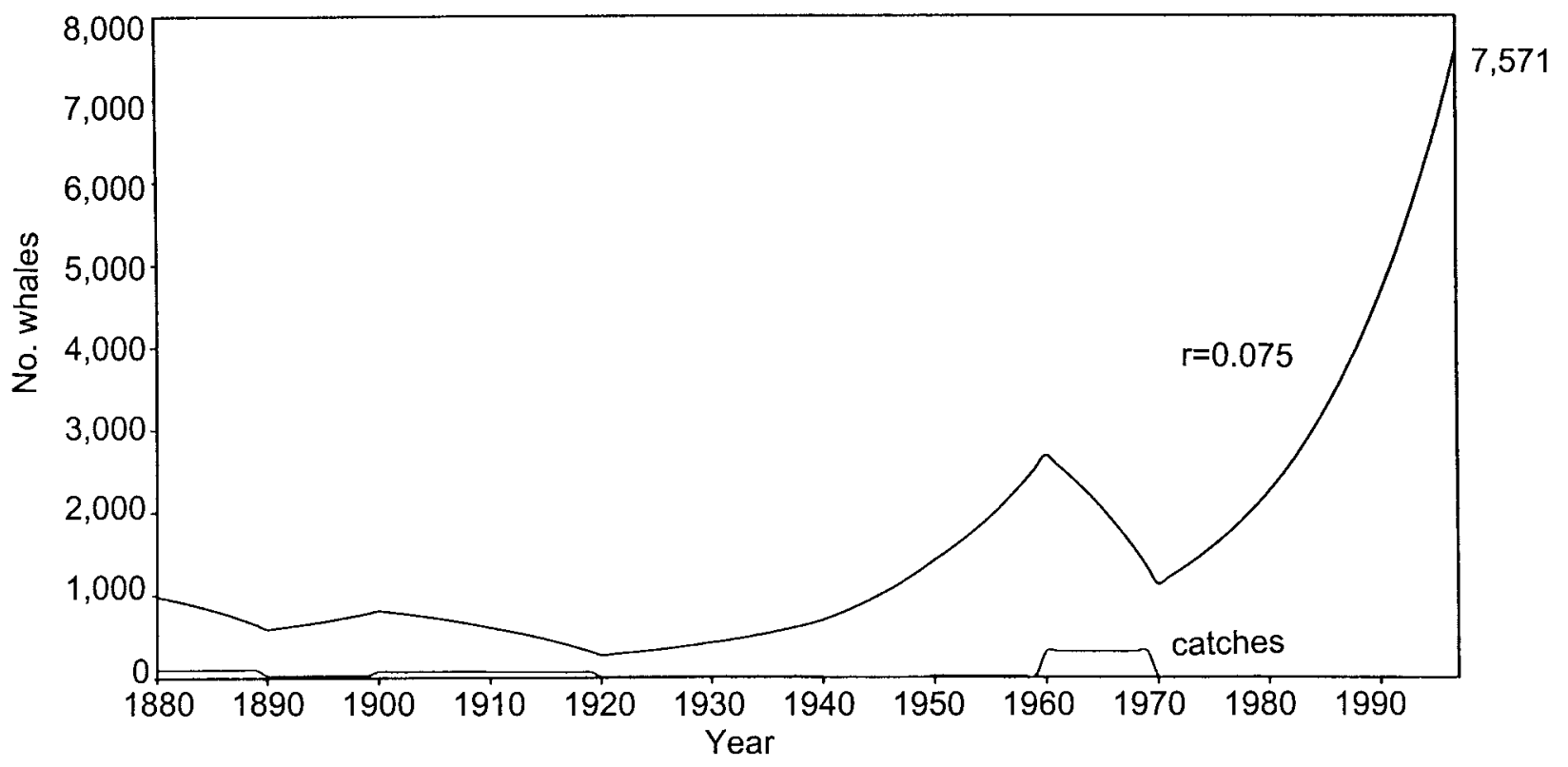

Fig. 7. Total population size and catches for 1880-1997 (all Southern Hemisphere combined).

number seems very low, but as, for instance the first right whale sightings for the whole Australian coast during the $20^{\text {th }}$ century were reported only for the 1950 s in the scientific literature (Chittleborough, 1956), right whale numbers in at least some of the current major concentration areas must have been very low. Alternatively, if there had been depensation effects (not allowed for in the current model), the minimum number in 1920 would have been higher than 300. However, the Workshop noted that there were still uncertainties surrounding both the historical catch series and the current projection and that aggregating the different breeding populations as in the current computations might distort impressions of lowest sizes; the exact numbers generated by the model should therefore be treated with caution.
In summary, the population modelling exercise confirms that the Southern Hemisphere population of right whales is still heavily depleted, perhaps at about $10 \%$ of its initial size (but see the caveats discussed above). The population model used suggests that the current growth rate should continue for some time before any marked density-dependent reduction might come into play, implying that the population as a whole should continue to grow with a doubling time of about 10 years for at least the next decade.

The Workshop recognised that the exercise above merely represented an initial attempt to determine the population trajectory and initial population size for southern right whales. It recommends that at least the following three modifications of the analysis above should be attempted in the future. 
(1) Hypotheses need to be developed to permit catch data to be allocated to management units based on breeding stocks. This will enable estimation of initial abundance for each of the breeding stocks for which there is considered to be sufficient information.

(2) The BALEEN II (and HITTER-FITTER) models should be used to take sex and maturity disaggregation of historic catches into account.

(3) The consequences of depensation at low population size should be explored.

\section{WORLDWIDE COMPARISON OF POPULATION STATUS}

The Workshop noted that several Southern Hemisphere populations (those off Argentina, Australia and South Africa) are increasing at annual rates of the order of $7-8 \%$. There is evidence that the New Zealand sub-Antarctic population has increased (at least at the Auckland Islands) since the 1940s. However, systematic research in the area has not yet been carried out for long enough to estimate whether the population is currently increasing. Nevertheless, there are other areas where major whaling operations were conducted for which there is no sign of recovery, although recent information is either absent or incomplete. The Workshop recommends that research be undertaken to determine the current status of right whales in these areas. For the three best known areas (Australia, Argentina and South Africa), the current estimated total abundance is about 7,000 (see Item 10.2 and Table 4). Should these populations continue to grow at $7-8 \%$ they will double in ten years. There have been no catches in the Southern Hemisphere since the early 1970s and there is no evidence that human-related mortality is affecting population recovery.

The situation in the North Pacific differs greatly between the western and eastern populations. Sightings survey estimates for the summer feeding ground indicate an abundance of around $900(95 \%$ CI 404; 2,108) in the Sea of Okhotsk. However, the Workshop expressed considerable concern about the situation in the eastern North Pacific. Over the past forty years, most sightings have been of single whales. During the last few years, small groups of right whales have been sighted in the eastern North Pacific. This is encouraging but there have been no confirmed sightings of calves in the $20^{\text {th }}$ century and the North Pacific animals are known to have been subjected to large illegal Soviet catches in the early 1960s. The Workshop recommends that research efforts to better understand the status of this population and any human-related problems it may have should be greatly expanded as a matter of urgency.

The situation in the North Atlantic gives great cause for concern. The eastern North Atlantic population probably numbers only in the low tens of animals and its future remains questionable. The Workshop expressed considerable concern about the situation of the western North Atlantic population. Whereas it may have increased since protection in 1935 (e.g. see Reeves et al., 1992) and may have been still increasing at a modest rate (about 2.5\%) in the 1980s (Knowlton et al., 1994), more recent data (near-failure of calf production from 1993-95, increased calving interval, and a relatively large number of human-induced mortalities) suggest that this modest recovery rate (by comparison with the Southern Hemisphere) may not have continued in the 1990s. North Atlantic parous females show an increase between 1985 and 1997 but with an apparent long-term oscillation in recruitment (Annex G). These features, together with the lack of significant increase in calving rates, support the need for age-structured models to account for the complexity of this population's dynamics. It is now unclear whether the population is declining, stationary, or increasing and the best estimate of current population size is only 300 animals (see Item 10.2). The Workshop recommends that, as a matter of urgency, increased efforts be undertaken to determine the recent trajectory of this population.

The Workshop noted the high rate of known entanglement and ship strikes in the western North Atlantic; not all dead whales are recorded, especially when they die, or are killed, offshore. In addition to these physical mortality factors, the western North Atlantic population shows a significantly increased calving interval and decreased fecundity compared with the Southern Hemisphere. The Workshop agreed that inbreeding, organic chemical exposure and nutritional factors need further study (see Item 12). It recommends that comparative studies are undertaken to try and determine factors that may explain the difference between Northern and Southern Hemisphere reproductive parameters.

The Workshop concluded that any human-related mortality could be detrimental to the long-term survival of the western North Atlantic population. Efforts to reduce human-induced mortality are of the greatest urgency if the chances of the western North Atlantic population recovering are to be maximised. The Workshop draws the Commission's attention to its recommendations under Item 14.

\section{FACTORS POTENTIALLY AFFECTING RECOVERY}

12.1 Genetic diversity and genetic problems in small populations (inbreeding depression)

\subsubsection{Context and definitions}

The Workshop noted that the amount of variation in a population is a consequence of long-term effective population size, and the mutation rate and selective coefficient of the genetic marker under analysis. Loss of genetic variation in small populations is an inevitable consequence of drift and can be modelled with simple equations that assume selective neutrality and random mating. In general, when populations are small (i.e. less than 500 census individuals) there is an increased chance of individuals sharing alleles that are identical by descent. This process is termed inbreeding. However, the distinction between loss of variation, inbreeding and inbreeding depression requires clarification. Inbreeding depression is an observed phenomenon where reduced reproductive fitness is correlated with a loss of genetic variation. This is generally a greater problem in formerly large, outbred populations which have been subsequently reduced in size. Although inbreeding depression is almost invariably associated with populations with reduced levels of genetic variation, there are populations with low levels of measured variability which are not known to suffer from a loss of reproductive success.

The Workshop examined the evidence concerning low genetic variation in some right whale populations and in particular whether there is evidence to link low genetic variation with reduced reproductive success in the western North Atlantic population. Currently, only anthropogenic problems facing this population can be addressed through management efforts (see Item 14). However, an understanding of the likelihood of inbreeding depression will be important in assessing the population's vulnerability. 


\subsubsection{Genetic diversity}

Estimates of diversity were available from a number of papers presented at the Workshop or previously published (SC/M98/RW5, 21, 23; Schaeff et al., 1991; 1993; 1997; Malik et al., 1999).

Available data involved the following molecular methods/diversity estimation: fingerprinting/bandsharing; microsatellites/\%polymorphic loci; average number of alleles per locus; and heterozygosity.

The Workshop noted that mitochondrial sequence data allow estimation of genetic diversity at two levels (resolutions): nucleotide diversity which incorporates nucleotide divergence between haplotypes; and haplotype diversity which considers only categorical differences between haplotypes (Nei, 1987).

\subsubsection{Estimating changes in genetic diversity 12.1.3.1 HISTORICAL RECONSTRUCTIONS}

The Workshop reviewed two papers that presented theoretical models for examining probable loss in genetic diversity (Amos, 1996; Seger, 1998). Whilst these models were considered instructive within themselves, it was agreed that they were not entirely applicable to the situation for right whales. It was also noted that modelling based on heterozygosity alone may be an insensitive measure of variation loss.

The Workshop discussed the results in Rosenbaum et al. (2000). Sequence data from the mtDNA control region of six samples from the eastern and western North Atlantic in the late $18^{\text {th }} /$ early $19^{\text {th }}$ century were compared with extant samples from the western North Atlantic. Of the five haplotypes found among the extant samples, four were also represented in the historical samples. The levels of haplotypic diversity among historical versus extant samples were found to be comparable. Because no unique alleles were identified among the historical samples, the study provides no evidence of loss of diversity in the western North Atlantic during the last hundred years. However, given the confidence limits associated with the maximum likelihood estimate from the small sample size, some loss of genetic variation may have occurred that would not be detected.

\subsubsection{CURRENT ESTIMATES OF DIVERSITY AND VALIDITY OF COMPARISONS}

The Workshop considered genetic diversity comparisons that have been made between the western North Atlantic and the southwest Atlantic/southwest Pacific using estimates from multilocus fingerprinting, microsatellites and mtDNA sequence data. Fingerprinting data (Schaeff et al., 1997) showed significant differences in genetic diversity between presumably unrelated right whales in the western North Atlantic and South Atlantic. Preliminary microsatellite analyses also suggested a lower level of genetic diversity among western North Atlantic right whales (SC/M98/RW5). Available mtDNA sequence data showed similar levels of nucleotide diversity for the South Atlantic (SC/M98/RW21) and the western South Pacific (SC/M98/RW23), but which were considerably higher than those for the western North Atlantic (SC/M98/RW5). Comparisons of haplotype diversity between the western North Atlantic and South Atlantic also showed lower levels in the western North Atlantic, although western South Pacific haplotype diversities were comparable to those for the western North Atlantic. These results all point to a lower level of overall genetic diversity in the western North Atlantic, at least relative to the South Atlantic. The Workshop identified two possible and not mutually exclusive explanations for this: (1) western North Atlantic diversity may always have been lower than the South Atlantic; (2) a loss of diversity may have occurred in the western North Atlantic as a result of a long period of exploitation (i.e. population bottlenecks). The difference in haplotype diversity estimates between the southwest Atlantic and the southwest Pacific might be similarly explained.

\subsubsection{Recommendations for improving diversity estimates} The Workshop recommends that further theoretical modelling should be undertaken that considers multiple measures of diversity and the use of appropriate models for the molecular marker chosen. Theoretical models (e.g. PVA) should be used to account for multiple population bottlenecks in accordance with the exploitation history of right whales and stochastic factors.

The Workshop agreed that the best measure of a loss of genetic diversity would involve analysis of historical samples versus extant samples. It noted the potential for use of samples from the years 1530-1610 in the western North Atlantic (Cumbaa, 1986), although obtaining a sufficient sample size for the analysis may be difficult. It recommends that the feasibility of such a study be examined. Based on the available data, the first priority for genetic analysis of historical diversity should be to sequence the mtDNA control region for comparative purposes.

Because estimates of haplotype diversity are dependent on the length of sequence examined, a longer segment of DNA is likely to reveal more haplotypes. The Workshop recommends that the effects of using differing sequence lengths for comparisons of haplotype diversity estimates be explored by sensitivity analysis.

The Workshop also noted that different estimates of haplotype mtDNA diversity in the western North Atlantic have resulted from two different sampling schemes: (1) the direct assignment of haplotypes from sequence data of sampled individuals $(n=180)$; (2) the direct plus inferred assignment of haplotypes using sightings records of photo-identified individuals $(n=269$; SC/M98/RW5; Malik et al., 1999). It recommends that further consideration be given to the choice of sampling scheme for current as well as historical comparisons of diversity.

\subsubsection{Inbreeding depression}

The Workshop identified a number of trends that would be consistent with inbreeding depression in a population:

(1) high juvenile mortality (non-anthropogenic);

(2) low fertility (proportion of reproductive females);

(3) low fecundity;

(4) decreases in recruitment rates;

(5) decreases in population increase rates;

(6) increases in diseased animals.

Many of these expected trends have been identified in the western North Atlantic population (SC/M98/RW44; Knowlton et al., 1994; Schaeff, 2001) but it is difficult to link them directly with an inferred loss of genetic variability. Correlations between observed trends and genetic diversity estimates may lend further support to the hypothesis of inbreeding depression. For example, Schaeff et al. (1993) observed lower than expected bandsharing among first degree relatives which could be a consequence of unsuccessful matings between genetically similar individuals (a direct measure of inbreeding depression). Incest avoidance could also account for this pattern (SC/M98/RW44). Since the expected value in Schaeff et al. 
(1993) was based on matings between presumably unrelated animals, such inbreeding avoidance would also require that right whales avoid mating with animals that are not close relatives but nonetheless share common alleles.

\subsubsection{RECOMMENDATIONS}

The Workshop agreed that current evidence for inbreeding depression in the western North Atlantic population of right whales is inconclusive. An improved understanding of the extent of inbreeding depression in this population could be gained through detailed pedigree analysis similar to that used to quantify inbreeding depression in captive breeding colonies (Ralls et al., 1979). To this end, the Workshop recommends:

(1) estimating levels of heterozygosity among females and correlating them with female reproductive success as measured by all relevant reproductive parameters (parallel correlations of male reproductive success and heterozygosity could be performed if information on paternity is available, see (2));

(2) paternity analysis using microsatellite loci to estimate male effective population size and reproductive success;

(3) testing for an excess of heterozygotes among offspring of known parentage to corroborate the findings of Schaeff et al. (1997) that homozygote offspring are less viable.

\subsection{Trophic relationships and body condition}

\subsubsection{Trophic relationships}

The trophic structure and productivity of a habitat profoundly affect distribution, behaviour and fitness (SC/M98/RW29， SC/M98/RW30， SC/M98/RW31 and $\mathrm{SC} / \mathrm{M} 98 / \mathrm{RW} 39)$. Relevant indices of fitness in right whales include reproductive parameters discussed elsewhere in this report (Item 9.2.3) and body condition. Food density studies suggest that, in the western North Atlantic, plankton patch condition could be used to evaluate the quality of right whale feeding habitat (SC/M98/RW7 and SC/M98/RW45). However, with few exceptions (Tormosov et al., 1998), direct observations of feeding are not available from most of the presumed feeding areas. Isotope analyses of baleen and prey may be useful in identifying feeding areas.

\subsubsection{Body condition}

Reduction in habitat quality in the western North Atlantic could be reducing fecundity in northern right whales. Studies of land mammals indicate that fertility is affected by an insufficiency of body fat (Thomas, 1990), thus measurement of fat stores may be an index of fertility. It is now possible to measure blubber thickness of live animals at sea (SC/M98/RW27). From Soviet catch records it appears that there may be little seasonal variation in blubber thickness in individuals (Tormosov et al., 1998), however it has been hypothesised that there may be variation in blubber thickness between those that are and are not reproductively successful. In a preliminary comparison of blubber thickness in northern and southern right whales, Moore suggested that blubber may be thinner in western North Atlantic right whales than predicted by regressions of blubber thickness and body length based on Soviet catch data for southern right whales (Tormosov et al., 1998).

\subsubsection{Recommendations}

The Workshop recommends that:

(1) further studies of isotope ratios in baleen and prey species be carried out to try and link calving to feeding areas (and see Item 7.5) so that issues of habitat degradation can be examined in the context of population parameters;

(2) studies be undertaken on the trophic structure and productivity of right whale habitat (and see Item 12.3.4) for the assessment of possible prey availability limitations, habitat quality and feeding thresholds, causes of occupation and desertion of habitats, prediction of habitat use patterns (including remote sensing to predict as yet unidentified habitats);

(3) a comparative study be carried out on blubber thickness and lipid content in cow-calf pairs in the western North Atlantic and southern right whale populations;

(4) appropriate girth and blubber thickness measurements be made wherever possible during the examination of all right whale mortalities (see Item 9.1.3).

\subsection{Anthropogenic factors}

\subsubsection{Chemical pollution}

Contaminant data on right whales (Woodley, 1991; SC/M98/RW24) have been restricted to those from biopsy-derived samples apart from one necropsy sample. Wet-weight values were all in the parts per billion range. These data appear to be relevant to the whole animal given that lipid-normalised contaminant burden is comparable between different blubber depths and locations in large whales (Gauthier et al., 1997), although such an extrapolation was earlier questioned for fin whales (Aguilar and Borrell, 1991). No obvious geographic chemical trends were evident in samples from South Georgia and the western North Atlantic. Notwithstanding these low concentrations of accumulated organic compounds, a biochemical assay for cytochrome P450 1A (CYP1A) in biopsied dermal endothelia was significantly elevated in right whales feeding in the Bay of Fundy, Canada, as compared to those from calving habitats in both hemispheres, and from a southern feeding habitat near South Georgia (SC/M98/RW24). This may reflect chronic exposure of the Bay of Fundy animals to non-bioaccumulating compounds such as petroleum-derived polynuclear aromatic hydrocarbon or possibly natural compounds.

The Workshop recommends that:

(1) extant and future necropsy and biopsy samples should be analysed for PCBs, pesticides and dioxins;

(2) routine monitoring of CYP1A expression in right whales should be implemented;

(3) copepod and krill samples from known or presumed feeding habitats in both hemispheres should be analysed for PCBs, pesticides and dioxins.

It also recommends that local, regional and national authorities responsible for right whale habitat should develop contingency plans for oil and chemical spills.

\subsubsection{Entanglement in fishing gear}

A summary of available data on entanglements is given in Table 8 . It should be noted that since most entanglement events go unreported, these are minimum values. Rates of entanglements can be monitored over time through examination of photographs of entanglement scars collected primarily from shipboard surveys (SC/M98/RW28). Data from South Africa (SC/M98/RW25), Brazil and the western North Atlantic (SC/M98/RW28) indicate that in most cases whales free themselves. However, in damaging and/or persistent entanglements, deaths have been reported (SC/M98/RW8 and RW25). The greatest impediment to 
successful rescue is lack of entanglement reporting. Disentanglement efforts greatly improve the whale's chances of survival if trained disentanglement teams are available (SC/M98/RW47). A number of steps have been taken to reduce the likelihood of right whale entanglement, including: (a) gear modifications (or proposed modifications) to reduce the likelihood of entanglement and to facilitate the whale freeing itself (USA); (b) time and area closures of certain fisheries (USA); (c) complete prohibition of fishing activities in protected areas (Head of the Bight, Australia and state waters in Florida, USA). In addition, data from observers that accompany fishing operations help lead to quantification of entanglement rates by fishery operation observers (USA).

The Workshop recommends that:

(1) research continues on methods to reduce right whale entanglements in fishing gear;

(2) entanglement rates and the success of steps to reduce entanglement are determined and monitored (e.g. through periodic analysis of scarring rates and levels of severe entanglement in photo-identification databases);

(3) if the above monitoring indicates that protective measures are insufficient, they are upgraded as appropriate;

(4) disentanglement programmes (including training from experienced persons) are established where appropriate;

(5) consideration is given to the prohibition of any gear that might entangle right whales in high use habitats, and especially in calving, breeding or feeding areas and sanctuaries.

\subsubsection{Shipping}

Right whale injuries and mortalities are attributed to ship strikes on the basis of external signs of trauma and necropsy results indicating internal trauma. External evidence of vessel collision has been documented on living and dead right whales in both hemispheres (Annex $\mathrm{H}$ ).

Propeller lacerations demonstrate that vessels of various sizes strike right whales, but that large vessels are most often associated with fatal encounters, based on the presence of larger propeller cuts, broken bones, severed flukes and broad areas of blunt trauma (SC/M98/RW8 and SC/M98/RW28). Of over 40 known or suspected encounters, on only three occasions has a particular vessel been identified as killing right whales and information on vessel speed is known for only two of these events (Annex H).

Right whale behaviour may make them more vulnerable to ship strikes than other large whale species. It has been observed that right whales engaged in surface active behaviour, skim feeding and nursing, seem to make no effort to avoid the approach of small boats. Other general factors that may increase whale vulnerability to shipping include reduced ship noise in front of the bow and hydrodynamic effects of ships which could draw a whale into the ship (Knowlton et al., 1997). Little is known about right whale behaviour in the vicinity of large ships.

In the western North Atlantic, where ship strikes have been of increasing concern, efforts are underway to reduce them. Efforts include aerial surveys to notify mariners of the location of right whales on a real-time basis (SC/M98/RW6), educational pamphlets distributed to mariners, delineation of major right whale habitats on nautical charts, broadcast Notices to Mariners, and the inclusion of information in the Coast Pilot and Sailing Directions (documents that must be on the bridge of all large vessels), describing right whale distribution and precautionary measures. Other possibilities that have been explored are measures through the International Maritime Organisation (IMO) such as mandatory ship reporting and ship routing. These measures have to be proposed by a member country and approved by the IMO.

\subsubsection{RECOMMENDATIONS}

The Workshop recommends that the Scientific Committee requests the Commission to:

(1) urge its member nations to:

(a) initiate or expand preventative measures including Notices to Mariners, notifications on charts and informational brochures in or to other areas where right whales and high levels of shipping overlap;

Table 8

Right whale entanglement in fishing gear.

\begin{tabular}{|c|c|c|c|c|c|c|}
\hline Location & $\begin{array}{l}\text { Number of known/ } \\
\text { reported entangled }\end{array}$ & $\begin{array}{l}\text { Known } \\
\text { (or presumed) } \\
\text { mortality }\end{array}$ & Type of gear & $\begin{array}{l}\text { Entanglement } \\
\text { scarring in the } \\
\text { population (\%) }\end{array}$ & $\begin{array}{l}\text { Successful } \\
\text { disentanglement } \\
\text { (by humans) }\end{array}$ & Source \\
\hline South Africa & $\begin{array}{l}14 \text { (7 more possible) } \\
(1963-1997)\end{array}$ & $\begin{array}{l}5 \text { ( } 1 \text { of these } \\
\text { 'possible') }\end{array}$ & $\begin{array}{l}\text { Crayfish trap lines, longlines, shark nets; } \\
\text { spearfishing float lines; boat anchor lines }\end{array}$ & $3-4$ & 7 & RW25 \\
\hline \multirow[t]{2}{*}{$\begin{array}{l}\text { Brazil - Santa } \\
\text { Catarina }\end{array}$} & $\begin{array}{l}\text { approx. 4/yr (1989- } \\
1997)\end{array}$ & $\begin{array}{l}1 \text { calf }(1986) \\
1 \text { unconfirmed } \\
\text { calf }(1996)\end{array}$ & $\begin{array}{l}\text { Fixed nylon gillnets of artisanal fishery for } \\
\text { sharks and sciaenids }\end{array}$ & None observed & - & $\begin{array}{l}\text { Palazzo, pers. } \\
\text { comm. }\end{array}$ \\
\hline & $4(1982-93)$ & - & Unknown & - & - & Lodi et al. (1996) \\
\hline Brazil - Sao & $1(1996)$ & 1 & 'Evidence of entrapment' & - & - & RW35 \\
\hline Paulo Coast & $2(1982-83)$ & - & Unknown & - & - & Lodi et al. (1996) \\
\hline $\begin{array}{l}\text { Brazil - Rio } \\
\text { de Janeiro }\end{array}$ & $3(1981-92)$ & - & Unknown & - & - & Lodi et al. (1996) \\
\hline Argentina & $3(1969-90)$ & 0 & 1 rope through baleen; 2 seed mussel ropes & $<2.6 \%$ & - & RW13 \\
\hline Australia & 4 (1991-1997) & 0 & $\begin{array}{l}\text { Rope/netting; } 1 \text { individual towing buoy; pot } \\
\text { line }\end{array}$ & None observed & 1 reported & $\begin{array}{l}\text { Burnell, pers. } \\
\text { comm. }\end{array}$ \\
\hline $\begin{array}{l}\text { Auckland } \\
\text { Islands }\end{array}$ & $2(1995-1997)$ & - & 1 heavy rope around tailstock; 1 unknown & None observed & - & $\begin{array}{l}\text { Patenaude, pers. } \\
\text { comm. }\end{array}$ \\
\hline North Pacific & $2(1986,1992)$ & 1 & $\begin{array}{l}1 \text { salmon drift gillnet around tail stock; } 1 \\
\text { thick 'rope' around tail }\end{array}$ & No data & - & RW10, RW11 \\
\hline $\begin{array}{l}\text { W. North } \\
\text { Atlantic }\end{array}$ & 24 (1980-1998) & $\begin{array}{l}2 \text { known, } \\
8 \text { presumed }\end{array}$ & Lobster gear; pelagic driftnets; sink gillnets & $\begin{array}{l}61.6 \text { (from } \\
\text { shipboard) }\end{array}$ & 6 (estimated) & RW8, RW28 \\
\hline
\end{tabular}


(b) develop mitigating options, areas to be avoided, early warning systems, sonar detection of whales, acoustic deterrents, and the shifting of shipping lanes and reductions in ship speed;

(2) seek cooperation from the IMO to provide protection for right whales, including but not limited to mandatory ship reporting and ship routing, especially where commercial vessels are entering calving, breeding or feeding areas.

It also recommends that studies be undertaken to determine how whales respond to approaching ships to determine the acoustic characteristics, vessel speeds or other features of ships that put right whales at particular risk.

Given the serious concern over the status of western North Atlantic right whales (see Item 11), the Workshop developed specific recommendations for that area. These are given in Annex I.

\subsubsection{Habitat loss}

The Workshop identified four categories of right whale habitats (these are not necessarily mutually exclusive):

(1) feeding - areas developing copepod and krill densities that routinely elicit feeding behaviour and are visited seasonally;

(2) calving - areas routinely used for calving and neonatal nursing;

(3) nursery - aggregation area(s) where nursing females feed and suckle;

(4) breeding - locations where mating behaviour leading to conception occurs. Breeding areas are not known for any population.

Given the conservation problems associated with the western North Atlantic stock (Item 11), the Workshop agreed that fine scale characterisation of the area is a priority. Information on southern right whale habitats is also necessary both as a reference for northern right whales and as a baseline for future Southern Hemisphere development (SC/M98/RW14). It can be assumed that there is some level of threshold for various stressors, above which habitat abandonment would occur. Anthropogenic stressors possibly important in displacing right whales from chosen habitat include: noise from close vessels or aircraft; seismic exploration; low frequency active sonar; oil, gas and mineral exploration and production. Food webs may be altered by eutrophication, coastal development and contaminants. Dredging, filling, aquaculture, fishing and recreational activities may also be significant stressors.

\subsubsection{RECOMMENDATIONS}

The Workshop recognised the importance of quantitative studies of right whale habitats. It noted the increasing importance that the Scientific Committee has placed on environmental change and habitat studies (e.g. IWC, 1998). In this context it recommends that the Committee considers convening a workshop to develop approaches to quantify key features of whale habitats, including trophic structure; right whales should be considered as a potential key species. Such a workshop would involve a variety of disciplines.

With respect to right whales, particular attention should be paid to comparative studies of Northern and Southern Hemisphere populations. Such studies should: (1) identify the most important parameters characterising right whale habitats and standardise methods to measure them; (2) assess 'threshold' levels of disturbance (including noise, temperature, food availability); (3) identify potential sources of disturbance.
Given the potential of noise pollution to affect right whales, the Workshop recognised the importance of understanding the anatomy and physiology of right whale hearing. It noted that such studies are being undertaken by D. Ketten (Woods Hole, USA). It recommends that where possible, suitable samples (frozen or fixed middle and inner ears) be collected for Southern Hemisphere animals, following the protocol given in Blaylock et al. (1996).

\subsubsection{Other}

The Workshop recognised three other important issues relevant to the question of the recovery of right whale populations.

\subsubsection{GULL HARASSMENT}

Kelp gull harassment of right whales off Peninsula Valdés, Argentina (Rowntree et al., 1998 and SC/M98/RW13) has grown substantially worse in parallel with increasing areas of open waste disposal sites and concomitant growth in gull populations. Avoidance reactions of the whales significantly impact their behaviour and perhaps their distribution (SC/M98/RW13). The Workshop recommends that the Commission be asked to urge relevant member governments that these disposal sites be aggressively regulated.

\subsubsection{CLIMATE CHANGE}

SC/M98/RW29 and SC/M98/RW30 considered the impact of climate change on right whales. The issue of climate change has recently been considered in depth by the Scientific Committee (IWC, 1997a). The Workshop reaffirmed that the issue may well be of concern with respect to the recovery of right whale populations.

\subsubsection{MONITORING HUMAN ACTIVITIES}

Recognising in particular that the entire known breeding population of New Zealand sub-Antarctic southern right whales concentrates in a very small area and that adverse effects of human-related activities could potentially have a serious impact on this recovering population, the Workshop recommends that the Commission be asked to urge the New Zealand Government to carefully evaluate and monitor any existing or proposed human-related activities (e.g. whalewatching, oil or gas exploration, vessel traffic and fishing operations) in the New Zealand sub-Antarctic for any potential negative effects.

\subsection{Health and pathology}

The Workshop had little specific information available on this topic, but it noted that chronic skin lesions of diverse types including crater-like welts and white patches with indistinct edges have been described in the western North Atlantic. Most welts and patches resolve over a period of months (Hamilton et al., 1995). Scars may remain. No material from this condition has been obtained to date as necropsy derived samples tend to be heavily compromised by decomposition.

\subsubsection{Recommendations}

The Workshop recommends that coordinated studies of health in right whales should be undertaken, from both biopsy- and necropsy-derived samples. Where possible, researchers should:

(a) obtain biopsy and/or necropsy samples of skin lesions for histology and microbiology; 
(b) examine histology samples and necropsy data from all right whale mortalities.

Such studies will be greatly enhanced if all workers follow a standard approach to reporting necropsies (see Item 9.1).

\section{WHALEWATCHING}

The Workshop established a Working Group to consider issues related to right whales and whalewatching. Its report is given as Annex J. The Working Group considered the following: positive and negative aspects of whalewatching; legislation, regulations and guidelines; management recommendations. Recommendations are discussed under Item 14.

\section{MANAGEMENT IMPLICATIONS}

The Workshop discussions resulted in a number of recommendations that require management action to attempt to reduce or eliminate non-natural mortality of right whales and disturbance to their habitat. These are particularly important for those stocks for which the Workshop has expressed concern over their status.

\subsection{Mortality}

Under Item 12, the Workshop identified ship strikes and incidental entanglements in fishing gear as the most significant cause of human-induced mortality of right whales.

With respect to ship strikes (see Item 12.3.3), given the serious concern over the status of western North Atlantic right whales (see Item 11), the Workshop strongly recommends that the Committee urges the Commission to make every effort to encourage the adoption by relevant governments of the specific recommendations for this area given in Annex I.

In more general terms the Workshop (see Item 12.3.2) recommends that the Scientific Committee requests the Commission to:

(1) urge member nations to

(a) initiate or expand preventative measures including Notices to Mariners, notifications on charts and informational brochures in or to other areas where right whales and high levels of shipping overlap; and

(b) develop mitigating options, areas to be avoided, early warning systems, sonar detection of whales, acoustic deterrents, and the shifting of shipping lanes and reductions in ship speed;

(2) seek cooperation from the International Maritime Organisation to provide protection for right whales, including but not limited to mandatory ship reporting and ship routing, especially where commercial vessels are entering calving, breeding or feeding areas.

With respect to entanglements (see Item 12.3.2), the Workshop recommends that the Scientific Committee requests the Commission to urge member governments to ensure that:

(1) research continues on methods to reduce right whale entanglements in fishing gear;

(2) entanglement rates and the success of steps to reduce entanglement are determined and monitored (e.g. through periodic analysis of scarring rates and levels of severe entanglement in photo-identification databases);

(3) if the above monitoring indicates that protective measures are insufficient, they are upgraded as appropriate;

(4) disentanglement programmes (including training from experienced persons) are established where appropriate; and

(5) consideration is given to the prohibition of any gear that might entangle right whales in high use habitats, especially in calving, breeding or feeding areas and sanctuaries.

\subsection{Disturbance and habitat issues}

The Workshop recommends that the Scientific Committee requests the Commission to request member nations to urge local, regional and national authorities responsible for right whale habitat to develop contingency plans for oil and chemical spills, where these do not exist (see Item 12.3.1).

The Workshop also made specific recommendations on habitat related issues that require management action by individual governments (see Item 12.3.5). The Workshop recommends that the Committee requests the Commission to ask the relevant governments to take the necessary action.

\subsection{Facilitation of research}

The Workshop recommends that the Committee requests the Commission to urge member governments to provide funding for the research items it has identified (see Item 15). In addition, the Workshop draws attention to the following recommendations that require action but not funding per se.

\subsubsection{Sample collection}

The Workshop has made a number of research recommendations with respect to the collection of biopsy samples. It recommends that the Scientific Committee requests the Commission to urge member governments to facilitate the issue of national permits to collect sufficient biopsy samples from adult and calf right whales to address the research recommendations identified in this report (see Items 7 and 9).

\subsubsection{Necropsies}

The Workshop has noted the need for detailed necropsies of right whales, particularly for those populations for which there is concern over their status. It recommends that the Scientific Committee urges the Commission to request that member governments ensure that appropriate programmes are initiated and, where necessary, permits granted to enable this work to take place (see Item 9.1.3).

\subsubsection{Surveys in territorial waters}

The Workshop identified the need for a further research cruise to assess the abundance of right whales in the western North Pacific. It recommends that the Scientific Committee requests the Commission to urge relevant member nations to cooperate in this exercise and in particular that the Russian Federation be urged to grant permission for vessels to survey within 12 n.miles of the Okhotsk Sea coast (see Item 10.2). 


\subsubsection{Whalewatching}

The Workshop endorsed the IWC's general principles for whalewatching (IWC, 1997b, p.105) and recommends that these be applied to all whalewatching activities involving right whales. It was agreed that it was critical to: (1) manage the development of new and fledgling whalewatching operations to minimise the risk of adverse affects; and (2) take appropriate regulatory measures in areas where directed research demonstrates negative impacts on whales from established whalewatching activities.

The Workshop agreed that special protected areas provide a framework for the implementation of site-specific regulations for whalewatching and that such areas are important in conserving coastal habitats. It therefore recommends that studies be undertaken to assess the establishment of special protected areas in areas of known right whale concentration (e.g. the Central-South Coast of Santa Catarina, Brazil).

\section{FUTURE RESEARCH}

During its discussions of the various Agenda Items, the Workshop made a number of recommendations for future research (Table 9). It reiterates the value it attaches to all of those recommendations. However, as at previous IWC Workshops, it recognises the need to assign priority to research items in the context of the Commission's interests. In particular, this applies to questions associated with the 'trend and condition of whale stocks' and 'measures for the[ir] conservation' (Article IV of the Convention), as reaffirmed in the Terms of Reference for this meeting (Item $1.2)$.

Table 9

Specific research recommendations by Agenda Item.

\begin{tabular}{ll}
\hline Research & References in text (Agenda Items) \\
\hline Taxonomy & 6 \\
Genetics & $7.1 .5,7.2 .5,7.3 .7,7.4 .6,7.6 .1,7.6 .2$ \\
Sampling & $7.1 .5(1,3), 7.4 .6,7.5 .1,12.4(1 \mathrm{a}), 9.1 .2 .1,9.1 .2 .3$ \\
Comparisons & $7.2 .5,7.3 .7,751,9.1 .2$ \\
Photo-identification & $9.2,12.3 .2(2), 9.1 .1 .2$ \\
Mortality reduction & $12.3 .1(3), 12.3 .2(1,3,4), 12.3 .3$ \\
Habitat studies & $12.3 .4,12.2 .1$ \\
Feeding & $12.2 .1(1.3)$ \\
Contaminants & $12.3 .1(1,2,3)$ \\
Population parameters & $10.3(1,2) 9.2 .3,10$ \\
Modelling trajectories & 10.3 \\
Health and pathology & $12.4,9.1 .3$ \\
Surveys & $7.1 .5,7.5,7.5 .1$ \\
\hline
\end{tabular}

\subsection{Trends and status}

The Workshop confirms the view already expressed by the Scientific Committee on several previous occasions (e.g. IWC, 1990b) of the extreme importance of maintaining research effort when investigating trends in both abundance and in biological parameters. It therefore stresses that high priority should be given to the continuation of both demographic photo-identification studies (Item 9) and surveys designed to improve knowledge of absolute abundance and current trends (see Item 10). Similarly, high priority should be given to the processing and analysis of such data. This is particularly important for the western North Atlantic where there are serious concerns over the status of the stock (see Item 11).

The Workshop also notes the need to initiate and improve such studies in areas of identified concentrations where they are either absent or in their infancy. High priority should be given to those areas where it is believed there is most chance of success.

In order to interpret data on trends and abundance it is important to determine appropriate management units. In this context, high priority should be given to stock identification studies that will answer questions believed to be hindering the Committee's ability to address important conservation questions (see Item 7). Genetic sampling programmes should be initiated where needed, and maintained in areas where increased sample sizes are needed for statistical validity.

\subsection{Measures for conservation}

The Workshop agreed that high priority should be given to research that will lead directly to improved methods of reducing anthropogenic mortality (e.g. reducing ship strikes and fishing gear entanglements) for stocks for which there is concern over their survival (see Item 11).

Priority should also be given to research examining environmental factors that affect the fecundity and mortality rates of right whale populations (e.g. food limitation, pollution, see Item 12). Such research should ultimately lead to improved recommendations for appropriate and effective management action. Comparative studies between stocks that are recovering and stocks that do not appear to be (see Item 10) may be particularly valuable in this context. Studies that improve information on feeding grounds in the Southern Hemisphere will facilitate such comparisons.

From the genetic standpoint, two questions are of high priority:

(1) what are the implications of the low haplotype diversity detected in certain populations; and

(2) is the effective population size of right whales significantly lower than the abundance estimates?

\section{PUBLICATION}

The Workshop agreed that the papers submitted were of sufficient quality to warrant the publication of a special issue. Details will be discussed at the next meeting of the Editorial Board.

\section{ANY OTHER BUSINESS}

Payne presented a proposal for the creation of a global right whale catalogue, to facilitate, inter alia, a study of the degree of mixing between populations of right whales worldwide. He believed that such a comparison was becoming more practicable given the development of computerised callosity pattern matching aids (e.g. SC/M98/RW38). The Workshop agreed that consideration of this proposal should be included within the context of a broader proposal for a Southern Hemisphere Right Whale Consortium (Annex K and below).

It was noted that prior to this Workshop, few opportunities had existed for cooperation and collaborative research in the Southern Hemisphere. In contrast, the foundation of the North Atlantic Right Whale Consortium in 1986 had 
provided the framework for a collaborative and uniform approach to the research and conservation of right whales in the western North Atlantic.

The Workshop recognised that creation of a similar framework for collaborative research could provide similar benefits for southern right whale research. A Southern Hemisphere Consortium might also serve as a vehicle for identifying and seeking support for right whale research worldwide.

Some concern was expressed over the scientific rationale behind the concept of a 'global' catalogue for right whale photo-identifications. The Workshop preferred to support the facilitation of inter-catalogue comparisons which would in time permit promotion of a single 'global' catalogue, should it be deemed necessary.

The objectives of a Southern Hemisphere Right Whale Consortium could include:

(1) standardisation of data collection;

(2) facilitation of regional inter-catalogue comparisons of photo-identifications;

(3) development of comparable analytical methods;

(4) sharing of resources, especially sophisticated and expensive laboratory techniques (e.g. for genetic, isotopic and pollutant analysis);

(5) exchange of scientific personnel and samples;

(6) where appropriate, assistance in the development of joint management strategies and policy.

The Workshop agreed that there was merit in the proposal and recommends that the Scientific Committee approves the principle of establishing a Southern Hemisphere Right Whale Consortium and that it consequently recommends it to the Commission. Subject to such approval, it was agreed that a Steering Committee, comprising representatives of each Southern Hemisphere nation currently involved in right whale research, should be established to develop the details of the proposal. In this regard, funding should be sought from, inter alia, the IWC, national governments and other sponsors to convene a meeting of interested parties to formally establish a Southern Hemisphere Right Whale Consortium with appropriate terms of reference.

\section{ADOPTION OF REPORT}

The Workshop accepted all the available draft sections of the report but agreed that Donovan, Bannister, Best and Brownell should carry out final editing of the report to ensure its completeness, clarity and consistency.

It agreed that considerable progress had been made at the Workshop. In accordance with the Terms of Reference it had identified the current data available for carrying out the Comprehensive Assessment and undertaken some preliminary analyses. In that light it had identified both further theoretical work and additional data required. It had not been possible in the time available to develop a timetable for the work and hence for the completion of the Comprehensive Assessment.

The success of the Workshop was aided by the extremely hard work of the local convenor, Peter Best and his staff, particularly Desray Reeb, Margaret Best and Leonie Juritz. Thanks are also due to: MTN Cape Whale Route, especially Darden Lotz, not only for their sponsorship but also for logistical support; the Two Oceans Aquarium who hosted the symposium; IFAW for facilitating the attendance of three participants; Mondi (SA) for donation of photocopying paper; and Price Forbes for donation of document bags. The hospitality shown by Rodger Bunney and his staff at the Monkey Valley Beach Resort was much appreciated. Thanks are also due to Moira Dykes who cheerfully typed the report and dealt with the administration of the meeting.

\section{REFERENCES}

Aguayo, L.A. and Torres N, D. 1986. Records of the southern right whale, Eubalaena australis (Desmoulins, 1822), from Chile between 1976 and 1982. Rep. int. Whal. Commn (special issue) 10:159-60.

Aguilar, A. 1986. A review of old Basque whaling and its effect on the right whales (Eubalaena glacialis) of the North Atlantic. Rep. int. Whal. Commn (special issue) 10:191-9.

Allen, G.M. 1916. The whalebone whales of New England. Mem. Boston Soc. Nat. Hist. 8(2):106-322.

Aguilar, A. and Borrell, A. 1991. Heterogeneous distribution of organochlorine contaminants in the blubber of baleen whales: implications for sampling procedures. Mar. Environ. Res. 31(4):275-86.

Allen, K.R. 1977. A computer programme to calculate sustainable yield and fishing mortality for male sperm whales (SPMST). Rep. int. Whal. Commn 27:262.

Allen, K.R. and Kirkwood, G. 1977. Programme to calculate time series of sperm whale population components for given catches (SPDYN). Rep. int. Whal. Commn 27:264-7.

Amos, W. 1996. Levels of genetic variability in cetacean populations have probably changed little as a result of human activities. Rep. int. Whal. Commn 46:657-8.

Bannister, J.L. 1986a. Notes on nineteenth century catches of southern right whales (Eubalaena australis) off the southern coasts of Western Australia. Rep. int. Whal. Commn (special issue) 10:255-9.

Bannister, J.L. 1986b. Report of the Workshop on the Status of Right Whales, Appendix 11. To what extent have right whale calves been recorded away from the coast? Rep. int. Whal. Commn (special issue) 10:32-3.

Bannister, J.L. 1990. Southern right whales off western Australia. Rep. int. Whal. Commn (special issue) 12:279-88.

Bannister, J., Burnell, S., Burton, C. and Kato, H. 1997. Right whales off southern Australia: direct evidence for a link between onshore breeding grounds and offshore probable feeding grounds. Rep. int. Whal. Commn 47:441-4.

Bannister, J.L., Pastene, L.A. and Burnell, S.R. 1999. First record of movement of a southern right whale (Eubalaena australis) between warm water breeding grounds and the Antarctic Ocean, South of $60^{\circ}$ S. Mar. Mammal Sci. 15(4):1337-42.

Best, P.B. 1987. Estimates of the landed catch of right (and other whalebone) whales in the American fishery, 1805-1909. Fish. Bull. 85(3):403-18.

Best, P.B. 1990. Natural markings and their use in determining calving intervals in right whales off South Africa. S. Afr. J. Zool. 25(2):114-23.

Best, P.B. 1994. Seasonality of reproduction and the length of gestation in southern right whales Eubalaena australis. J. Zool,. Lond.232:175-89.

Best, P.B. and Kishino, H. 1998. Estimating natural mortality rate in reproductively active female southern right whales, Eubalaena australis. Mar. Mammal Sci. 14(4):738-49.

Best, P.B. and Ross, G.J.B. 1986. Catches of right whales from shorebased establishments in southern Africa, 1792-1975. Rep. int. Whal. Commn (special issue) 10:275-89.

Best, P.B. and Rüther, H. 1992. Aerial photogrammetry of southern right whales, Eubalaena australis. J. Zool., London. 228:595-614.

Best, P.B. and Schell, D.M. 1996. Stable isotopes in southern right whale (Eubalaena australis) baleen as indicators of seasonal movements, feeding and growth. Mar. Biol. 124(4):483-94.

Best, P.B., Payne, R., Rowntree, V., Palazzo, J.T. and Both, M.D. 1993. Long-range movements of South Atlantic right whales Eubalaena australis. Mar. Mammal Sci. 9(3):227-34.

Blaylock, R.A. and Mase, B.G. 1996. Report of the Workshop to Coordinate Large Whale Stranding Response in the Southeast US, Charleston, NC (unpublished). 34pp. [Available from: Blair. Mase@noaa.gov].

Brown, S.G. 1986. Twentieth-century records of right whales (Eubalaena glacialis) in the northeast Atlantic Ocean. Rep. int. Whal. Commn (special issue) 10:121-7.

Brownell, R.L. 1986. Report of the Workshop on the Status of Right Whales, Appendix 9. Right whale survivorship around Peninsula Valdes, Argentina. Rep. int. Whal. Commn (special issue) 10:31. 
Buckland, S.T., Cattanach, K.L. and Miyashita, T. 1992. Minke whale abundance in the northwest Pacific and the Okhotsk Sea, estimated from 1989 and 1990 sighting surveys. Rep. int. Whal. Commn 42:387-92.

Burnell, S.R. 1997. An incidental flight network for the photoidentification of southern right whales off southeastern Australia. A summary of research activities undertaken in the 1995 and 1996 seasons. Report by Eubalaena Pty. Ltd to BHP Petroleum Pty. Ltd. and Esso Australia Ltd. 30pp. [Available from: sburnell@bigfoot.com].

Burnell, S.R. and Bryden, M.M. 1997. Coastal residence periods and reproduction timing in southern right whales (Eubalaena australis). J. Zool., Lond. 241:613-21.

Bushuev, S.G. 1988. Occurrence of ectoparasites and commensals on bodies of Antarctic minke whales as a marker of natural whale groupings. Paper SC/40/Mi13 presented to the IWC Scientific Committee, May 1988 (unpublished). 36pp. [Paper available from the Office of this Journal].

Chittleborough, R.G. 1956. Southern right whale in Australian waters. J. Mammal. 37(3):456-7.

Cumbaa, S.L. 1986. Archaeological evidence of the 16th century Basque right whale fishery in Labrador. Rep. int. Whal. Commn (special issue) 10:187-90.

Dakin, W.J. 1963. Whalemen Adventurers. Sirius Books, Sydney. 263pp. [Reprint of Angus and Robertson Ltd, Sydney].

Dawbin, W.H. 1986. Right whales caught in waters around south eastern Australia and New Zealand during the nineteenth and early twentieth centuries. Rep. int. Whal. Commn (special issue) 10:261-7.

de la Mare, W.K. 1989. Report of the Scientific Committee, Annex L. The model used in the HITTER and FITTER programs (Program:FITTER.SC40). Rep. int. Whal. Commn 39:150-1.

Desmoulins. 1822. Eubalaena australis in Boryde St.-Vincent. Dict. Class. Hist. Nat. (Paris) 2:161+unnumbered plate.

Dizon, A.E., Perrin, W.F., Amos, W., Baker, C.S., Chivers, S.J., Costa, A.S., Curry, B.E., Gaggiotti, O., Hoelzel, A.R., Hofman, R., LeDuc, R.G., Loughlin, T.R., Lux, C.R., O'Corry-Crowe, G.M., Rosel, P.E., Rosenberg, A., Scribner, K.T. and Taylor, B.L. 1997. Report of the Workshop on the Analysis of Genetic Data to Address Problems of Stock Identity as Related to Management of Marine Mammals. pp. 3-48. In: A.E. Dizon, S.J. Chivers and W.F. Perrin (eds.) Molecular Genetics of Marine Mammals. The Society for Marine Mammalogy, Lawrence, KS.

Donovan, G.P. 1991. A review of IWC stock boundaries. Rep. int. Whal. Commn (special issue) 13:39-68

Donovan, G.P. 1992. The International Whaling Commission: Given its past, does it have a future? pp. 23-44. In: J.J. Symoens (ed.) Symposium «Whales: Biology - Threats - Conservation». Royal Academy of Overseas Sciences, Brussels, Belgium. 261pp.

Du Pasquier, T. 1986. Catch history of French right whaling mainly in the South Atlantic. Rep. int. Whal. Commn (special issue) 10:269-74.

Findlay, K.P., Best, P.B., Peddemors, V.M. and Gove, D. 1994. The distribution and abundance of humpback whales on their southern and central Mozambique winter grounds. Rep. int. Whal. Commn 44:311-20.

Gauthier, J.M., Metcalfe, C.D. and Sears, R. 1997. Validation of the blubber biopsy technique for monitoring of organochlorine contaminants in balaenopterid whales. Mar. Environ. Res. 43:157-79.

Hamilton, P.K., Marx, M.K. and Kraus, S.D. 1995. Skin lesions on Northern right whales. Abstracts of the 11th Biennial Conference on the Biology of Marine Mammals, 14-18 December 1995, Orlando, FL, USA. p.49.

Hamilton, P.K., Knowlton, A.R., Marx, M.K. and Kraus, S.D. 1998. Age structure and longevity in North Atlantic right whales (Eubalaena glacialis). Mar. Ecol. Prog. Ser. 171:285-92.

Hammond, P.S. 1986. Estimating the size of naturally marked whale populations using capture-recapture techniques. Rep. int. Whal. Commn (special issue) 8:253-82.

International Whaling Commission. 1986a. Report of the Workshop on the Status of Right Whales. Rep. int. Whal. Commn (special issue) 10:1-33.

International Whaling Commission. 1986b. Report of the Workshop on the Status of Right Whales, Appendix 7. Historical catches of right whales by area. Rep. int. Whal. Commn (special issue) 10:27-30.

International Whaling Commission. 1990a. Report of the subcommittee on stock identity. Rep. int. Whal. Commn 40:87-93.

International Whaling Commission. 1990b. Report of the Workshop on Individual Recognition and the Estimation of Cetacean Population Parameters, La Jolla, 1-4 May 1988. Rep. int. Whal. Commn (special issue) $12: 3-40$
International Whaling Commission. 1991. Report of the Workshop on the Genetic Analysis of Cetacean Populations, La Jolla, 27-29 September 1989. Rep. int. Whal. Commn (special issue) 13:3-21.

International Whaling Commission. 1993. Report of the Scientific Committee, Annex H. Draft specification for the calculation of catch limits in a Revised Management Procedure (RMP) for baleen whales. Rep. int. Whal. Commn 43:146-52.

International Whaling Commission. 1994. Report of the Scientific Committee. Rep. int. Whal. Commn 44:41-201.

International Whaling Commission. 1997a. Report of the IWC Workshop on Climate Change and Cetaceans. Rep. int. Whal. Commn 47:293-319.

International Whaling Commission. 1997b. Report of the Scientific Committee. Rep. int. Whal. Commn 47:59-258.

International Whaling Commission. 1997c. Report of the Scientific Committee, Annex K. Requirements and guidelines for conducting surveys and analysing data within the Revised Management Scheme. Rep. int. Whal. Commn 47:227-35.

International Whaling Commission. 1998. Report of the Scientific Committee. Annex F. Report of the Standing Working Group on Environmental Concerns. Rep. int. Whal. Commn 48:160-9.

International Whaling Commission. 1999. International Convention for the Regulation of Whaling, 1946. Schedule as amended by the Commission at the 50th Meeting 1998, and replacing that dated February 1998. Ann. Rep. Int. Whaling Comm. 1998:71-82.

Ivanova, E.I. 1961a. K morfologii yaponskogo kita (Eubalaena sieboldi Gray) [The morphology of the Japanese right whale (Eubaleana sieboldi Gray)]. Trudy Inst. Morfol. Zhivot. 34:216-25. [In Russian].

Ivanova, E.I. 1961b. Proportsii tel I kharakter rosta kitov Dal'nego vostoka [Proportions of the body and the nature of growth in whales from the Far East]. Trudy Soveshch. Ikhtiol. Kom. 12:72-8. [In Russian].

Klumov, S.K. 1962. Gladkie (Yaponskie) kity Tikhogo Okeana [The right whales in the Pacific Ocean]. Tr. Inst. Okeanol. Akad. Nauk SSSR 58:202-97. [In Russian].

Knowlton, A.R. 1997. The regulation of shipping to protect North Atlantic right whales: need and feasibility. Masters Thesis, University of Rhode Island. 188pp.

Knowlton, A.R., Sigurjónsson, J., Ciano, J.N. and Kraus, S.D. 1992. Long-distance movements of North Atlantic right whales (Eubalaena glacialis). Mar. Mammal Sci. 8(4):397-405.

Knowlton, A.R., Kraus, S.D. and Kenney, R.D. 1994. Reproduction in North Atlantic right whales (Eubalaena glacialis). Can. J. Zool. 72(7):1,297-305.

Knowlton, A.R., Kraus, S.D., Meck, D.F. and Mooney-Seus, M.L. 1997. Shipping/Right Whale Workshop. A New England Aquarium Aquatic Forum, 17-18 April 1997. Series Report 97-3, New England Aquarium, Boston, Massachussets.

Kugler, R.C. 1986. Report of the Workshop on the Status of Right Whales, Appendix 4. Random notes on the history of right whaling on the northwest coast. Rep. int. Whal. Commn (special issue) 10:17-9.

Lien, J., Sears, R., Stenson, G.B., Jones, P.W. and Ni, I.-H. 1989. Right whale, Eubalaena glacialis, sightings in waters off Newfoundland and Labrador and the Gulf of St. Lawrence, 1978-1987. Can. FieldNat. 103(1):91-3.

Malik, S., Brown, M.W., Kraus, S.D., Knowlton, A.R., Hamilton, P.K. and White, B.N. 1999. Assessment of mitochondrial DNA structuring and nursery use in the North Atlantic right whale (Eubalaena glacialis). Can. J. Zool. 77(81):1217-22.

Matthews, L.H. 1938. Notes on the southern right whale, Eubalaena australis. Discovery Rep. 17:169-82.

Maury, M.F. 1853. A chart showing the favourite resort of the sperm and right whale by M.F. Maury, LLD Lieut. US Navy. Constructed from Maury's whale chart of the world, by Robert H. Wyman, Lieut. USN by Authority of Commo: Charles Morris USN Chief of Bureau of Ordnance and Hydrography. Washington, 1 sheet.

Mitchell, E.D., Kozicki, V.M. and Reeves, R.R. 1986. Sightings of right whales, Eubalaena glacialis, on the Scotian Shelf, 1966-1972. Rep. int. Whal. Commn (special issue) 10:83-107.

Miyashita, T. and Shimada, H. 1994. Minke whale abundance in the Okhotsk Sea, the Sea of Japan and off the Pacific coast of Northern Japan estimated from sighting data. Paper SC/46/NP6 presented to the IWC Scientific Committee, May 1994 (unpublished). 9pp.[Paper available from the Office of this Journal].

Muller, J. 1954. Observations on the orbital region of the skull of the Mystacoceti. Zool. Meded. (Leiden) 32:23.

Nei, M. 1987. Molecular Evolutionary Genetics. Columbia University Press, New York. $\mathrm{x}+512 \mathrm{pp}$. 
Ohsumi, S. and Kasamatsu, F. 1986. Recent off-shore distribution of the southern right whale in summer. Rep. int. Whal. Commn (special issue) 10:177-85.

Omura, H. 1953. Biological study on the humpback whales in the Antarctic whaling Areas IV and V. Sci. Rep. Whales Res. Inst., Tokyo 8:81-101.

Omura, H. 1986. History of right whale catches in the waters around Japan. Rep. int. Whal. Commn (special issue) 10:35-41.

Palazzo, J.T., Jr. and Carter, L.A. 1983. A caça de baleias no Brasil. Porto Alegre: Assoc. Gaúcha de Prot. Amb. Natural. 25pp. [In Portuguese].

Palumbi, S.R. and Baker, C.S. 1994. Contrasting population structure from nuclear intron sequences and mtDNA of humpback whales. Mol. Biol. Evol. 11:426-35.

Payne, R., Brazier, O., Dorsey, E.M., Perkins, J.S., Rowntree, V.J. and Titus, A. 1983. External features in southern right whales (Eubalaena australis) and their use in identifying individuals. pp. 371-445. In: R. Payne (ed.) Communication and Behavior of Whales. AAAS Selected Symposia Series 76. Westview Press, Colorado. xii+643pp.

Payne, R., Rowntree, V., Perkins, J.S., Cooke, J.G. and Lankester, K. 1990. Population size, trends and reproductive parameters of right whales (Eubalaena australis) off Peninsula Valdes, Argentina. Rep. int. Whal. Commn (special issue) 12:271-8.

Ralls, K., Brugger, K. and Ballou, J. 1979. Inbreeding and juvenile mortality in small populations of ungulates. Science 206:1101-3.

Reeves, R.R. and Mitchell, E. 1986a. American pelagic whaling for right whales in the North Atlantic. Rep. int. Whal. Commn (special issue) 10:221-54.

Reeves, R.R. and Mitchell, E. 1986b. The Long Island, New York, right whale fishery: 1650-1924. Rep. int. Whal. Commn (special issue) 10:201-20.

Reeves, R.R., Breiwick, J.M. and Mitchell, E. 1992. Pre-exploitation abundance of right whales off the eastern United States. In: The Right Whale in the Western North Atlantic: a Science and Management Workshop, 14-15 April 1992, Silver Spring, Maryland. NOAA/National Marine Fisheries Service, Northeast Fisheries Science Center Reference Document 92-05.

Reeves, R.R., Breiwick, J.M. and Mitchell, E.D. 1999. History of whaling and estimated kill of right whales, Balaena glacialis, in the northeastern United States, 1620-1924. Mar. Fish. Rev. 61(3):1-36.

Rice, D.W. 1998. Marine Mammals of the World. Systematics and Distribution. Special Publication No. 4. The Society for Marine Mammology, Lawrence, Kansas. 231pp.

Richards, R. 1990. The commercial exploitation of sea mammals at Isles Crozet and Prince Edward Island before 1850. Polar Monograph 1 [Available from: Scott Polar Research Institute, Cambridge].

Richards, R. 1993. Into the South Seas: The Southern Whale Fishery Comes of Age on the Brazil Banks 1765 to 1812. The Paramatta Press, Wellington. 128pp.

Richards, R. and du Pasquier, T. 1989. Bay whaling off southern Africa, c. 1785-1805. S. Afr. J. mar. Sci. 8:231-50.

Rosenbaum, H. and Deinard, A. 1998. Caution before claim: an overview of microsatellite analysis in ecology and evolutionary biology. In: R. DeSalle and B. Schierwater (eds.) Individuals, Populations and Species: Molecular Approaches and Perspectives. Birkhauser, Basal.

Rosenbaum, H.C., Egan, M.G., Clapham, P.J., Brownell, R.L., Brown, M.W., White, B.N., Malik, S., Walsh, P.D. and DeSalle, R. 2000. World-wide genetic differentiation of Eubalaena: questioning the number of right whale species. Mol. Ecol. 9(11): 1793-1802.

Roussel de Vauzeme, A. 1834. Memoire sur le Cyamus ceti (Latr.) de la classe des Crustaces. Ann. Sci. Nat. (Zool.), Paris 2(1):239-55, 257-65.

Rowntree, V.J., McGuiness, P., Marshall, K., Payne, R., Sironi, M. and Seger, J. 1998. Increased harassment of right whales (Eubalaena australis) by kelp gulls (Larus dominicanus) at Península Valdés, Argentina. Mar. Mammal Sci. 14(1):99-115.

Scarff, J.E. 1986. Historic and present distribution of the right whale (Eubalaena glacialis) in the eastern North Pacific south of $50^{\circ} \mathrm{N}$ and east of $180^{\circ} \mathrm{W}$. Rep. int. Whal. Commn (special issue) 10:43-63.
Schaeff, C.M. 2001. Right whale (Eubalaena) molecular ecology. In: C. Pfeiffer (ed.) Cell and Molecular Biology of Marine Mammals. Krieger Publishing Inc.

Schaeff, C.M. and Hamilton, P.K. 1999. Genetic basis and evolutionary significance of ventral skin color markings in North Atlantic right whales (Eubalaena glacialis). Mar. Mammal Sci. 15(3):701-11.

Schaeff, C., Kraus, S., Brown, M., Perkins, J., Payne, R., Gaskin, D., Boag, P. and White, B. 1991. Preliminary analysis of mitochondrial DNA variation within and between the right whale species Eubalaena glacialis and Eubalaena australis. Rep. int. Whal. Commn (special issue) 13:217-23.

Schaeff, C.M., Kraus, S.D., Brown, M.W. and White, B.N. 1993. Assessment of the population structure of western North Atlantic right whales (Eubalaena glacialis) based on sighting and mtDNA data. Can. J. Zool. 71(2):339-45.

Schaeff, C.M., Kraus, S.D., Brown, M.W., Perkins, J.S., Payne, R.S. and White, B.N. 1997. Comparisons of genetic variability of North and South Atlantic right whale (Eubalaena) using DNA fingerprinting. Can. J. Zool. 75:1073-80.

Schaeff, C.M., Best, P.B., Rowntree, V.J., Payne, R., Jarvis, C. and Portway, V.A. 1999. Dorsal skin color patterns among southern right whales (Eubalaena australis): Genetic basis and evolutionary significance. J. Hered. 90(4):464-71.

Schevill, W.E. 1986. Report of the Workshop on the Status of Right Whales, Appendix 5. Right whale nomenclature. Rep. int. Whal. Commn (special issue) 10:19.

Seger, J. 1998. How much genetic variation have North Atlantic right whales lost in the last 1000 years? (Unpublished). 3pp. [Paper available from the author: seger@bionix.biology.utah.edu].

Slay, C. and Kraus, S. 1997. Right whale satellite tagging and habitat use patterns in the coastal waters of the southeastern United States. Final Report under contract No. 50WCNF606026 to the US National Marine Fisheries Service, Charleston, South Carolina.

Starbuck, A. 1878. History of the American whale fishery from its earliest inception to the year 1876. Appendix A. pp. 1-768+6pls. In: Report of the US Commissioner on Fish and Fisheries, Part 4, 1875-76. Government Printing Office, Washington, DC. [Reprinted in 1964 in two volumes by Argosy Antiquarian Ltd, New York].

Thomas, V.G. 1990. Control of reproduction in animals species with high and low body fat reserves. Prog. Reprod. Biol. Med. $14: 27-41$.

Thompson, D.W. 1928. On whales landed at the Scottish whaling stations during the years 1908-1914 and 1920-1927. Fish. Board Scotl. Sci. Invest. 3:3-39.

Tønnessen, J.N. and Johnsen, A.O. 1982. The History of Modern Whaling. C. Hurst \& Co., London. i-Xx+798pp.

Tormosov, D.D., Mikhalev, Y.A., Best, P.B., Zemsky, V.A., Sekiguchi, K. and Brownell Jr, R.L. 1998. Soviet catches of southern right whales, Eubalaena australis, 1951-1971; biological data and conservation implications. Biol. Conserv. 86(2):185-97.

Townsend, C.H. 1935. The distribution of certain whales as shown by logbook records of American whaleships. Zoologica (NY) 19(1-2):1-50+6 maps.

Van Waerebeek, K., Reyes, J. and Aranda, C. 1992. Southern right whales (Eubalaena australis) off southern Peru. Mar. Mammal Sci. $8(1): 86-8$.

Whitehead, H. and Payne, R. 1981. New techniques for measuring whales from the air. US Marine Mammal Commission Report No. MMC-76/22, Washington DC. 36pp.

Whitehead, H., Gordon, J., Mathews, E.A. and Richard, K.R. 1990. Obtaining skin samples from living sperm whales. Mar. Mammal Sci. 6(4):316-26.

Woodley, T.H. 1991. Organochlorine levels in North Atlantic right whale (Eubalaena glacialis) blubber. Arch. Environ. Contam. Toxicol. 21(1):141-5.

Yablokov, A.V. 1994. Validity of whaling data. Nature, Lond. 367(6459): 108 .

Zeh, J.E., Clark, C.W., George, J.C., Withrow, D., Carroll, G.M. and Koski, W.R. 1993. Current population size and dynamics. pp. 409-89. In: J.J. Burns, J.J. Montague and C.J. Cowles (eds.) Special Publication. No. 2. The Bowhead Whale. The Society for Marine Mammalogy, Lawrence, Kansas. 787pp. 


\section{Annex A List of Participants}

Scott Baker

School of Biological Sciences

University of Auckland

Private Bag 92019

Auckland

NEW ZEALAND

Tel: +64 93737999 ext. 7280

Fax: +64 93737417

E-mail:cs.baker@auckland.ac.nz

John Bannister

c/o Western Australia Museum

Francis Street

Perth

Western Australia 6000

AUSTRALIA

Tel: +61 894272700

Fax: +61 893288686

E-mail:106174.3301@compuserve.com

Peter B. Best

MRI Whale Unit

c/o South African Museum

P.O. Box 61

Cape Town 8000

SOUTH AFRICA

Tel: +2721243330

Fax: +2721246716

E-mail: pbest@samuseum.ac.za

Anabela Brandão

Department of Mathematics and Applied Mathematics

University of Cape Town

Private Bag

Rondebosch 7700

SOUTH AFRICA

Tel: +27 216503655

E-mail: bela@maths.uct.ac.za

Solange Brault

Department of Biology

University of Massachusetts

100 Morrissey Boulevard

Boston, MA 02125

USA

Tel: +1 6172876683

Fax: +1 6172876650

E-mail: brault@umbsky.cc.umb.edu
Miranda Brown

Department of Mathematics and Applied

Mathematics

University of Cape Town

Private Bag

Rondebosch 7700

SOUTH AFRICA

Tel: +27216502390

Fax: +27 216500477

E-mail:miranda@maths.uct.ac.za

Moira W. Brown

Center for Coastal Studies

P.O. Box 1036

59 Commercial Street

Provincetown, MA 02657

USA

Tel: +1 5084873622

Fax: +1 5084874495

E-mail: mbrown@wn.net

and

East Coast Ecosystems

P.O. Box 36

Freeport

Nova Scotia BOV 1BO

CANADA

Tel/Fax: +1 9028392962

Robert L. Brownell, Jr.

Southwest Fisheries Science Center

P.O. Box 271

La Jolla, CA 92038

USA

Tel: +1 6195467165

Fax: +1 6195465653

E-mail: brownell@caliban.ucsd.edu

Stephen Burnell

c/o Australian Marine Mammal Research Centre B01 JD Stewart Bldg.

Sydney

AUSTRALIA

Tel: +61 293513051

Fax: +61 293516880

E-mail: sburnell@mail.usyd.edu.au 
Doug Butterworth

Department of Mathematics and Applied

Mathematics

University of Cape Town

Private Bag

Rondebosch 7700

SOUTH AFRICA

Tel: +27 216502343

Fax: +27216502334

E-mail:DLL@maths.uct.ac.za

\section{Carole Carlson}

25 Nickerson Street

Provincetown, MA 02657

USA

Tel: +1 5084870374

Fax: +1 5084877508

E-mail: ccarlson/ifaw@mcimail.com

Mike Donoghue

Department of Conservation

Auckland Conservancy

Private Bag 6908

Newton

Auckland

NEW ZEALAND

Tel: +64 93079279

Fax: +64 93772919

E-mail: mdonoghue@doc.govt.nz

Greg Donovan

The Red House

135 Station Road

Impington

Cambridge

CB4 9NP

Tel: +44 1223233971

Fax: +44 1223232876

E-mail: greg@iwcoffice.org

Ken Findlay

5 Sand Close

Glen Eagles

Lakeside 7945

Cape Town

SOUTH AFRICA

Tel: +27 217888476

E-mail: findlay@physci.uct.ac.za

Paulo Flores

International Wildlife Coalition/Brasil

P.O. Box 5087

Florianopolis S.C

BRAZIL 88040-970

Tel: +55489627713

Fax: +55 48234 1580/0021

E-mail: paflores@mbox1.ufsc.br

Philip Hamilton

New England Aquarium

Central Wharf

Boston, MA 02110

USA

Tel: +1 6179735253

Fax: +1 6177239705

E-mail:phamiltn@neaq.org
Lex Hiby

Conservation Research Ltd

110 Hinton Way

Great Shelford

Cambridge

CB2 5AL

UK

Tel: +44 1223842387

Fax: +44 1223842387

E-mail: lex@contres.demon.co.uk

Leonie Juritz

MRI Whale Unit

c/o South African Museum

P.O. Box 61

Cape Town 8000

SOUTH AFRICA

Tel: +27 21243330

Fax: +27 21246716

E-mail:leonie@samuseum.ac.za

Amy Knowlton

New England Aquarium

Central Wharf

Boston, MA 02139

USA

Tel: +1 6179730210

Fax: +1 6177239705

E-mail: aknowlton@neaq.org

Scott D. Kraus

New England Aquarium

Central Wharf

Boston, MA 02139

USA

Tel: +16179735200

E-mail:skraus@neaq.org

Darden Lotz

MTN/MTN Capewhale Route

P.O. Box 797

Howard Place

Pinelands

Cape Town 7450

SOUTH AFRICA

Tel: +27 832121075

Fax: +27 214017303

E-mail:lotz_d@mtn.co.za

Charles 'Stormy' Mayo

Center for Coastal Studies

59 Commercial Street

P.O. Box 1036

Provincetown, MA 02657

USA

Tel: +15084873622

Fax: +1 5084874495

E-mail: stormym33@pobox.com

Tomio Miyashita

National Research Institute of Far Seas Fisheries

5-7-1 Orido

Shimizu-shi

Shizuok 4248633

JAPAN

Tel: +81543366054

Fax: +81543358962

E-mail:mitachan@enyo.affrc.go.jp 
Michael Moore

Mailstop 33

Biology Department Redfield 244

Woods Hole Oceanographic Institution

Woods Hole, MA 02543

USA

Tel: +15082893228

Fax: +1 5084572169

E-mail:mmoore@whoi.edu

José Truda Palazzo, Jr

Brazilian Right Whale Project

P.O. Box 5087

88040970 Florianopolis-SC

BRAZIL

Tel: +55519825157

Fax: +55 482341580

E-mail:palazzo@nutecnet.com.br

Nathalie Patenaude

School of Biological Sciences

University of Auckland

Private Bag 92019

Auckland

NEW ZEALAND

Tel: +64 93737599 ext.4588

Fax: +64 93734717

E-mail: n.patenaude@auckland.ac.nz

Roger Payne

Whale Conservation Institute

2 Moore Place

Woodstock, VT 05091

USA

Tel: +1 8084573744

Fax: +1 8024579411

E-mail:74201.247@compuserve.com

Eva Plaganyi

Department of Mathematics and Applied

Mathematics

University of Cape Town

Private Bag

Rondebosch 7700

SOUTH AFRICA

Tel: +27216503208

Fax: +27 216860477

E-mail:eva@maths.uct.ac.za

Victoria Portway

Smithsonian Institution

MRC 315

Washington, DC 20560

USA

Tel: +1 2023932847

Fax: +1 2027862566

E-mail:vportway@ceps.nasm.edu
Desray Reeb

MRI Whale Unit

c/o South African Museum

P.O. Box 61

Cape Town 8000

SOUTH AFRICA

Tel: +27 21243330

Fax: +27 21246716

E-mail:dreeb@samuseum.ac.za

Randall Reeves

Okapi Wildlife Associates

27 Chandler Lane

Hudson

Quebec JOP $1 \mathrm{HO}$

CANADA

Tel: +1 5144586685

Fax: +1 5144587383

E-mail:rrreeves@total.net

Howard C. Rosenbaum

Molecular Systematics Laboratory

American Museum of Natural History

$79^{\text {th }}$ Street and Central Park West

New York, NY 10024

USA

Tel: +1 2127695608

Fax: +1 2127695277

E-mail:hcr@amnh.org

Vicky Rowntree

Department of Biology

University of Utah

Salt Lake City, UT 84103

USA

Tel: +1 8015818478

Fax: +1 8015814668

E-mail: rowntree@bionix.biology.utah.edu

Cathy Schaeff

Biology Department, American University

4400 Mass. Avenue NW

Washington, DC 20016

USA

Tel: +1 2028852175

Fax: +1 2028852182

E-mail: schaeff@american.edu

Gregory Silber

Office of Protected Resources

National Marine Fisheries Service

1315 East West Highway

Silver Spring, MD 20910

USA

Tel: +1317132322

Fax: +1 3017130376

E-mail: greg.silber@noaa.gov 
Chris Slay

173 Virginia Avenue

Athens, Georgia 3601

USA

Tel: +17065436859

Fax: +1 7065436859

E-mail: cslay@ibm.net

Steven Swartz

NOAA Fisheries

75 Virginia Beach Drive

Miami, FL 33149

USA

Tel: +13053614487

Fax: +1 3053614478

E-mail: steven.swartz@noaa.gov
Dmitri Tormosov

Environmental Centre for Administration and

Technology (ECAT)

Ul. Gorkogo 25

236040 Kaliningrad

RUSSIA

Tel: +7 0112275380

Fax: +7 0112275110

E-mail:ecatk@online.ru

Les Underhill

Avian Demography Unit

Department of Statistical Sciences

University of Cape Town

Rondebosch 7700

Cape Town

SOUTH AFRICA

Tel: +27 216503277

Fax: +27 216897578

E-mail:lgu@maths.uct.ac.za

\section{Annex B \\ Agenda}

1. Arrangements for meeting

1.1 Practical details

1.2 Terms of reference

2. Election of Chairman

3. Appointment of rapporteurs

4. Adoption of agenda

5. Review of documents and available data

6. Systematics

7. Stock identity: distribution and population separation

8. Historical and modern catches

9. Biological parameters

9.1 Data collection: field and analysis techniques

9.2 Methodology and estimates

9.2.1 Age and growth

9.2.2 Mortality rates

9.2.3 Reproductive parameters

9.2.3.1 Age at sexual maturity

9.2.3.2 Pregnancy rate and calf production

9.2.3.3 Reproductive cycle/seasonality

10. Estimates of abundance and trends
10.1 Estimates of initial abundance

10.2 Estimates of current abundance

10.3 Population trends

11. Worldwide comparison of population status

12. Factors potentially affecting recovery

12.1 Genetic diversity and genetic problems in small populations (inbreeding depression)

12.2 Trophic relationships

12.3 Anthropogenic factors

12.3.1 Chemical pollution

12.3.2 Entanglement in fishing gear

12.3.3 Boat collisions

12.3.4 Habitat loss

12.3.5 Other

12.4 Assessment of condition and pathology

13. Whalewatching

14. Management implications

15. Future research

16. Publication

17. Any other business

18. Adoption of report 


\section{Annex C List of Documents}

$*$ = Revised and published in this volume.

SC/M98/RW1. KRAUS, S., HAMILTON, P.K., KENNEY, R.D., KNOWLTON, A. and SLAY, C.K. Status and trends in reproduction of the North Atlantic right whale.*

SC/M98/RW2. HAMILTON, P.K., KENNEY, R.D., KNOWLTON, A.R., KRAUS, S.D., MARX, M.K., MAYO, C.A. and SLAY, C.K. The North Atlantic Right Whale Catalogue: the strengths and limitations of using photo identification to assess population parameters.

SC/M98/RW3. CASWELL, H., FUJIWARA, M. and BRAULT, S. Declining survival probability and its implications for the North Atlantic right whale.

SC/M98/RW4. REEVES, R.R. Progress report: catch history, historical abundance and distribution of right whales in the western North Atlantic.*

SC/M98/RW5. BROWN, M.W. Genetic aspects of the western North Atlantic right whales.

SC/M98/RW6. SLAY, C.K., KRAUS, S.D., HAMILTON, P.K., KNOWLTON, A.R. and CONGER, L.A. Early warning system 1994-1997. Aerial surveys to reduce ship/whale collisions in the North Atlantic right whale calving ground.

SC/M98/RW7. MAYO, C.A. and GOLDMAN, L. Fine scale characteristics of copepod patches foraged by the northern right whale (Eubalaena glacialis).

SC/M98/RW8. KNOWLTON, A.R. and KRAUS, S.D. Mortality and serious injury in North Atlantic right whales.*

SC/M98/RW9. SILBER, G.K. and PAYNE, P.M. Implementation of the Northern Right Whale Recovery Plan.

SC/M98/RW10. BROWNELL JR., R.L., CLAPHAM, P.J., MIYASHITA, T. and KASUYA, T. Conservation status of North Pacific right whales.*

SC/M98/RW11. MIYASHITA, T. and KATO, H. Recent data on the status of right whales in the NW Pacific Ocean.

SC/M98/RW12. COOKE, J.G., PAYNE, R. and ROWNTREE, V. Updated estimates of demographic parameters for the southern right whales (Eubalaena australis) observed off Peninsula Valdés, Argentina.*

SC/M98/RW13. ROWNTREE, V.J., PAYNE, R.S. and SCHELL, D.M. Changing patterns of habitat use by southern right whales (Eubalaena australis) identified on the nursery ground at Peninsula Valdés, Argentina.
SC/M98/RW14. PALAZZO JR, J. and FLORES, P.A. de C. Right whales (Eubalaena australis) in southern Brazil: a summary of knowledge and research needs.

SC/M98/RW15. BEST, P.B. and UNDERHILL, L.G. Population size, growth rate and survival of southern right whales (Eubalaena australis) off South Africa, 1979-1996.

SC/M98/RW16. BEST, P.B., BRANDAO, A. and BUTTERWORTH, D. Demographic parameters of southern right whales off South Africa.*

SC/M98/RW17. FINDLAY, K. Aspects of whale watching for right whales off South Africa.

SC/M98/RW18. BANNISTER, J. Status of right whales off Australia.*

SC/M98/RW19. BURNELL, S.R. Aspects of the reproductive biology and behavioural ecology of right whales off Australia.*

SC/M98/RW20. PATENAUDE, N.J. and BAKER, C.S. Population status and habitat use of southern right whales in the sub-Antarctic Auckland Islands of New Zealand.*

SC/M98/RW21. PORTWAY, V.A., SCHAEFF, C.M., BEST, P.B., ROWNTREE, V., PAYNE, R., MOORE, M.J. and HAMILTON, P.J. Genetic population structure of South Atlantic right whales (Eubalaena australis).

SC/M98/RW22. BAKER, C.S., PATENAUDE, N.J., BANNISTER, J.L., ROBINS, J. and KATO, H. Distribution and diversity of mtDNA lineages among southern right whales (Eubalaena australis) from Australia and New Zealand.

SC/M98/RW23. ROSENBAUM, H., BROWNELL JR, R.L., BROWN, M., SCHAEFF, C., PORTWAY, V., WHITE, B., MALIK, S., PASTENE, L., BEST P.B., CLAPHAM, P.J., HAMILTON, P., MOORE, M., PAYNE, R., ROWNTREE, V., TYNAN, C. and DESALLE, R. A genetic review of inter relationships between right whales in different ocean areas.

SC/M98/RW24. MOORE, M.J., MILLER, C.A., WEISBROD, A.V., SHEA, D., HAMILTON, P.K., KRAUS, S.D., ROWNTREE, V.J., PATENAUDE, N. and STEGMAN, J.J. Cytochrome P450 1A and chemical contaminants in dermal biopsies of northern and southern right whales.

SC/98/RW25. BEST, P.B., PEDDEMORS, V.M., COCKCROFT, V.G. and RICE, N. Mortalities of right whales and related anthropogenic factors in South African waters, 1963-1997.* 
SC/98/RW26. MOORE, M.J., BERROW, S.D., JENSEN, B.J., CARR, P., SEARS, R., ROWNTREE, V., PAYNE, R. and HAMILTON, P.K. Right whale and other cetacean sightings around South Georgia (1979-1997).

SC/M98/RW27. MILLER, C.A., MORSS, M.S., ARTHUR, R., LANGE, W.A., PRADA, K.E. and MOORE, M.J. Ultrasonic measurement of blubber thickness in right whales.*

SC/M98/RW28. HAMILTON, P.K., MARX, M.K. and KRAUS, S.D. Scarification analysis of North Atlantic right whales (Eubalaena glacialis) as a method of assessing human impacts.

SC/M98/RW29. KENNEY, R.D. Global climate change and whales: Western North Atlantic right whale calving rate correlates with the Southern Oscillation Index.

SC/M98/RW30. KENNEY, R.D. Anomalous 1992 Spring and Summer right whale (Eubalaena glacialis) distributions in the Gulf of Maine: local effects of global scale changes.*

SC/M98/RW31. KENNEY, R.D. Rarity in North Atlantic right whales: is there a natural component?

SC/M98/RW32. RIVAROLA, M., CAMPAGNA, C. and TAGLIORETTE, A. Growth and effects of commercial whale-watching at Peninsula Valdes, Argentina.*

SC/M98/RW33. STEWART, R. and TODD, B. Observations of southern right whales at Campbell Island, New Zealand.*

SC/M98/RW34. PATENAUDE, N., TODD, B. and STEWART, R. Movements of southern right whales between the sub-Antarctic Auckland and Campbell Islands, New Zealand.*

SC/M98/RW35. DE OLIVEIRA SANTOS, M.C., SICILIANO, S. and DE SOUZA, S.P. Contribution to the knowledge of southern right whales (Eubalaena australis) along southeastern Brazilian coast.*

SC/M98/RW36. SCHAEFF, C.M. and BEST, P.B. Reproductive and social behaviour of right whales off South Africa: preliminary results of genetic analyses.
SC/M98/RW37. RICHARDS, R. Southern right whales: original global stocks.

SC/M98/RW38. HIBY, L. and LOVELL, P. Trials of a computerised aid for matching right whale callosity patterns.*

SC/M98/RW39. HOLST, R.J. Possible factors affecting southern right whale calving at Doubtful Island, south Western Australia.

SC/M98/RW40. TORMOSOV, D.D. Some data on the right whale, E. glacialis australis, by materials of 1960-1970.

SC/M98/RW41. BROWN, M.W., KNOWLTON, A.R., HAMILTON, P.K., KENNEY, R.D., MAYO, C. and KRAUS, S.D. Geographic heterogeneity of right whales in five areas of seasonal occupancy in the western North Atlantic, 1980-1992.*

SC/M98/RW42. BURNELL, S.R., REID, B., SHANNON, D. and HEDLEY, M. A prototype system for the computer assisted matching of individually identified southern right whales (Eubalaena australis).*

SC/M98/RW43. ROSENBAUM, H., BROWNELL JR, R.L., TYNAN, C., PITMAN, R. and CLAPHAM, P.J. Genetic variation in North Pacific right whales: first historic and extant specimens.

SC/M98/RW44. BROWNELL, JR, R.L., RALLS, K. and TAYLOR, B. Do North Atlantic right whales suffer from inbreeding depression?

SC/M98/RW45. MAYO, C. and GOLDMAN, L. Food consumption and caloric intake of a right whale, Eubalaena australis, in Cape Cod Bay.

SC/M98/RW46. GREIG, A.B., SECCHI, E.R., ZERBINI, A.N. and DALLA ROSSA, L. Is the high mortality of southern right whales, Eubalaena australis, along the south Brazilian coast due to anthropogenic factors?*

SC/M98/RW47. MAYO, C.A., LYMAN, E. and MATTILA, D.K. Disentanglement of northern right whales: a model for immediate response. 


\section{Annex D \\ Summaries of Relative Abundance of Right Whales by Month}

This Annex is an attempt to summarise what is known or surmised about the present (last decade) distribution and relative abundance of right whales by month based upon both survey and opportunistic data. The first table for each region summarises the relative abundance and the second provides information on the mean number and range of whales and information on survey effort. It is important to remember that the first table indications of abundance refer to relative abundance to the total in the area at the time, not to the total population size.

Table 1

Western North Atlantic. Key: Opp. = opportunistic; Dir. = directed; $\mathrm{C} / \mathrm{c}=$ cow-calf; Juv. $=$ juvenile; Ad-F $=$ adult female; $\mathrm{Ad}-\mathrm{M}=$ adult male. Popn $=$ population component; $0=$ none; $1=\mathrm{low} ; 2=\mathrm{high} ;$ ? $=$ unknown.

\begin{tabular}{|c|c|c|c|c|c|c|c|c|c|c|c|c|c|c|}
\hline & \multicolumn{6}{|c|}{ Southeast } & \multicolumn{4}{|c|}{ Mid-Atlantic corridor } & \multicolumn{4}{|c|}{ Great South Channel } \\
\hline & \multicolumn{2}{|c|}{ Effort } & \multicolumn{4}{|c|}{ Popn } & \multicolumn{2}{|c|}{ Effort } & \multicolumn{2}{|c|}{ Popn } & \multicolumn{2}{|c|}{ Effort } & \multicolumn{2}{|c|}{ Popn } \\
\hline & Opp. & Dir. & $\mathrm{C} / \mathrm{c}$ & Juv. & $\mathrm{Ad}-\mathrm{F}$ & Ad-M & Opp. & Dir. & $\mathrm{C} / \mathrm{c}$ & Other & Opp. & Dir. & $\mathrm{C} / \mathrm{c}$ & Other \\
\hline Jan. & Yes & 2 & High & High & Low & Low & Ycs & 0 & $?$ & Low & 0 & 1 & 0 & 0 \\
\hline Feb. & Yes & 2 & High & Low & Low & Low & Yes & 0 & $?$ & Low & 0 & 1 & 0 & 0 \\
\hline Mar. & Yes & 2 & Low & Low & Low & Low & Yes & 0 & Med. & Low & 0 & 1 & 0 & Low \\
\hline Apr. & Yes & 1 & 0 & 0 & 0 & 0 & Yes & 0 & Med. & Low & 0 & 2 & 0 & Low \\
\hline May & Yes & 0 & 0 & 0 & 0 & 0 & Yes & 0 & 0 & Low & 0 & 2 & Low & High \\
\hline Jun. & Yes & 0 & 0 & 0 & 0 & 0 & Yes & 0 & 0 & Low & 0 & 2 & Low & Med. \\
\hline Jul. & Yes & 0 & 0 & 0 & 0 & 0 & Ycs & 0 & 0 & Low & 0 & 2 & 0 & Low \\
\hline Aug. & Yes & 0 & 0 & 0 & 0 & 0 & Yes & 0 & 0 & Low & 0 & 1 & 0 & 0 \\
\hline Sep. & Yes & 0 & 0 & 0 & 0 & 0 & Yes & 0 & 0 & Low & 0 & 1 & 0 & 0 \\
\hline Oct. & Yes & 1 & 0 & 0 & 0 & 0 & Ycs & 0 & 0 & Low & 0 & 1 & 0 & 0 \\
\hline Nov. & Yes & 1 & Low & 0 & 0 & 0 & Yes & 0 & 0 & Med. & 0 & 1 & 0 & 0 \\
\hline Dec. & Yes & 2 & Med. & Med. & Med. & Med. & Yes & 0 & 0 & Med. & 0 & 1 & 0 & 0 \\
\hline
\end{tabular}

\begin{tabular}{|c|c|c|c|c|c|c|c|c|c|c|c|c|c|c|c|}
\hline & \multicolumn{4}{|c|}{ Cape Cod Bay } & \multicolumn{5}{|c|}{ Roseway Basin } & \multicolumn{6}{|c|}{ Bay of Fundy } \\
\hline & \multicolumn{2}{|c|}{ Effort } & \multicolumn{2}{|c|}{ Popn } & \multicolumn{2}{|c|}{ Effort } & \multicolumn{3}{|c|}{ Popn } & \multicolumn{2}{|c|}{ Effort } & \multicolumn{4}{|c|}{ Popn } \\
\hline & Opp. & Dir. & $\mathrm{C} / \mathrm{c}$ & Other & Opp. & Dir. & $\mathrm{C} / \mathrm{c}$ & Ad-M & Ad-F & Opp. & Dir. & $\mathrm{C} / \mathrm{c}$ & Juv. & Ad-F & Ad-M \\
\hline Jan. & No & 1 & 0 & Med. & 0 & 0 & $?$ & $?$ & $?$ & No & 0 & $?$ & $?$ & $?$ & $?$ \\
\hline Feb. & No & 1 & 0 & Med. & 0 & 0 & $?$ & $?$ & $?$ & No & 0 & $?$ & $?$ & $?$ & $?$ \\
\hline Mar. & Yes & 2 & 0 & High & 0 & 0 & $?$ & $?$ & $?$ & No & 0 & $?$ & $?$ & $?$ & $?$ \\
\hline Apr. & Yes & 2 & Med. & High & 0 & 0 & $?$ & $?$ & $?$ & No & 0 & $?$ & $?$ & $?$ & $?$ \\
\hline May & Yes & 2 & Med. & Med. & 0 & 0 & $?$ & $?$ & $?$ & No & 0 & $?$ & $?$ & $?$ & $?$ \\
\hline Jun. & Yes & 2 & Low & Low & 0 & 2 & 0 & $?$ & $?$ & Yes & 1 & Low & Low & Low & Low \\
\hline Jul. & Yes & 2 & 0 & 0 & 0 & 2 & 0 & $?$ & $?$ & Yes & 2 & Low & Low & Low & Low \\
\hline Aug. & Yes & 2 & 0 & 0 & 0 & 2 & 0 & High & Low & Yes & 2 & High & High & High & High \\
\hline Sep. & Yes & 2 & 0 & 0 & 0 & 2 & 0 & High & Low & Yes & 2 & High & High & High & High \\
\hline Oct. & Yes & 2 & 0 & 0 & 0 & 2 & 0 & $?$ & $?$ & Yes & 2 & Med. & Med. & Med. & High \\
\hline Nov. & No & 0 & 0 & $?$ & 0 & 2 & 0 & $?$ & $?$ & No & 1 & Low? & Low? & Low? & Low? \\
\hline Dec. & No & 1 & 0 & Low & 0 & 0 & $?$ & $?$ & $?$ & No & 0 & $?$ & $?$ & $?$ & $?$ \\
\hline
\end{tabular}

\begin{tabular}{|c|c|c|c|c|c|}
\hline ocation & $\begin{array}{l}\text { Months } \\
\text { observed }\end{array}$ & Range & Mean & $\begin{array}{l}\text { Years } \\
\text { included }\end{array}$ & $\begin{array}{c}\text { Years } \\
\text { surveyed }\end{array}$ \\
\hline outheast USA & Dec.-Mar. & $6-83$ & 29 & $1984-96$ & $1984-96$ \\
\hline ape Cod & Jan.-Jun. & $21-78$ & 41 & $1983-96$ & $1983-96$ \\
\hline it. S. Channel & Mar.-Jul. & $0-94$ & 22 & $1980-96$ & $1980-92$ \\
\hline ay of Fundy & Jun.-Nov. & $23-185$ & 76 & $1980-96$ & $1980-96$ \\
\hline oscway Basin & Aug.-Sep. & $0-118$ & 39 & $1980-96$ & $1983-92,1997$ \\
\hline
\end{tabular}


Table 2

North Pacific. Key: Opp. $=$ opportunistic; Dir. $=$ directed; $\mathrm{C} / \mathrm{c}=$ cow-calf; Juv. $=$ juvenile; Ad-F $=$ adult female; Ad-M = adult male. Popn = population component; $0=$ none; $1=$ low; $2=$ high; $?=$ unknown Western North Pacific

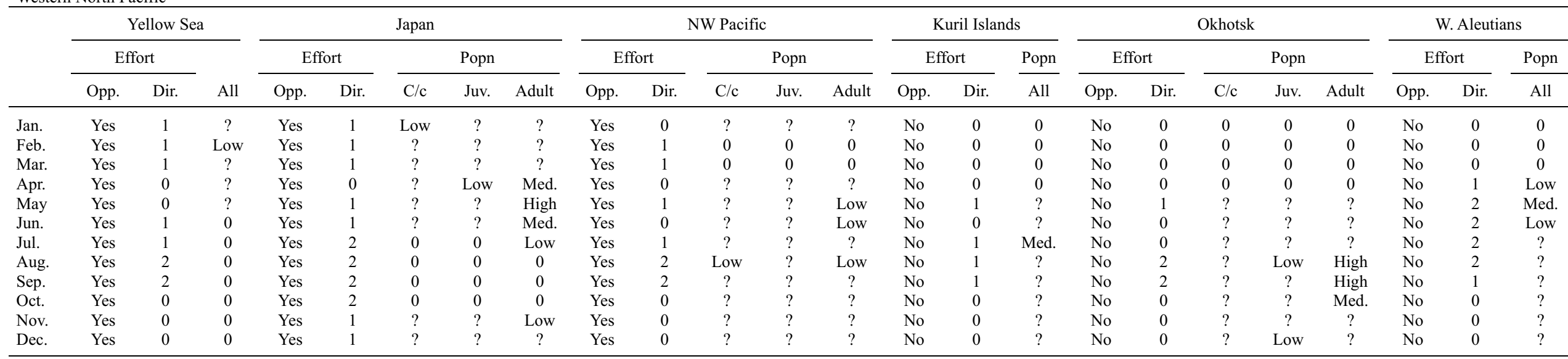

\section{$\overline{\mathrm{s}}$}

Eastern North Pacific

\begin{tabular}{|c|c|c|c|c|c|c|c|c|c|c|c|c|c|c|c|c|c|c|c|c|}
\hline \multirow[b]{3}{*}{ Month } & \multicolumn{3}{|c|}{ Hawaii } & \multicolumn{5}{|c|}{ West Coast } & \multicolumn{3}{|c|}{ NE Pacific } & \multicolumn{3}{|c|}{ Northwest Ground } & \multicolumn{3}{|c|}{ Eastern Aleutians } & \multicolumn{3}{|c|}{ Bering Sea } \\
\hline & \multicolumn{2}{|c|}{ Effort } & \multirow{2}{*}{$\frac{\text { Popn }}{\text { All }}$} & \multicolumn{2}{|c|}{ Effort } & \multicolumn{3}{|c|}{ Popn } & \multicolumn{2}{|c|}{ Effort } & \multirow{2}{*}{$\frac{\text { Popn }}{\text { All }}$} & \multicolumn{2}{|c|}{ Effort } & \multirow{2}{*}{$\begin{array}{c}\text { Popn } \\
\text { All }\end{array}$} & \multicolumn{2}{|c|}{ Effort } & \multirow{2}{*}{$\frac{\text { Popn }}{\text { All }}$} & \multicolumn{2}{|c|}{ Effort } & \multirow{2}{*}{$\frac{\text { Popn }}{\text { All }}$} \\
\hline & Opp. & Dir. & & Opp. & Dir. & $\mathrm{C} / \mathrm{c}$ & Juv. & Adult & Opp. & Dir. & & Opp. & $\overline{\text { Dir. }}$ & & Opp. & Dir. & & Opp. & Dir. & \\
\hline Jan. & Yes & 0 & $?$ & Yes & 0 & $?$ & ? & Low & No & 0 & ? & Yes & 0 & $?$ & No & 0 & ? & No & 0 & ? \\
\hline Feb. & Yes & 0 & ? & Yes & 0 & $?$ & $?$ & Low & No & 0 & $?$ & Yes & 0 & $?$ & No & 0 & ? & No & 0 & $?$ \\
\hline Mar. & Yes & 0 & High & Yes & 0 & $?$ & ? & High & No & 0 & ? & Yes & 0 & ? & No & 0 & ? & No & 0 & ? \\
\hline Apr. & Yes & 0 & $?$ & Yes & 0 & $?$ & ? & Med. & No & 0 & ? & Yes & 0 & ? & No & 0 & ? & No & 0 & ? \\
\hline May & Yes & 0 & ? & Yes & 1 & $?$ & ? & Low & No & 1 & ? & Yes & 1 & ? & No & 2 & ? & No & 1 & ? \\
\hline Jun. & Yes & 0 & $?$ & Yes & 1 & $?$ & $?$ & $?$ & No & 2 & Low & Yes & 2 & $?$ & No & 2 & High & No & 2 & Med. \\
\hline Jul. & Yes & 1 & Low & Yes & 2 & $?$ & $?$ & $?$ & No & 2 & Med. & Yes & 2 & High & No & 2 & Med. & No & 2 & High \\
\hline Aug. & Yes & 1 & $?$ & Yes & 1 & $?$ & $?$ & Low & No & 2 & High & Yes & 2 & High & No & 2 & $?$ & No & 2 & Med. \\
\hline Sep. & Yes & 1 & ? & Yes & 1 & $?$ & $?$ & Low & No & 1 & $?$ & Yes & 0 & $?$ & No & 1 & ? & No & 1 & Low \\
\hline Oct. & Yes & 0 & ? & Yes & 0 & $?$ & $?$ & $?$ & No & 0 & ? & Yes & 0 & $?$ & No & 0 & ? & No & 0 & $?$ \\
\hline Nov. & Yes & 0 & ? & Yes & 0 & $?$ & Low & ? & No & 0 & ? & Yes & 0 & ? & No & 0 & ? & No & 0 & ? \\
\hline Dec. & Yes & 0 & ? & Yes & 0 & $?$ & $?$ & $?$ & No & 0 & $?$ & Yes & 0 & $?$ & No & 0 & $?$ & No & 0 & ? \\
\hline
\end{tabular}




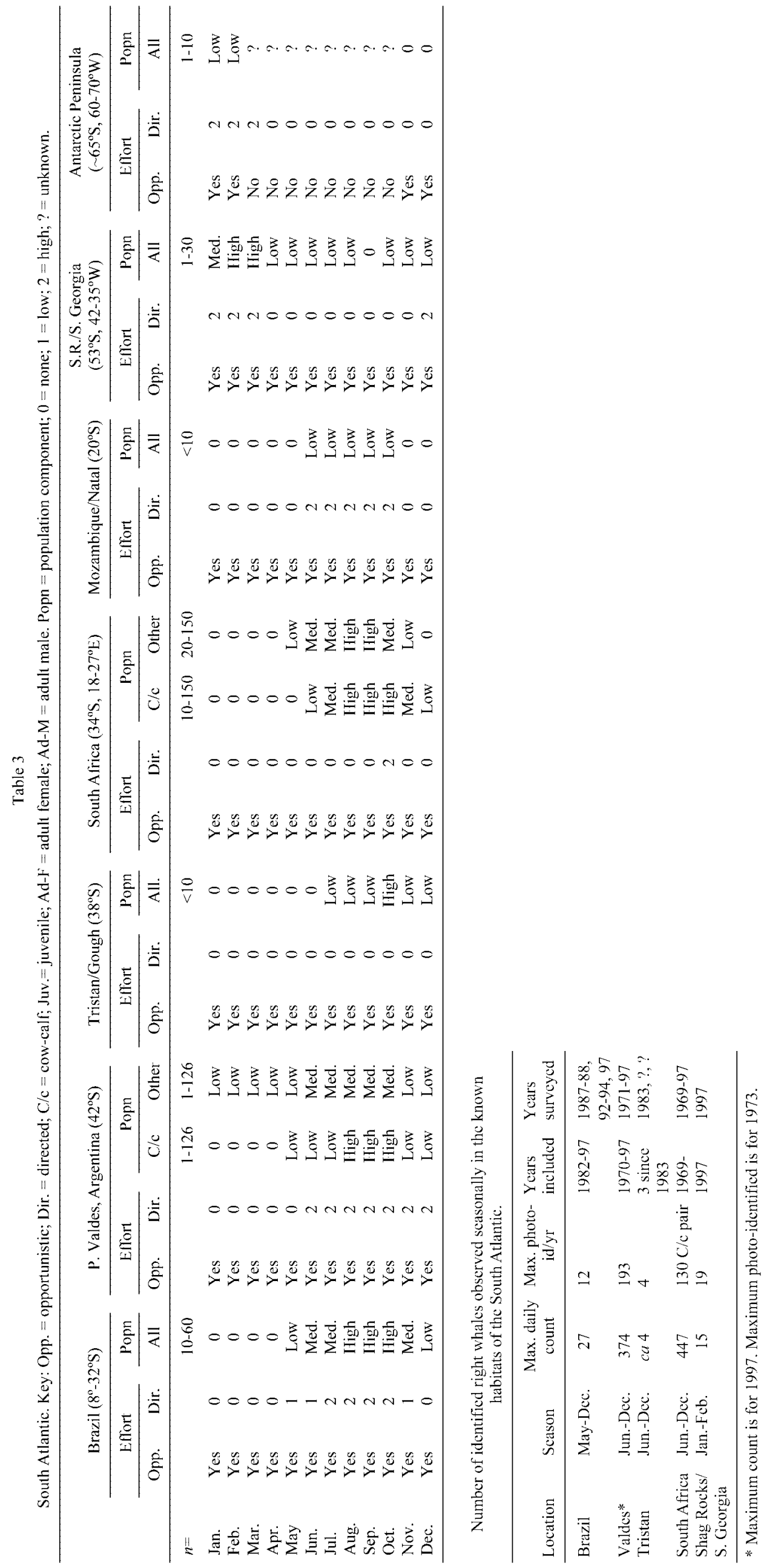


Table 4

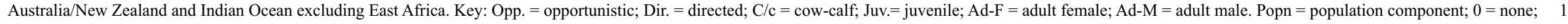
low; 2 = high; ? = unknown

\begin{tabular}{|c|c|c|c|c|c|c|c|c|c|c|c|c|c|c|c|c|c|c|c|c|c|c|c|c|c|c|c|c|c|c|c|c|c|c|c|c|c|c|c|}
\hline \multicolumn{5}{|c|}{ South/West Australia } & \multicolumn{7}{|c|}{ South/Central Australia } & \multicolumn{4}{|c|}{ South/East Australia } & \multicolumn{4}{|c|}{$\begin{array}{l}\text { Mainland New } \\
\text { Zealand }\end{array}$} & \multicolumn{7}{|c|}{ Auckland Islands } & \multicolumn{5}{|c|}{ Campbell Islands } & \multicolumn{4}{|c|}{$\begin{array}{c}\text { S. Ocean } \\
\left(90^{\circ}-150^{\circ} \mathrm{E}\right)\end{array}$} & \multicolumn{4}{|c|}{$\begin{array}{c}\text { Antarctic } \\
\left(90^{\circ}-150^{\circ} \mathrm{E}\right)\end{array}$} \\
\hline & \multicolumn{2}{|c|}{ Effort } & \multicolumn{2}{|c|}{ Popn } & \multicolumn{2}{|c|}{ Effort } & \multicolumn{5}{|c|}{ Popn } & \multicolumn{2}{|c|}{ Effort } & \multicolumn{2}{|c|}{ Popn } & \multicolumn{2}{|c|}{ Effort } & \multicolumn{2}{|c|}{ Popn } & \multicolumn{2}{|c|}{ Effort } & \multicolumn{5}{|c|}{ Popn } & \multicolumn{2}{|c|}{ Effort } & \multicolumn{3}{|c|}{ Popn } & \multicolumn{2}{|c|}{ Effort } & & opn & Effo & & & opn \\
\hline & Opp. & & $\mathrm{C} / \mathrm{c}$ & Other & Opp. & Dir. & $\mathrm{C} / \mathrm{c}$ & Juv. & Ad-F & Ad-M & Ad? & Opp. I & ir. & $\mathrm{C} / \mathrm{c}$ & Othe & Opp. I & Dir. & $\mathrm{C} / \mathrm{c} \mathrm{C}$ & Othe & Opp. I & Dir. & $\mathrm{C} / \mathrm{c}$ & Juv. & Ad-F & Ad-M & Ad? & Opp. I & & $\mathrm{C} / \mathrm{c}$ & Juv. & Ad? & Opp. I & Dir. & $\mathrm{C} / \mathrm{c}$ & Other & Opp. & Dir. & $\mathrm{C} / \mathrm{c}$ & Other \\
\hline $\mathrm{l}=$ & & & $10-100$ & $10-100$ & & & 10-100 1 & 10-100 & $<10$ & $10-100$ & $10-100$ & & & $<10$ & $10-100$ & & & $<10$ & $<10$ & & & 10-100 1 & $10-100$ & $10-100$ & $10-100$ & $10-100$ & & & $<10$ & $<10$ & $10-100$ & & & $<10$ & $10-100$ & & & 0 & $10-100$ \\
\hline an. & Yes & 0 & 0 & 0 & Yes & 0 & 0 & ? & ? & ? & 0 & Ye & 0 & vLow & 0 & & 0 & & 0 & $\mathrm{Y}$ & 0 & $?$ & $?$ & $?$ & ? & Low & No & & ? & ? & ? & No & 2 & 0 & High & No & 2 & 0 ? & ow \\
\hline & Yes & 0 & 0 & 0 & & 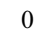 & 0 & & 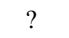 & ? & 0 & & 0 & 0 & 0 & & 0 & 0 & 0 & Yes & 0 & $?$ & ? & ? & ? & & & 1 & & ? & Low & & 2 & & & 10 & 2 & $?$ & ow \\
\hline Iar. & Yes & 0 & 0 & 0 & Yes & 0 & 0 & ? & ? & : & 0 & $\mathrm{Y}$ & 0 & 0 & Low & Yes & 0 & 0 & Low & No & $0 \mathrm{I}$ & Low $^{*}$ & $?$ & Med." & Med. ${ }^{*}$ & & Yes & 1 & ? & ? & Low & No & 2 & 0 & Low & No & 2 & $0 ?$ & High \\
\hline pr. & Yes & 0 & 0 & Low & Yes & 0 & 0 & ? & ? & ? & Low & Yes & 0 & 0 & Low & Yes & 0 & 0 & 0 & No & $0 \quad \mathrm{I}$ & Low $^{*}$ & ? & Med." & Med." & & No & 0 & ? & ? & 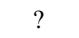 & Yes & 0 & Low & Low & No & 0 & ? & ? \\
\hline ay & Yes & 0 & 0 & Low & Yes & 0 & 0 & ? & ? & . & Lc & $\mathrm{Y}$ & 0 & 0 & & Yes & 0 & 0 & 0 & Yes & 0 & $?$ & $?$ & 8 & $?$ & Low & $\mathrm{Ye}$ & 0 & Low & $?$ & Low & No & 0 & ? & 8 & Jo & ( & $?$ & ? \\
\hline un. & Yes & 0 & Low & Low & Yes & 2 & Low & Med. & Med. & Low & Low & Yes & 2 & Low & Low & Yes & 0 & 0 & 0 & Yes & 0 & ? & $?$ & ? & $?$ & Low & Yes & 21 & High & High & High & $\mathrm{N}$ & 0 & & ? & o & 0 & 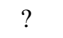 & ? \\
\hline 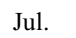 & Yes & 1 & & High & Yes & 2 & & High & High & High & High & Yes & , & & High & Yes & 0 & $0 \quad \mathrm{H}$ & High $^{*}$ & Yes & 21 & High 1 & High & High & High & & & 2 & & & & & 0 & ? & ? & & & $?$ & ? \\
\hline ug. & Yes & 2 & High & High & Yes & 2 & High & High & Med. & Med. & Med. & Yes & 2 & High & Med. & Yes & $0 \quad \mathrm{H}$ & High & 0 & Yes & 21 & High 1 & High & High & High & High & Yes & 2 & High & High & High & No & 0 & ? & ? & Io & 0 & . & ? \\
\hline & Yes & 2 & & Med. & & 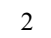 & & Med. & Low & vLow & Med. & $\mathrm{Ye}$ & 2 & Med & Low & Yes & 0 & High 1 & High & Yes & 1 & Low & 0 & 2 & $?$ & Med. & Yes & 1 & High & High & High & 1 & 0 & r. & ? & o & 0 & r. & 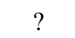 \\
\hline ct. & Yes & 2 & Med. & Low & Yes & 2 & Med. & Low & 0 & 0 & Low & Yes & 2 & Low & 0 & Yes & 0 & $0 \quad 1$ & High & No & 0 & ? & ? & ? & ? & 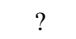 & Yes & 0 & $?$ & $?$ & Low & 1 & 0 & ? & ? & o & 0 & 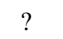 & $?$ \\
\hline . & $\mathrm{Y}$ & 1 & Low & Low & Yes & 0 & LO & 2 & 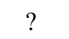 & $?$ & Low & Y & 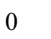 & 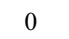 & & Y & 0 & & 0 & . & 0 & ? & & & & & No & & & & & & 1 & $?$ & & No & & $?$ & ? \\
\hline ec. & Yes & 0 & 0 & 0 & Yes & 0 & 0 & ? & ? & $?$ & 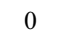 & Yes & 0 & 0 & 0 & Yes & 0 & 0 & 0 & No & 0 & ? & ? & ? & $?$ & ? & No & 0 & ? & ? & $?$ & No & 2 & High & High & No & 0 & $?$ & ? \\
\hline
\end{tabular}

* To be confirmed

Number of identified right whales observed seasonally in the known

habitats of Australia/New Zealand and Indian Ocean excluding Eas

Africa.

\begin{tabular}{|c|c|c|c|c|c|}
\hline Location & Season & $\begin{array}{l}\text { Max. daily } \\
\text { count }\end{array}$ & $\begin{array}{c}\text { Max. } \\
\text { photo-id/yr }\end{array}$ & $\begin{array}{l}\text { Years } \\
\text { included }\end{array}$ & $\begin{array}{l}\text { Years } \\
\text { surveyed }\end{array}$ \\
\hline SW Australia & $\begin{array}{l}\text { Apr.- } \\
\text { Nov. }\end{array}$ & 143 & $\sim 70$ & $1976-97$ & $1977-97$ \\
\hline SC Australia & $\begin{array}{l}\text { Apr.- } \\
\text { Nov. }\end{array}$ & 102 & 101 & $1991-97$ & $1991-97$ \\
\hline SE Australia & Mar.-Oct. & none & 39 & $1995-97$ & 1995-97 \\
\hline Mainland NZ & Mar.-Oct. & $\sim 5$ & $\sim 2$ & $1975-98$ & none \\
\hline Auckland Is & Jan.-Sep. & $80-146$ & 125 & $1950-97$ & $\begin{array}{l}1950-70,95- \\
97\end{array}$ \\
\hline Campbell l. & Feb.-Oct. & 44 & 31 & $1983-97$ & $1983,95-97$ \\
\hline S. Ocean & $\begin{array}{l}\text { Nov.- } \\
\text { Apr. }\end{array}$ & 75 & $5^{+}$ & $1981-96$ & $\begin{array}{l}1981-82,93 \\
1995-96\end{array}$ \\
\hline Antarctic & Jan-Mar. & $22 * *$ & $2+$ & $1963-67$ & $1963-67,96$ \\
\hline
\end{tabular}




\section{Annex E Review of Biopsy Sampling Methods and Available Samples}

A summary of some of the methodologies and equipment used by different groups in different areas is given below. Success rate refers to the frequency of obtaining a sample following a successful 'hit' on the whale.

\section{FLORIDA/GEORGIA}

Slay reported on biopsy of western North Atlantic right whales on a calving ground using a 70lb longbow with long shafted arrows and Larsen tips (30mm length, $5 \mathrm{~mm}$ internal diameter, three rearward facing barbs, Palsbøll et al., 1991), fired from onboard a $6 \mathrm{~m}$ inflatable boat. Successful samples were taken at ranges up to and exceeding 20 metres. No retrieval was used. There was injection moulded flotation on the arrow, also serving as the stop collar. $100 \%$ success rate $(n=9)$ had been obtained; all samples contained skin and blubber. The Larsen bolt and tip with flotation costs approximately US\$60-80.

\section{BAY OF FUNDY/ROSEWAY BASIN}

Brown described a system using an Excalibur 'Vixen' crossbow (68kg prod with longer track than the 'wildcat' bow described below) using Larsen (as above) or North Atlantic tips $(30 \mathrm{~mm}$ length, $6 \mathrm{~mm}$ internal diameter, centre single barbed pin), with a $25 \mathrm{~mm}$ diameter stop collar and $13 \mathrm{~kg}$ test retrieval line (Brown et al., 1991). The Larsen tips were considered more effective (90\% success rate, $n=40)$ than the North Atlantic tips which 'stuck' more often, provided blubber samples only $30 \%$ of the time and had a lower overall success rate $(70 \%, n=430)$. $85 \%$ of biopsy darting was undertaken from a $9 \mathrm{~m}$ boat at average range $5-15 \mathrm{~m}$, aiming for a perpendicular strike to maximise the chance of a blubber sample. The cost of the North Atlantic bolt and tip was approximately US\$30.

\section{AUCKLAND ISLANDS, NEW ZEALAND/ AUSTRALIA/SOUTH GEORGIA}

Patenaude used a Barnett 'Wildcat' crossbow (68kg prod) and tips from the North Atlantic right whale project with a $19 \mathrm{~mm}$ stop collar. Most attempts were made at ranges of 5-15 metres and a $18 \mathrm{~kg}$ test retrieval line was used due to $95 \%$ of darts 'sticking' in the whale. There was a $90 \%$ success rate from a $5 \mathrm{~m}$ inflatable boat $(n=195)$. Perpendicular strikes were aimed to maximise the chance of a blubber sample. It was noted that the use of the Larsen tips did not reduce the incidence of darts 'sticking' in this study.

Researchers from South Georgia and Australia described similar experiences with darts sticking using the same or very similar equipment. Using this equipment, Bannister reported a $66 \%$ success rate using rear oblique shots off Western Australia $(n=25)$.

\section{SOUTH AFRICA}

Best described the 'PAXARMS' rifle system used in South Africa. A .22 calibre rifle cartridge is used to propel a short dart from a 12 gauge shotgun barrel. The standard floating, plastic dart from PAXARMS was used with a custom made tip (25mm length, 3mm internal diameter) and no retrieval line. The propellant charge can be varied and the system is accurate at ranges up to 40 metres. There was a $90 \%$ success rate from small boats and $33 \%$ of samples included blubber. Most attempts are made obliquely from the rear of the animal. The cost of a rifle was US\$650 and the dart and tip US\$25.

\section{REFERENCES}

Brown, M.W., Kraus, S.D. and Gaskin, D.E. 1991. Reaction of North Atlantic right whales (Eubalaena glacialis) to skin biopsy sampling for genetic and pollutant analysis. Rep. int. Whal. Commn (special issue) 13:81-9.

Palsbøll, P.J., Larsen, F. and Hansen, E.S. 1991. Sampling of skin biopsies from free-ranging large cetaceans in West Greenland: development of new biopsy tips and bolt designs. Rep. int. Whal. Commn (special issue) 13:71-9.

Table 1

The number, location/date and archive location of right whale skin samples currently available from different geographic areas. Years in parentheses represent the range of years in which biopsies have been collected.

\begin{tabular}{lrrr}
\hline Sampling location/date & $\begin{array}{c}\text { No. skin } \\
\text { samples }\end{array}$ & $\begin{array}{c}\text { Skin/ } \\
\text { blubber }^{2}\end{array}$ & $\begin{array}{c}\text { DNA archive } \\
\text { location }^{3}\end{array}$ \\
\hline Western North Atlantic (1988-97) & 470 & 82 & 1 \\
North Pacific (1997) & 6 & 0 & 2 \\
Argentina (1989) & 17 & 0 & 1 \\
$\quad 21$ & - & 3 \\
$\quad$ South Georgia (1994-96) & 8 & 3 & $1,3,4$ \\
South Africa (1995-97) & $\sim 660$ & 80 & 3 \\
Madagascar (1997) & 1 & 0 & 5 \\
Western Australia (1993-95) & 25 & 0 & 6,7 \\
Southern Ocean (South of W. & 5 & 0 & 6,7 \\
$\quad$ Australia) Japan/IWC (1995-96) & & & \\
Southern Ocean (Areas IV and V) & $6-8$ & 0 & 8 \\
$\quad$ IDCR/JARPA (1995-98) & & & \\
South Australia (1992) & 4 & 0 & 9 \\
Auckland Islands, NZ (1995-97) & 195 & 17 & 7
\end{tabular}

${ }^{1}$ Not necessarily equal to the number of individuals. ${ }^{2}$ Formalin fixed, paraffin embedded; archived at Woods Hole Oceanographic Institute. ${ }^{3}$ Institutions: 1 = McMaster University, Canada; 2 = Southwest Fisheries Science Centre, USA; 3 = American University, Washington DC, USA; 4

$=$ Woods Hole Oceanographic Institute, USA; $5=$ American Museum of Natural History, USA; $6=$ Western Australia Museum, Australia; 7 = Auckland University, New Zealand; $8=$ Institute of Cetacean Research, Japan; $9=$ South Australian Museum, Australia. 


\section{Annex F \\ Ongoing Studies that could be Assisted by Necropsy Data}

\section{BLUBBER ASSESSMENT}

Worldwide assessment of individual body condition, contaminant burdens and effects can be furthered by a uniform collection of data and samples. In addition to basic body measurements, dorsal, lateral and ventral blubber thickness should be measured at three or more stations evenly spaced from the blowholes to the peduncle. They should be measured on the cut face of the blubber after the removal of the adjacent coat. Maximum girth should also be measured after decomposition gasses have been vented. The blubber/muscle interface should be regarded as the first white fibrous layer at the base of the blubber and the skin should be included (if flensing is not undertaken, a $15 \mathrm{~cm}$ diameter core should be cut out and measured). Additionally, a measurement should be made at the mid-lateral flank perpendicular to the anus for comparison with Soviet whaling data. For contaminant analysis, a full core of blubber removed from the dorsal, lateral and ventral surface at the middle of the back region should be removed and frozen at $-20^{\circ} \mathrm{C}$. Any available kidney and liver tissue should also be collected and frozen at $-20^{\circ} \mathrm{C}$. Contact: $\mathrm{M}$. Moore.

\section{BARNACLES}

Barnacles (Tubicinella) have been found embedded in the callosities of right whales only off South Africa. Because these animals may be obscured by cyamids and may not be visible from photographs of live animals, particular attention should be made during necropsies of right whales from other areas to inspect the callosities for barnacles. Stable isotope ratios of barnacle shells may also provide evidence of migration. Samples of barnacles should be stored dry or in $70 \%$ alcohol. Contact: P. Best.

\author{
ISOTOPE RATIO ANALYSES OF BALEEN AND \\ PREY
}

Baleen plates of adult whales can provide a chronological record of feeding and migratory behaviour over a period of 10-15 years (Schell et al., 1989). Comparisons of the carbon and nitrogen isotope ratios of baleen with that of the whales' prey in various geographic locations can estimate the whales feeding grounds (Schell et al., 1989; Best and Schell, 1996; SC/M98/RW13). Given the difficulty in accessing the feeding grounds of the Southern Hemisphere and North Pacific right whales, it would be valuable to use isotopic ratio analyses to help identify right whale feeding grounds and to identify the relationship between the calving and feeding grounds. Prey samples (copepods, euphausiids) necessary for these analyses may already exist in fishery departments that have surveyed Southern Hemisphere oceans. Prey samples and baleen plates from adult right whales should be contributed to isotopic analyses wherever possible. One of the longest baleen plates from any non-calf whale should be collected with the gum and be stored dry. Prey should be stored dry or in $70 \%$ alcohol. Contact: V. Rowntree.

\section{MIDDLE AND INNER EAR}

Discussed under Item 12.3.3. Contact: D. Ketten.

\section{REFERENCES}

Best, P.B. and Schell, D.M. 1996. Stable isotopes in southern right whale (Eubalaena australis) baleen as indicators of seasonal movements, feeding and growth. Mar. Biol. 124(4):483-94.

Schell, D.M., Saupe, S.M. and Haubenstock, N. 1989. Natural isotope abundances in bowhead whale (Balaena mysticetus) baleen: markers of ageing and habitat usage. Ecol. Stud. 68:260-9. 


\section{Annex G \\ Estimating Population Rate of Increase of the North Atlantic Right Whale (see Item 10.1)}

\section{METHOD 1}

Brault attempted to obtain an index of population rate of increase using the number of cow-calf pairs identified in each year in all observation areas in the northeast, as presented in Table 1, column 1 below.

Table 1

Number of cow-calf pairs observed every year from $1982-97$ in the western North $\Lambda$ tlantic.

\begin{tabular}{lcc}
\hline Ycar & No. of cow-calf pairs & No. of parous females \\
\hline 1982 & 11 & \\
1983 & 9 & \\
1984 & 13 & \\
1985 & 11 & 41 \\
1986 & 13 & 46 \\
1987 & 11 & 50 \\
1988 & 8 & 52 \\
1989 & 19 & 51 \\
1990 & 12 & 51 \\
1991 & 17 & 51 \\
1992 & 12 & 52 \\
1993 & 8 & 54 \\
1994 & 9 & 57 \\
1995 & 7 & 57 \\
1996 & 22 & 66 \\
1997 & 20 & 74 \\
\hline
\end{tabular}

The natural $\log$ of the number of cow-calf pairs from 1982-1997 were regressed against time, with the following results:

$\ln$ (no. of pairs) versus year

$n=16$

$R^{2}=0.048$

Slope $=0.0159, \mathrm{SE}=0.0189, p$ value $=0.41$

$95 \%$ CI of slope estimate $=[-0.0246,0.0564]$

It was noted that this regression would result in an underestimate of the rate of increase for the 1980s period of relatively even conditions, because the calving interval has significantly increased during the observation period.

\section{METHOD 2}

A simple linear regression of the number of parous females by year (Table 1, column 2, taken from SC/M98/RW1) shows an increase between 1985 and 1997 of $0.0345(95 \%$ CI $0.0238,0.0452$ ).

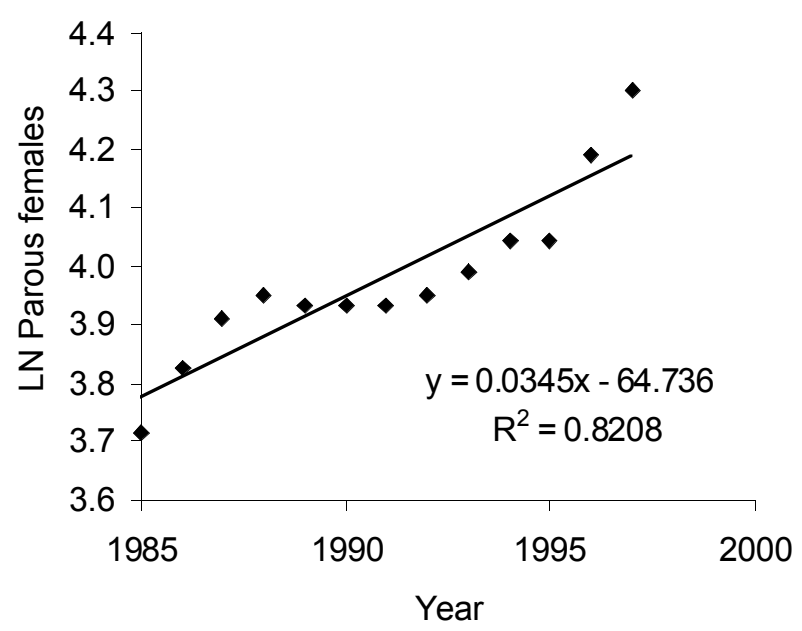

Fig. 1. Regression on the number of parous females against year (see text)

\section{METHOD 3}

In SC/M98/RW3, equation 17 provides rates of increase values calculated from: (1) an upper bound of annual survival $(S=0.99)$ and the lower bound $(S=0.94)$ of the estimates from the analysis in that paper; and (2) an annual reproductive output per individual, $m$, itself calculated from three quantities:

(1) the inter-calf interval $T$ of breeding females: 3.7 years from early years of observation, and 5 years from the recent period;

(2) the proportion $R$ of females in the population, taken at 0.5 ;

(3) the proportion $M$ of these females that are mature. A value of 0.38 was used from an estimate from Brown (1994) (see point 3 below for alternative value of 0.40 calculated from the North Atlantic catalogue data at the meeting) such that:

$m=(1 / T) * R * M=0.051$ (for $M=0.40, m=0.054$ ).

The lambda value of 1.041 in equation 17 , is equivalent to an annual rate of increase of $4.1 \%$. Using the alternative $M$ value, the rate of increase is $4.3 \%$, which can then be interpreted as an upper bound to the population growth rate for the North Atlantic right whale. However this approach works on the assumption of stable population increase, i.e. that the population has been increasing at a steady rate prior and during the observation period. For that reason this exercise should only apply the 1980s portion of the observation period, given the increase in calving interval and the change in geographical distribution in the 1990s. 


\section{ANALYSIS OF THE NORTH ATLANTIC RIGHT} WHALE CATALOGUE AS OF MARCH 241998

\section{6}

244 whales had been seen from the beginning of the observation period to the end of 1986 . Two of those had died, making a total of 242 whales in 1986, of which 48 were parous females. Given a $50 \%$ sex ratio, the proportion of females that are parous in this population is:

$48 /(242 \times 0.5)=0.40$

\section{9}

299 whales had been seen by the end of 1989 . Three of those had died, making a total of 296 whales in 1989, 59 of which were parous females.
$59 /(296 \times 0.5)=0.40$

Calculations do not include:

(1) presumed mortalities;

(2) known mortalities of unidentified individuals; or

(3) calves that were born but not photo-identified.

Calculations are not comparable to those in SC/M98/RW1 (table 1).

\section{REFERENCES}

Brown, M.W., Kraus, S.D., Gaskin, D.E. and White, B.N. 1994. Sexual composition and analysis of reproductive females in the North Atlantic right whale, Eubalaena glacialis, population. Mar. Mammal Sci. 10(3):252-65. 


\section{Annex H}

\section{Fatal and Non-Fatal Ship Collisions}

\begin{tabular}{|c|c|c|c|c|c|c|}
\hline $\begin{array}{l}\text { Date seen } \\
\text { injured/dead } \\
\text { (last date seen } \\
\text { uninjured) }\end{array}$ & Animal's fate & $\begin{array}{l}\text { Age (or } \\
\text { range) } \\
\text { when struck }\end{array}$ & Sex & $\begin{array}{l}\text { Geographical area injury } \\
\text { or mortality was } \\
\text { documented }\end{array}$ & $\begin{array}{l}\text { Date survivors } \\
\text { most recently } \\
\text { seen }\end{array}$ & Remarks \\
\hline \multicolumn{7}{|c|}{ Western North Atlantic* } \\
\hline 30 Jan. 1972 & Fatal & Calf & $\mathrm{U}$ & Texas & $\mathrm{n} / \mathrm{a}$ & $\begin{array}{l}\text { Body severed } \sim 1 \mathrm{~m} \text { forward of tail stock. Only documentation is a photograph published in a local newspaper (Brazosport Facts) } \\
\text { in Freeport. TX. }\end{array}$ \\
\hline 15 Apr. 1976 & Fatal & Calf & M & Massachusetts & $\mathrm{n} / \mathrm{a}$ & Large area of bruising observed behind skull. Scientist noted as probable ship collision. \\
\hline 5 Nov. 1976 & Fatal & Unknown & $\mathrm{U}$ & Maine & $\mathrm{n} / \mathrm{a}$ & Severe lacerations observed on back. \\
\hline 5 Mar. 1979 & Fatal & Juvenile & M & New York & $\mathrm{n} / \mathrm{a}$ & Tail severed. \\
\hline 28 May 1980 & Non-fatal & Unknown & M & Great South Channel & 5 Sep. 1989 & Cut along back crossing spine $\sim 1.5 \mathrm{~m}$ long, $15 \mathrm{~cm}$ deep. \\
\hline 13 Aug. 1980 & Non-fatal & Unknown & M & Bay of Fundy & 8 Mar. 1997 & Series of 8 propeller cuts running along left flank and over back. Max. $\sim 1.2 \mathrm{~m}$ length and $15 \mathrm{~cm}$ deep. \\
\hline $\begin{array}{l}21 \text { Feb.1983 } \\
(18 \text { Sep. } 1981)\end{array}$ & Fatal & 2 years & M & New Jersey & $\mathrm{n} / \mathrm{a}$ & Severed tail. \\
\hline 5 Aug. 1984 & Non-fatal & Unknown & $\mathrm{U}$ & Browns Bank & 29 May 1988 & Series of 5 propeller cuts $\sim 60 \mathrm{~cm}$ long, $10 \mathrm{~cm}$ deep on left flank and near spine. \\
\hline $\begin{array}{l}14 \text { Aug. } 1986 \\
\text { (May 1984) }\end{array}$ & Presumed fatal & $\begin{array}{l}7 \text { years } \\
(5-7 \text { years })\end{array}$ & $\mathrm{F}$ & Bay of Fundy & 3 Oct. 1986 & $\begin{array}{l}\text { 1m diameter necrotic wound } \sim 1 \mathrm{~m} \text { behind blowholes. Last seen } 3 \text { Oct. } 1986 \text { in Cape Cod Bay. Status: poor - slow swimming, } \\
\text { orange cyamids, infection. }\end{array}$ \\
\hline $\begin{array}{l}7 \text { Aug. } 1986 \\
\text { (9 Sep. } 1985)\end{array}$ & Fatal & 1 year & $\mathrm{F}$ & Massachusetts Bay & $\mathrm{n} / \mathrm{a}$ & 2 propeller cuts, max. $\sim 4.5 \mathrm{~m}$ long, $1 \mathrm{~m}$ deep running longitudinally along body. Severed spine. \\
\hline 14 Feb. 1987 & Non-fatal & Calf & $\mathrm{F}$ & Southeast US & 26 Aug. 1997 & Series of 5 propeller cuts $\sim 30 \mathrm{~cm}$ long and $8 \mathrm{~cm}$ deep on left fluke tip. Fluke tip eventually came off because of cuts. \\
\hline 9 Jul. 1987 & Fatal & Juvenile & M & Nova Scotia & $\mathrm{n} / \mathrm{a}$ & $\begin{array}{l}2-3 \text { observed propeller cuts on left flank, } 20-25 \mathrm{~cm} \text { deep, shallow gash and swelling observed on right flank. Animal buried } \\
\text { without a necropsy. }\end{array}$ \\
\hline 28 Aug. 1987 & Non-fatal & Unknown & $\mathrm{U}$ & Browns Bank & 28 Sep. 1997 & $\sim 1 \mathrm{~m}$ of right fluke tip missing. Severed by propeller. \\
\hline 11 Feb. 1991 & Non-fatal & Calf & $\mathrm{F}$ & Southeast US & 1997 & Series of 3 propeller cuts, max. $1.2 \mathrm{~m}$ long, $15 \mathrm{~cm}$ deep on left flank. Cuts healed. \\
\hline $\begin{array}{l}12 \text { Mar. } 1991 \\
\text { (21 Feb. 1991) }\end{array}$ & Fatal & 2 years & $\mathrm{F}$ & Florida & $\mathrm{n} / \mathrm{a}$ & $\begin{array}{l}\text { Seen in Bay of Fundy, Oct. } 1990 \text { with line, gillnets and buoys wrapped around tailstock. Seen off the coast of Florida on } 21 \text { Feb. } \\
1991 \text { with skin lesions on head. Swimming laboriously. Stranded on } 12 \text { Mar. } 1991 \text { in Florida. Flensed carcass revealed a } \\
\text { shattered skull, from ship strike. }\end{array}$ \\
\hline $\begin{array}{l}5 \text { Sep. } 1992 \\
\text { (23 Aug. } 1992)\end{array}$ & Fatal & Adult & $\mathrm{F}$ & Bay of Fundy & $\mathrm{n} / \mathrm{a}$ & $\begin{array}{l}\text { No external sign of injury. Necropsy revealed extensive internal haemorrhaging caused by impact from ship. Carcass flensed, no } \\
\text { broken bones. }\end{array}$ \\
\hline 5 Jan. 1993 & Fatal & Calf & M & Florida & $\mathrm{n} / \mathrm{a}$ & $\begin{array}{l}\text { Two series of large propeller cuts from a twin engine, } 82 \text { foot Coast Guard cutter. Max. depth } 40.5 \mathrm{~cm} \text {, max. length } 104 \mathrm{~cm} \\
\text { Animal not seen by vessel operators before impact. Vessel struck whale at a speed of } 15 \text { knots. Carcass not recovered until } 8 \\
\text { Jan., full necropsy } 9 \text { Jan. }\end{array}$ \\
\hline \multirow[t]{2}{*}{6 Dec. 1993} & Fatal & Unknown & $\mathrm{F}$ & Virginia & $\mathrm{n} / \mathrm{a}$ & $\begin{array}{l}\text { Found floating belly up, back side not observed. Not retrieved. Large straight gash running from right ventral to right lateral } \\
\text { surface anterior to flukes. }\end{array}$ \\
\hline & Fatal & Unknown & $\mathrm{U}$ & Virginia & $\mathrm{n} / \mathrm{a}$ & Another dead floating right whale found on same day, 28 miles to the south. Cause of death undetermined. Carcass not retrieved. \\
\hline $\begin{array}{l}22 \text { Feb. } 1994 \\
\text { (27 Jan.1994) }\end{array}$ & Presumed fatal & Calf & $\mathrm{U}$ & Florida & - & $\begin{array}{l}\text { Several deep cuts on head and lower lip regions from line or cable. Probable propeller cuts on both sides of dorsal flukes. Injury } \\
\text { maybe while fishing vessel retrieving gear. }\end{array}$ \\
\hline $\begin{array}{l}\text { 13 Aug. } 1995 \\
\text { (22 Mar. 1992) }\end{array}$ & Unknown & Adult & $\mathrm{F}$ & Gulf of Maine & - & $\begin{array}{l}\text { Cut } \sim 60-90 \mathrm{~cm} \text { deep on right side of head below rostrum and cutting into the lower lip and extending down for undetermined } \\
\text { length. Orange cyamids on tail and along lip edge, greying of skin. Status: poor. }\end{array}$ \\
\hline $\begin{array}{l}16 \text { Sep. } 1995 \\
\text { (8 Sep. } 1995)\end{array}$ & Non-fatal & 4 years & M & Bay of Fundy & 1997 & Series of propeller cuts, max. $\sim 1 \mathrm{~m}$ long, $8 \mathrm{~cm}$ deep on tail stock and tail. Fishing gear through mouth was partially removed. \\
\hline $\begin{array}{l}19 \text { Oct. } 1995 \\
\text { (8 Oct. } 1995)\end{array}$ & Fatal & Unknown & M & Bay of Fundy & $\mathrm{n} / \mathrm{a}$ & $4.8 \mathrm{~m}$ long gash in back, broken vertebral discs. Full necropsy impossible as whale found on inaccessible beach. \\
\hline 30 Jan. 1996 & Fatal & Adult & M & Georgia & $\mathrm{n} / \mathrm{a}$ & No external sign of impact. Broken skull, vertebrae and ribs found when carcass floated. Blunt impact from ship. \\
\hline
\end{tabular}


Table cont.

\begin{tabular}{|c|c|c|c|c|c|c|}
\hline $\begin{array}{l}\text { Date seen } \\
\text { injured/dead } \\
\text { (last date seen } \\
\text { uninjured) }\end{array}$ & Animal's fate & $\begin{array}{l}\text { Age (or } \\
\text { range) } \\
\text { when struck }\end{array}$ & Sex & $\begin{array}{l}\text { Geographical area injury } \\
\text { or mortality was } \\
\text { documented }\end{array}$ & $\begin{array}{l}\text { Date survivors } \\
\text { most recently } \\
\text { seen }\end{array}$ & Remarks \\
\hline $\begin{array}{l}9 \text { Mar. } 1996 \\
\text { (3 Oct. 1995) }\end{array}$ & Fatal & Unknown & M & Massachusetts & $\mathrm{n} / \mathrm{a}$ & $\begin{array}{l}\text { 3.3m long gash in back, broken skull. Lobster line including a trap caught through mouth and around tail. Entanglement } \\
\text { occurred in Dec. in Bay of Fundy. Carcass severely decomposed. }\end{array}$ \\
\hline 19 Aug. 1997 & Fatal & Unknown & $\mathrm{F}$ & Bay of Fundy & $\mathrm{n} / \mathrm{a}$ & $\begin{array}{l}\text { No external sign of injury. Necropsy revealed } 6 \mathrm{~m} \text { long haematoma along left side and broken right mandible. Carcass flensed, } \\
\text { no other broken bones observed. }\end{array}$ \\
\hline \multicolumn{7}{|l|}{ Brazil } \\
\hline $\begin{array}{l}1989 \\
\text { (several times, }\end{array}$ & Fatal & Juvenile & $\mathrm{U}$ & Rio Grande do Sul & $\mathrm{n} / \mathrm{a}$ & Stranded with propeller cuts on head. Sighted several times during two weeks prior to stranding. \\
\hline $\begin{array}{l}\text { days prior) } \\
1991\end{array}$ & Fatal & Unknown & $\mathrm{U}$ & Rio Grande do Sul & $\mathrm{n} / \mathrm{a}$ & Two halves of a right whale were found approximately $1 / 2$ mile apart. \\
\hline 1992 & Unknown & Unknown & $\mathrm{U}$ & Rio Grande do Sul & $\mathrm{n} / \mathrm{a}$ & Trawler reported striking a right whale. No other information. \\
\hline Oct. 1993 & Fatal & Unknown & $\mathrm{U}$ & Rio Grande do Sul & $\mathrm{n} / \mathrm{a}$ & Right whale stranded $16 \mathrm{~km}$ south of Rio Grande $\left(32^{\circ} 08^{\prime} \mathrm{S}\right)$ with four propeller cuts on tail stock. \\
\hline \multicolumn{7}{|l|}{ South Africa } \\
\hline 27 Jul. 1983 & Fatal & Adult & $\mathrm{F}$ & Beachview, Port Elizabeth & $\mathrm{n} / \mathrm{a}$ & Died at sea. Five apparent propeller marks. Shark bites also noted. \\
\hline 8 Feb. 1984 & Fatal & Adult & $\mathrm{U}$ & Jakkalsfontein & $\mathrm{n} / \mathrm{a}$ & Seen from air. Major damage around the midlength. Possible ship strike. \\
\hline 16 Oct. 1984 & Fatal & Calf & & East London Harbour & $\mathrm{n} / \mathrm{a}$ & $\begin{array}{l}\text { Crew of cargo ship reported the presence of cow/calf pair of right whales at the harbour entrance. Despite this, the calf was later } \\
\text { struck, at } 0730 \text { hours, by a hopper dredge leaving the harbour. The dredge captain reported the pair surfaced suddenly off his } \\
\text { bow. Vessel speed unknown. }\end{array}$ \\
\hline 21 Nov. 1986 & Non-fatal & Unknown & $\mathrm{U}$ & - & - & $\begin{array}{l}\text { Fisheries vessel struck whale causing some damage to whale and boat. Vessel abandoned but later towed in. Whale cut but } \\
\text { apparently OK. }\end{array}$ \\
\hline 10 Sep. 1988 & Fatal & Adult & M & $25 \mathrm{~km}$ E of Sundays River & $\mathrm{n} / \mathrm{a}$ & $\begin{array}{l}\text { On } 7 \text { Sep. } 1988 \text {, nine whales were sighted ahead of roll-on/roll-off ferry M/V Barrier as it gained speed leaving Port Elizabeth } \\
\text { harbour at } 0653 \text { hours. They apparently did not react to the approaching vessel, which was travelling } 12-13 \text { knots. Impact was } \\
\text { felt by crew and blood was observed in the water. Two whales stranded } 10 \text { Sep. } 1983 \text {, on a beach } 15 \text { n.miles from strike. One } \\
\text { had propeller slashes and damaged rostrum. One showed no outward sign of impact. }\end{array}$ \\
\hline 10 Sep. 1988 & Fatal & Adult & M & $25 \mathrm{~km}$ E of Sundays River & $\mathrm{n} / \mathrm{a}$ & See above. \\
\hline 16 Aug. 1993 & Fatal & Calf & $\mathrm{U}$ & $\begin{array}{l}\text { Between Long Beach and } \\
\text { Koppie Alleen }\end{array}$ & $\mathrm{n} / \mathrm{a}$ & Found dead, blubber and appendages. Tail cut off. Possible ship strike. \\
\hline 10 Oct. 1993 & Fatal & Calf & $\mathrm{F}$ & Lekkerwater, De Hoop & $\mathrm{n} / \mathrm{a}$ & Found dead, decomposing. Tail cut off. Possible ship strike. \\
\hline 22 Sep. 1994 & Fatal & Juvenile & $\mathrm{F}$ & $\begin{array}{l}\text { Kabeljoubank, Breede } \\
\text { River }\end{array}$ & $\mathrm{n} / \mathrm{a}$ & $\begin{array}{l}\text { Found dead. Bystanders claimed that there had been a boat struck in the adjoining bay } 2-3 \text { days before and that the animal had } \\
\text { cuts across the back. Possible ship strike. }\end{array}$ \\
\hline 10 Nov. 1994 & Fatal & Juvenile & M & Shell Bay, St Helena Bay & $\mathrm{n} / \mathrm{a}$ & Found dead. Diagonal slash through the blubber near the genital aperture through which viscera protruded. Possible ship strike. \\
\hline 6 Jan. 1995 & Non-fatal & Unknown & $\mathrm{U}$ & & - & Boat damage, whale apparently survived. \\
\hline 28 Jul. 1996 & Fatal & Adult & $\mathrm{F}$ & $\begin{array}{l}\text { Scarborough, Cape } \\
\text { Peninsula }\end{array}$ & $\mathrm{n} / \mathrm{a}$ & $\begin{array}{l}\text { Stranded dead. No external signs of injury but when the skeleton was later being prepared for museum display the rostrum was } \\
\text { found to be broken and skull fragments were missing. Possible ship strike. }\end{array}$ \\
\hline 6 Sep. 1997 & & Unknown & $\mathrm{U}$ & - & - & Boat damage, whale apparently survived. \\
\hline
\end{tabular}

* Vessel strikes resulting in propeller cuts less than $8 \mathrm{~cm}$ in depth are not included.

\section{REFERENCES}

Bannister, J.L. 1986. Southern right whales: status off Australia from twentieth century 'incidental' sightings and aerial survey. Rep. int. Whal. Commn (special issue) 10:153-8

Tønnessen, J.N. and Johnsen, A.O. 1982. The History of Modern Whaling. C. Hurst and Co., London. I-xx+798pp.

Tormosov, D.D., Mikhalev, Y.A., Best, P.B., Zemsky, V.A., Sekiguchi, K. and Brownell Jr, R.L. 1998. Soviet catches of southern right whales, Eubalaena australis, 1951-1971;

biological data and conservation implications. Biol. Conserv. 86(2):185-97. 


\section{Annex I \\ Specific Recommendations for Reducing Ship Strikes (see Item 12.3.3 and Item 14)}

\begin{abstract}
WESTERN NORTH ATLANTIC
Southeast USA

Calving right whales give birth and overwinter in the coastal waters between Savannah, Georgia (GA) and West Palm Beach, Florida (FL). The primary aggregation occurs along 80 n.miles of coastline between Sapelo Island, GA and St. Augustine, FL. Most sightings of right whales occur west of 8100W (Kraus et al., 1993; SC/M98/RW6). Three major shipping channels serve three commercial ports and two military bases located within this area of aggregation. These are the Brunswick Harbour entrance (Brunswick, GA), the St. Marys River entrance (Fernandina Beach, FL) and the St. Johns River entrance (Jacksonville, FL).

The Workshop recommends that these three channels be extended due east, from their respective sea-buoys, to $81^{\circ} 00 \mathrm{~W}$. During the calving season (December to March), all vessels greater than $25 \mathrm{~m}$ in length, using these channels, should travel the entire length of the channels. All vessels greater than $25 \mathrm{~m}$ in length should operate at less than 10 knots (or minimum safe steerage) while in the federally designated critical habitat. The Workshop further recommends that a mandatory ship reporting system be implemented to acquire information on the numbers of vessels transiting this area.
\end{abstract}

\section{Bay of Fundy}

Right whales are present in the Bay of Fundy from June to November, with a peak in August and September. In recent years, cow-calf pairs, juveniles and adults identified in the Bay represent some two-thirds of the catalogued population. The aggregation of right whales overlaps with the outbound shipping lane from Saint John, New Brunswick, and the inbound vessel lane for ports in Maine and New Brunswick. These lanes are monitored by a Vessel Traffic System. Since 1992, there have been three mortalities from ship collisions in the Bay of Fundy (SC/M98/RW8).

To reduce the potential for ship/whale collisions the Workshop recommends that the shipping lanes be narrowed and moved about $10 \mathrm{~km}$ to the east away from right whale aggregations.

\section{Roseway Basin}

Roseway Basin is an offshore feeding habitat which has been observed with high numbers of right whales from July to September. Although no shipping lanes transit the area and no mortalities have been documented, ship traffic has been observed transiting this habitat.

The Workshop recommends that this high-use area be designated as an area to be avoided by shipping.

\section{Great South Channel}

Right whales are present in high numbers in this offshore area from April to June. Shipping traffic to/from Boston Harbour use the shipping lanes in the Great South Channel.
Other Gulf of Maine shipping traffic traverses the entire breadth of the Great South Channel. Little is known about the level of ship traffic and how it overlaps with right whale habitat use.

The Workshop recommends that a mandatory ship reporting system be implemented to acquire information on the numbers of vessels transiting this area and to provide these ships with information on real time sighting locations obtained of right whales observed from aerial surveys.

\section{Cape Cod Bay}

Right whales are present in limited numbers in this area from December to May. An unknown level of vessel traffic transits through this high-use area.

The Workshop recommends that a mandatory ship reporting system be implemented to acquire information on the numbers of vessels transiting this area and to provide these vessels with information on right whale sighting locations obtained from aerial and shipboard surveys.

\section{High speed ferries}

The Workshop expressed serious concern over the proposed use of large (>100ft) high speed (>30 knot) ferries transiting right whale migration corridors and habitat, and recommends consideration of ship/whale collision risks in permit review.

\section{OTHER AREAS}

The Workshop agreed that many of the problems faced by North Atlantic right whales with regard to ship traffic either currently or potentially exist in other parts of the world where right whales concentrate.

For areas where there is information on right whale distribution and densities, or critical habitats have been defined, the control of shipping activity should be investigated. This may include:

(a) moving shipping lanes to areas of lower right whale densities;

(b) slowing ship speeds;

(c) educating mariners on right whale distribution and vulnerability;

(d) assessing regions where there is increased potential for whale/ship interaction with increasing or expanding right whale populations.

\section{REFERENCE}

Kraus, S.D., Kenney, R.D., Knowlton, A.R. and Ciano, J.N. 1993. Endangered right whales of southwestern North Atlantic. p.69. In: Final Report, Minerals Management Service Contract No. 14-35-0001-30486. Edgerton Research Laboratory, New England Aquarium, Boston, MA. 


\section{Annex J Report of the Whalewatching Working Group}

\author{
Members: Findlay (Convenor), Brown, Burnell, Carlson, \\ Donoghue, Flores, Juritz, Knowlton, Lotz, Mayo, Palazzo Jr, \\ Patenaude, Payne, Reeb, Rowntree, Silber, Slay, Swartz.
}

\section{ELECTION OF CHAIRMAN}

Findlay was appointed Chairman.

\section{ELECTION OF RAPPORTEURS}

Carlson and Donoghue were appointed Rapporteurs.

\section{ADOPTION OF THE AGENDA}

The adopted agenda is given as Appendix 1.

\section{REVIEW OF AREAS}

The group reviewed areas where watching of right whales occurs around the world and noted that regulation of whalewatching activities varied greatly between countries. It did not have adequate information to provide precise numbers for boats operating in many areas; broad estimates were provided where exact numbers were not known.

\section{POSITIVE AND NEGATIVE ASPECTS OF WATCHING RIGHT WHALES}

\subsection{Positive aspects}

Positive aspects of watching right whales were discussed under the following general categories: education (IFAW, 1996; Orams, 1996); research (IFAW, 1995); economic (Hoyt, 1995; Findlay, 1997; IFAW, 1998); protection (IFAW, 1999); political; and benefits to whales.

\subsubsection{Education/emotional response/public awareness}

The group agreed that right whales, like other whale species, can be effective in highlighting issues of ocean conservation. The coastal habits of right whales in some areas increase their visibility to the public and as a result may facilitate protection of coastal and marine environments. Right whales are of great interest to the public and provide a sense of awe in whalewatchers, thus providing advocacy for wider protection of the marine environment upon which the whales depend.

\subsubsection{Research}

Whalewatching vessels can be excellent platforms for data collection. Mayo noted that in New England, considerable research and entanglement data have been collected from whalewatching vessels, however, data collection has been limited by the 500-yard approach regulation. Participants noted that in Argentina, operators provide information on photo-identification, entanglements and carcasses, and in
Brazil, tourists and locals provide sighting data for researchers.

Patenaude noted that levies are charged on commercial dolphin-watching vessels in the Bay of Islands, New Zealand. There is no such levy for right whalewatching operations. However, in some cases, whalewatching operators have provided salaries for researchers and support for research through the sale of souvenirs.

\subsubsection{Economics}

Several communities around the world have derived economic benefits from whalewatching industries. In such cases, numerous aspects of community life benefit (Hoyt, 1995; IFAW, 1998).

It was noted that the Mobile Telephone Network (MT) believes their sponsorship of the Cape Whale Route in South Africa provides more public interest than their sponsorship of high profile sporting events.

Shore-based whalewatching in Santa Catarina, Brazil is being promoted as the main winter alternative for coastal tourism which is otherwise very scarce. In at least one location in Australia, shore-based whalewatching and general tourism has resulted in increased opportunities for terrestrial and marine conservation as a result of revenues generated. Although Peninsula Valdés, Argentina is remote, over 44,000 tourists took whalewatching trips in 1994. Because the local community is earning money from whales, they are protective of the resource and associated infrastructure.

The group recognised that there are examples of economic benefits to local communities from whalewatching activities based on other species, such as gray whales.

\subsubsection{Protection}

Shore-based whalewatching may provide extra protection to right whales because any vessels interacting with the whales are more easily observed, promoting self-regulation. In the Bay of Fundy, Canada, boat-based whalewatching is self-regulated by a code of ethics agreed by the operators. There is also self-regulation by boat operators in Argentina. Community monitoring and local pressures in these areas may be more effective than legislation alone.

\subsubsection{Political}

Whalewatching is a significant way to generate political support for increased protection of whales. For example, Burnell noted that the Head of the Bight Right Whale Sanctuary in Southern Australia gained increased political support when it was realised that the revenues from whalewatching could equal or exceed previous revenues from fishing. 


\subsubsection{Potential benefits to whales}

Whalewatching can be an important element in habitat protection. In areas where populations are recovering, whales may be reoccupying previously used habitats, parts of which are now severely degraded (e.g. western North Atlantic). Political pressure, much of it generated by whalewatching, can result in better protection of such habitats.

As a further example, Payne reported that right whales in Peninsula Valdés, Argentina seek the shelter of whalewatching boats to escape gull harassment.

\subsection{Potential negative aspects}

\subsubsection{Short-term impacts}

There are few studies which demonstrate short-term, negative effects of whalewatching activities. The group noted that short-term effects may depend on: the vessel (number, duration of encounter, speed, angle of approach, type and acoustic signature of vessel); the whales (behaviour, group composition, past experience with vessels); and the environment (habitat type, sea state and water depth). It was noted that short-term effects may include changes in dive times, respiration, swimming speed and direction, and behaviour including acoustic behaviour.

\subsubsection{BOAT-BASED WHALEWATCHING}

Studies in Peninsula Valdés, Argentina showed that individuals without calves in Golfo Nuevo (whalewatching permitted) exhibited greater swimming speeds than individuals without calves in Golfo San Jose (protected; no whalewatching), whereas whales with calves did not (Colombo et al., 1990). SC/M98/RW32 describes evasive responses by whales to 'threatening' approaches by boats (e.g. circling, chasing). Palazzo noted that threatening approaches in Brazil resulted in the temporary displacement of right whales to adjacent bays, whereas more careful approaches often resulted in whales approaching boats. Patenaude reported that small boat approaches in the Auckland Islands often resulted in the disturbance of cow-calf pairs when the boat was closer than $20 \mathrm{~m}$, but the whales quickly resumed normal behaviour after the boat left the immediate area.

Payne reported that right whales are more easily disturbed when approached by vessels on calm days. In the Bay of Fundy, right whales appear not to notice approaching vessels when the whales are resting on the surface or participating in surface active groups.

\subsubsection{AERIAL WHALEWATCHING}

Payne noted a general lack of response in Argentinian right whales exposed to fixed-wing aircraft during surveys. However, helicopters appear to cause disturbance. Burnell reported that in southeast Australia, research aircraft are not permitted to fly lower than $250 \mathrm{~m}$ over whales. Voluntary protocols restrict each encounter to three circuits. If required, further encounters are made after a minimum five-minute delay. It has been noted that photography becomes progressively more difficult after the first encounter/session as whales remain submerged for a longer period.

A number of studies have examined the effects of aircraft and boats on marine mammals, although the relevance of these results to whalewatching activities is not known. The group discussed several cases. For example, bowhead whales frequently react to circling aircraft at $305 \mathrm{~m}$ or less. Reactions include hasty dives, increased respiration, change of direction or dispersal from the area of disturbance (Richardson et al., 1995).

\subsubsection{Long-term effects}

The group noted the difficulty of linking long-term effects to whalewatching given the relatively few directed studies.

Although no long-term effects are known, the group acknowledged that they may result in: shifts in distribution or habitat use; lowered reproductive success (e.g. missed mating opportunities; separation of cow-calf pairs); changes in mortality/recruitment or feeding/energetics.

The group discussed the issue of repeat approaches and noted that this may result in habituation. It was suggested that habituation may increase the likelihood of ship strikes.

\subsubsection{BOAT-BASED WHALEWATCHING}

The group noted that there were no observed long-term negative effects of whalewatching on right whales.

In Peninsula Valdés, Argentina, cow-calf pairs have moved from the outer coast and a bay where whalewatching is not allowed, to an area in Golfo Nuevo that is adjacent to the centre of the whalewatching industry. These whales have therefore moved from an area of less human disturbance to one of more disturbance (SC/M98/RW13). However, the 1994/1997 cohort of calving females moved 50km away from the whalewatching area to an area with considerable boat activity and severe gull harassment of the whales. The reasons for this movement are unclear. It may be attributed to social cohesion, environmental factors or disturbance from whalewatching activities.

The group then discussed other species. Swartz noted that there had been changes in gray whale migratory corridors off California, USA. Increasing levels of recreational whalewatching were thought to be the reason for the shift, but a definitive link had not been established. He also noted that, unlike the other three bays, whalewatching in one of the four breeding lagoons in Mexican waters, Northern Magdalena Bay, was not regulated, and that gray whales appear to have abandoned this area as a result. Again, a clear cause-effect relationship had not been established.

The group noted that well-documented studies on humpback whales in New England (Mayo and Carlson, pers. comm.) and Glacier Bay, Alaska (Baker and Herman, 1989) had shown that initial concerns that whales had vacated these areas because of vessel traffic had later been demonstrated to be unfounded. Thus, distributional shifts cannot be attributed to whalewatching in all cases, and such shifts need to be carefully investigated.

Mayo noted that research on seasonally returning humpback whales conducted for the past 22 years has shown no long-term effects of boat-based whale-watching. In particular, the reproductive success of known individuals apparently has not been negatively affected.

\subsection{Other identified effects}

\section{Environment}

Mayo suggested that motor vessel traffic has an effect on the density of surface plankton patches, and therefore may affect right whale prey acquisition in Cape Cod Bay. The effect of this on right whales is not clear.

\section{Research}

The group noted that there are locations where cetacean tourism activities had interfered with research. These included examples from the Bay of Islands, New Zealand, Witsand and Hermanus, South Africa and New England, USA. 


\section{Economics/political}

Burnell noted that political influence based on economic motivation can affect whale conservation. For example, in Australia, the fishing industry has applied significant political pressure to inhibit legislation designed to protect whales. He stressed the importance of highlighting to politicians the economic value of whalewatching.

\section{Swimming with whales}

Payne noted that right whales provide a unique opportunity to generate increased support for whale conservation through close contact but recognised that this activity would have to be carefully regulated.

\section{REVIEW OF LEGISLATION, REGULATIONS AND GUIDELINES}

The group reviewed present legislation, regulations and guidelines which pertain to the watching of right whales around the world. The majority of these are presented in Carlson (1996).

\subsection{Protected areas}

The group noted that marine protected areas exist in certain parts of the world and identified a number of protected areas bearing on the protection of right whales. The extent of regulation within protected areas differs between nations or areas. Not all of these protected areas were established as a result of whalewatching or to protect right whales.

\section{Canada}

The Bay of Fundy and Roseway Basin Right Whale Conservation Areas were designated by the Federal Government of Canada. These areas encourage voluntary compliance for vessel approach guidelines. The areas provide a means for mariner awareness and education, but provide no a priori protection for right whales.

\section{USA}

National Marine Sanctuaries are generally designated for a particular marine resource or species, and serve to raise public awareness, rather than limit human activities. Although there are no sanctuaries established specifically for right whales, the range of the North Atlantic right whales includes the Gerry E. Studds Stellwagen Bank National Marine Sanctuary and Gray's Reef National Marine Sanctuary.

\section{RIGHT WHALE CRITICAL HABITAT}

Three Critical Habitats have been designated for right whales on the eastern seaboard of the USA. Designation of a Critical Habitat does not restrict human activity or mandate management action, but it does contribute to species conservation by raising public awareness about the importance of the area, and provides specific guidance for the regulation of federal activities in the area.

\section{Argentina}

Argentina created the first marine sanctuary for right whales. Golfo San Jose was declared a Provincial Marine Park in 1974 to maintain the pristine nature of the area as an important nursery area for right whales.

\section{Australia}

The South Australian Government established the Head of the Bight Right Whale Sanctuary in 1996, restricting all industrial, commercial and boat-based access. The
Commonwealth Government has proposed a large complementary Marine Park surrounding the whale sanctuary to cover a total of $21,000 \mathrm{~km}^{2}$, restricting access for the six-month period when right whales are in coastal waters and providing strict controls over access for the remainder of the year.

\section{Sub-Antarctic}

The Auckland Islands Marine Mammal Sanctuary includes all waters within a 12 n.mile radius of the Auckland Islands. Currently all commercial fishing is prohibited within this area, and further regulations are able to be promulgated by the Minister of Conservation.

\section{Other}

The Southern Ocean Whale Sanctuary and Indian Ocean Sanctuary have been designated by the IWC but the only provisions are for the prohibition of whaling.

\section{RECOMMENDATIONS FOR MANAGEMENT}

The group endorsed the IWC's general principles for whalewatching and recommended that these be applied to all whalewatching activities involving right whales. The group agreed that it was critical to: (1) manage the development of new and fledgling whalewatching operations to minimise the risk of adverse affects; and (2) take appropriate regulatory measures in areas where directed research demonstrated negative impacts on whales from established whalewatching activities.

The group agreed that special protected areas provide a framework for the implementation of site-specific regulations for whalewatching and that such areas are important in conserving coastal habitats. It is therefore recommended that studies be undertaken to assess the establishment of special protected areas in areas of known right whale concentration (e.g. the central-south coast of Santa Catarina, Brazil).

\section{ADOPTION OF REPORT}

The report was adopted at 10:30am on Sunday 22 March.

\section{REFERENCES}

Baker, C.S. and Herman, L.M. 1989. Behavioural responses of summering humpback whales to vessel traffic. Experimental and opportunistic observations. NPS-NR-TRS-89-01. Report from Kewalo Basin Marine Mammal Laboratory, Honolulu, for the US National Park Service, Anchorage, AK.

Carlson, C.A. 1996. A review of whalewatching guidelines and regulations around the world. Paper SC/48/O25 presented to IWC Scientific Committee, June 1996, Aberdeen (unpublished). 59pp. [Paper available from the Office of this Journal].

Colombo, G.A., Arias, A.M. and Garciamena, A.D. 1990. A possible effect of whale watching on right whales (Eubalaena australis). IV Reunión de Trabajo de Especialistas en Mamíferos Acuáticos de América del Sur, Valdivia, Chile [Abstract].

Findlay, K. 1997. Attitudes and expenditures of whale watchers in Hermanus, South Africa. S. Afr. J. Wildl. Res. 27(2):57-62.

Hoyt, E. 1995. The worldwide value and extent of whale watching 1995. A special report from the Whale and Dolphin Conservation Society. 36pp. [Available from: sarahcl@wdcs.org.uk].

IFAW. 1996. Report on the International Workshop on the Special Aspects of Watching Sperm Whales, Roseau, Commonwealth of Dominica, 8-11 January 1996. Paper SC/48/O 26 presented to IWC Scientific Committee, June 1996, Aberdeen (unpublished). 32pp. [Paper available from the Office of this Journal].

IFAW. 1995. Report of the Workshop on the Scientific Aspects of Managing Whalewatching, Montecastello di Vibio, Italy, 30 March 
- 4 April 1995. Paper SC/47/O 18 presented to the IWC Scientific Committee, May 1995 (unpublished). 45pp. [Paper available from the Office of this Journal].

IFAW. 1998. Report of the Workshop on the Socio-Economic Aspects of Whale Watching, Kaikoura, New Zealand, 8-12 December 1997. Paper IWC/50/WW1 presented to the IWC, Muscat, Oman, May 1998 (unpublished). 92pp. [Paper available from the Office of this Journal].

IFAW. 1999. Report of the Workshop on the Legal Aspects of Whale Watching, Punta Arenas, Chile, 17-20 November 1997. Paper
IWC/51/WW1 presented to the IWC, Grenada, WI, May 1999 (unpublished). 38pp. [Paper available from the Office of this Journal].

Orams, M. 1996. Cetacean education: can we turn tourists into 'greenies'? In: K. Colgon, S. Prosser and A. Jeffreys (eds.) Encounters with Whales 1995. Proceedings. Australian Nature Conservation Agency, Canberra.

Richardson, W.J., Greene Jr, C.R., Malme, C.I. and Thomson, D.H. 1995. Marine Mammals and Noise. Academic Press, San Diego. 576pp. 


\section{Annex K \\ Proposal for the Establishment of a Southern Hemisphere Right Whale Consortium}

\section{BACKGROUND}

Dedicated research has been carried out on southern right whales in Argentina, South Africa and Western Australia for the past thirty years or so (Whitehead et al., 1986; SC/M98/RW15). Recent studies have included work in Southern Australia, New Zealand sub-Antarctic, South Georgia and Brazil (Baker et al., 1997; Burnell, 1997; SC/M98/RW26; SC/M98/RW14). However, prior to this IWC-convened Right Whale Workshop, few opportunities existed for cooperation and collaborative research, and consequently the national programmes that have been developed have not shared common methodologies for data collection and analysis. Further, information on stock structure and life history parameters have only been partially elaborated because of the localised nature of study areas.

By contrast, in the North Atlantic, a collaborative research consortium has been formed, consisting of representatives from five independent research institutions, two national governments and their appropriate agencies and four US state agencies (see Appendix 1). This consortium was formed in 1986, when research teams from various institutions recognised the need to bring together the information that had been collected from study programmes on right whales in five different locations on the east coast of North America, and to standardise data collection protocols and methods for analysis. Additionally, establishment of the consortium has allowed the pooling of resources, the sharing of key personnel and the development of a broader overview of the biology and conservation requirements of the North Atlantic right whale.

\section{PROPOSAL}

Here we propose the establishment of a multinational consortium for the study of right whales in all oceans of the Southern Hemisphere. Such a multinational effort will provide insights into stock structure, population dynamics and conservation requirements that no single national research effort could hope to obtain. The consortium objectives might be:

(1) standardisation of data collection;

(2) facilitation of inter-catalogue comparisons of photo-identifications between regions;

(3) development of comparable analytical methods;

(4) sharing of resources, especially sophisticated and expensive laboratory techniques (e.g. for genetic, isotopic and pollutant analysis);

(5) exchange of scientific personnel and samples;

(6) and where appropriate, assistance in the development of joint management strategies and policy.

\author{
Membership \\ Members of such a consortium might include (but not be \\ limited to) the following.
}

\section{Government Agencies}

Brazil - IBAMA (National Environmental Authority).

Argentina - Advisory Committee on Right Whales as a Designated National Monument.

Chile - Ministry for the Environment.

South Africa - Department of Sea Fisheries.

Australia - Environment Australia.

New Zealand - Department of Conservation.

Provincial Agencies

Brazil - State Secretariat of the Environment, Santa Catarina.

Argentina - Organismo Provincial de Turismo, Chubut. Western Australia - Department of Conservation and Land Management South Australia.

\section{Academic Institutions}

University of Auckland.

Western Australia Museum.

University of Sydney.

MRI, University of Pretoria.

British Antarctic Survey.

\section{Independent Research Organisations}

Whale Conservation Institute. International Wildlife Coalition.

Fundacion Patagonia Natural. CODEFF (Chile).

Additionally, the proposed Southern Hemisphere Consortium would benefit from the active involvement (at least in the early stages) of some members of the North Atlantic Right Whale Consortium, for example, the New England Aquarium and the National Marine Fisheries Service (NMFS).

\section{REFERENCES}

Baker, C.S., Patenaude, N. and Bannister, J. 1997. Differences in mtDNA lineages of right whales from wintering grounds of southwest Australia and sub-Antarctic New Zealand. Paper SC/49/SH23 presented to the IWC Scientific Committee, September 1997, Bournemouth (unpublished). 8pp. [Paper available from the Office of this Journal]

Burnell, S.R. 1997. An incidental flight network for the photo-identification of southern right whales off southeastern Australia. A summary of research activities undertaken in the 1995 
and 1996 seasons. Report by Eubalaena Pty. Ltd to BHP Petroleum Pty. Ltd. and Esso Australia Ltd. 30pp. [Available from the author].
Whitehead, H., Payne, R. and Payne, M. 1986. Population estimate for the right whales off Peninsula Valdes, Argentina, 1971-1976. Rep. int. Whal. Commn (special issue) 10:169-71.

\section{Appendix 1}

\section{MEMBERS OF THE NORTH ATLANTIC RIGHT WHALE CONSORTIUM}

\section{National Government Agencies}

Canada

Department of Oceans and Fisheries

Ministry of Transport

Canadian Coastguard

USA

National Marine Fisheries Service

US Coastguard

US Navy

US Army Corps of Engineers

US Environmental Protection Agency

\section{US State Agencies}

Florida

Department of Marine Resources
Georgia

Department of Natural Resources

Massachusetts

Division of Marine Fisheries

Maine

Department of Marine Resources

\section{Private Institutions}

New England Aquarium

Centre for Coastal Studies

Woods Hole Oceanographic Institution

University of Rhode Island

McMaster University 


\section{Annex L \\ Summary of Available Catch Data for Southern Right Whales}

Table 1

South Atlantic right whale catches, by decade and area. For explanation of what is missing, redundant etc. see text. Square brackets denote that the indicated catch is subsumed within an estimate given in another column.

\begin{tabular}{|c|c|c|c|c|c|c|c|c|c|c|c|c|c|c|}
\hline \multirow[b]{2}{*}{ Period } & \multirow{2}{*}{\multicolumn{2}{|c|}{$\begin{array}{c}\text { S. African } \\
\text { shore (inc. } \\
\text { Natal) }\end{array}$}} & \multirow{2}{*}{$\begin{array}{l}\text { Brazil } \\
\text { shore }^{2}\end{array}$} & \multirow{2}{*}{$\begin{array}{l}\text { Brazil } \\
\text { shore }^{3}\end{array}$} & \multirow{2}{*}{$\begin{array}{c}\text { Total pelagic } \\
\text { Brazil/ } \\
\text { Falkands }\end{array}$} & \multirow{2}{*}{$\begin{array}{c}\text { French pelagic } \\
\text { Brazil/ } \\
\text { Falkands }^{5}\end{array}$} & \multirow{2}{*}{$\begin{array}{l}\text { US pelagic } \\
\text { S. Atlantic }\end{array}$} & \multirow{2}{*}{$\begin{array}{l}\text { S. Africa bay } \\
\text { whaling }{ }^{7 * *}\end{array}$} & \multirow{2}{*}{$\begin{array}{l}\text { French } \\
\text { pelagic }^{8}\end{array}$} & \multirow{2}{*}{$\begin{array}{c}\text { French } \\
\text { pelagic } \\
\text { unspecified }^{9}\end{array}$} & \multirow{2}{*}{$\begin{array}{c}\text { Modern } \\
(\text { S. Georgia } \\
\text { S. Shetlands) }{ }^{10}\end{array}$} & \multicolumn{2}{|c|}{$\begin{array}{l}\text { Illegal } \\
\text { Soviet }\end{array}$} & \multirow{2}{*}{$\begin{array}{l}\text { Modern } \\
\text { - German } \\
\text { pelagic }^{12}\end{array}$} \\
\hline & & & & & & & & & & & & SW & $\mathrm{SE}$ & \\
\hline $1770-9$ & - & - & 7,450 & - & 747 & - & - & - & - & - & - & - & - & - \\
\hline $1780-9$ & - & - & 4,700 & - & 3,690 & [205] & - & $\begin{array}{c}c a 600 / \text { season } \\
(1785-1805)\end{array}$ & - & - & - & - & - & - \\
\hline $1790-9$ & 128 & - & 1,950 & - & 4,329 & [238] & - & - & - & 360 & - & - & - & - \\
\hline $1800-9$ & 266 & - & 650 & - & 5,396 & [0] & {$[1,849]$} & - & - & - & - & - & - & - \\
\hline $1810-9$ & 378 & - & 154 & - & 504 & [119] & [149] & - & - & 11 & - & - & - & - \\
\hline $1820-9$ & 304 & - & - & - & - & 1,064 & 8,085 & - & - & 204 & - & - & - & - \\
\hline $1830-9$ & 270 & - & - & - & - & 743 & 14,564 & - & 382 & 49 & - & - & - & - \\
\hline $1840-9$ & 64 & - & - & - & - & - & 1,113 & - & - & - & - & - & - & - \\
\hline $1850-9$ & 49 & - & - & - & - & - & 940 & - & - & - & - & - & - & - \\
\hline $1860-9$ & 24 & - & - & - & - & - & 860 & - & - & - & - & - & - & - \\
\hline $1870-9$ & 16 & - & - & - & - & - & 481 & - & - & - & - & - & - & - \\
\hline $1880-9$ & 16 & - & - & - & - & - & 329 & - & - & - & - & - & - & - \\
\hline $1890-9$ & 41 & - & - & - & - & - & 67 & - & - & - & - & - & - & - \\
\hline $1900-9$ & 23 & $7-8$ & - & - & - & - & 67 & - & - & - & 258 & - & - & - \\
\hline $1910-9$ & 1 & 39 & - & - & - & - & 18 & - & - & - & 390 & - & - & - \\
\hline $1920-9$ & - & 39 & - & - & - & - & - & - & - & - & - & - & - & - \\
\hline $1930-9$ & - & 15 & - & - & - & - & - & - & - & - & - & - & - & 1 \\
\hline $1940-9$ & - & - & - & - & - & - & - & - & - & - & - & - & - & - \\
\hline $1950-9$ & - & 4 & - & 150 & - & - & - & - & - & - & - & - & - & 1 \\
\hline $1960-9$ & - & 1 & - & 150 & - & - & - & - & - & - & - & 1,408 & 767 & - \\
\hline $1970-9$ & - & - & - & 60 & - & - & - & - & - & - & - & - & - & - \\
\hline
\end{tabular}

* Estimates in this column include an adjustment for hunting loss (x1.2).** Walvis Bay, Delagoa Bay; i.e. includes some Indian Ocean catches. ${ }^{1}$ Best and Ross (1986). ${ }^{2}$ Richards (1993). ${ }^{3}$ Palazzo and Carter (1983; see IWC 1986, p.29). ${ }^{4}$ Richards (1993). ${ }^{5}$ Du Pasquier (1986 p. 30). ${ }^{6}$ Best (1987). ${ }^{7}$ Richards and Du Pasquier (1989). ${ }^{8}$ Tristan da Cunha, Du Pasquier (1986). ${ }^{9}$ Du Pasquier (1986). ${ }^{10}$ Tønnessen and Johnsen (1982). ${ }^{11}$ Tormosov et al. (1998) 233 in 1951/52-1959/60 and 237 in 1960/61-1970/71, some proportion of which would have been taken in this ocean. ${ }^{12}$ Kock (1996); Barthelmess et al. (1997).

Table 2

South Pacific.

\begin{tabular}{|c|c|c|c|c|c|c|}
\hline Period & Coast of Chile ${ }^{1}$ & $\begin{array}{c}\text { Early shore and bay } \\
\text { whaling, S. Australia, } \\
\text { NSW, Tasmania, Victoria }\end{array}$ & $\begin{array}{l}\text { 19th century US } \\
\text { pelagic }^{5}\end{array}$ & NZ bays ${ }^{6}$ & $\begin{array}{c}\text { French whaling } \\
\text { NZ/Australia }\end{array}$ & $\begin{array}{c}\text { Illegal Soviet SW } \\
\text { Pacific }^{10}\end{array}$ \\
\hline $1815-9$ & 31 & - & 1,958 & - & - & - \\
\hline $1820-9$ & 69 & 323 & 535 & - & - & - \\
\hline $1830-9$ & 2,211 & 6,777 & 5,580 & 2,237 & 2,723 & - \\
\hline $1840-9$ & 70 & 3,089 & 5,027 & 2,394 & 1,148 & - \\
\hline $1850-9$ & - & 431 & 740 & 347 & - & - \\
\hline $1860-9$ & - & 232 & 385 & 100 & - & - \\
\hline $1870-9$ & - & $62^{3}$ & 109 & $62^{7}$ & - & - \\
\hline $1880-9$ & - & $62^{3}$ & 308 & $62^{7}$ & - & - \\
\hline $1890-9$ & - & $62^{3}$ & - & $62^{7}$ & - & - \\
\hline $1900-9$ & 118 & $3^{4}$ & 10 & $30^{8}$ & - & - \\
\hline $1910-9$ & 191 & $2^{4}$ & - & $30^{8}$ & - & - \\
\hline $1920-9$ & 33 & $2^{4}$ & - & $30^{8}$ & - & - \\
\hline $1930-9$ & 104 & - & - & 3 & - & - \\
\hline 1940-9 & 1 & - & - & 1 & - & - \\
\hline $1950-9$ & 7 & - & - & 2 & - & - \\
\hline $1960-9$ & 4 & - & - & - & - & 372 \\
\hline $1970-9$ & 0 & - & - & - & - & - \\
\hline
\end{tabular}

${ }^{1}$ Includes French pelagic (Du Pasquier, 1986, as summarised in IWC, 1986, p.30) for $19^{\text {th }}$ century, Tønnessen and Johnsen (1982) for 1900-20 and IWC (1986, p.30) for 1920 onwards. ${ }^{2}$ Dawbin (1986). ${ }^{3}$ Dawbin (1986) lists a total catch of 185 for 1870-1900. ${ }^{4}$ Dawbin (1986) lists a total catch of 7 for 1901-30. ${ }^{5}$ Best (1987). ${ }^{6}$ Dawbin (1986), IWC (1986, p.30); including catches in New Zealand by whalers from NSW or Tasmania, and also Campbell Island catches. ${ }^{7}$ Dawbin (1986) lists a total catch of 186 for $1870-1900 .{ }^{8}$ Dawbin (1986) lists a total catch of 89 for 1901-30. ${ }^{9}$ Du Pasquier (1986). ${ }^{10}$ Tormosov et al. (1998). 
Table 3

Indian Ocean.

\begin{tabular}{|c|c|c|c|c|c|}
\hline \multirow[b]{2}{*}{ Period } & \multirow[b]{2}{*}{ Best (1987) } & \multirow{2}{*}{$\begin{array}{l}\text { W. Australia } \\
\text { bay whaling }^{1}\end{array}$} & \multirow[b]{2}{*}{ Kerguelen $^{2}$} & \multicolumn{2}{|c|}{ Illegal Soviet whaling ${ }^{3}$} \\
\hline & & & & Crozet (SW) & Other $^{4}$ \\
\hline $1830-9$ & 6,161 & 50 & - & - & - \\
\hline $1840-9$ & 4,360 & 121 & - & - & - \\
\hline $1850-9$ & 1,276 & 84 & - & - & - \\
\hline $1860-9$ & 438 & 11 & - & - & - \\
\hline $1870-9$ & 69 & - & - & - & - \\
\hline $1880-9$ & 9 & - & - & - & - \\
\hline $1890-9$ & 26 & - & - & - & - \\
\hline $1900-9$ & 154 & - & 1 & - & - \\
\hline $1910-9$ & - & - & - & - & - \\
\hline $1920-9$ & - & - & - & - & - \\
\hline $1930-9$ & - & - & - & - & - \\
\hline $1940-9$ & - & - & - & - & - \\
\hline $1950-9$ & - & - & - & - & - \\
\hline $1960-9$ & - & - & - & 309 & 25 \\
\hline $1970-9$ & - & - & - & - & - \\
\hline
\end{tabular}

(1998). ${ }^{4}$ Other areas of Indian Ocean and adjacent Antarctic.

\section{REFERENCES}

Bannister, J.L. 1986. Notes on nineteenth century catches of southern right whales (Eubalaena australis) off the southern coasts of Western Australia. Rep. int. Whal. Commn (special issue) 10:255-9.

Barthelmess, K., Kock, K.-H. and Reupke, E. 1997. Validation of catch data of the Olympic Challenger's whaling operations from 1950/51 to $1955 / 56$. Rep. int. Whal. Commn 47:937-40.
Best, P.B. 1987. Estimates of the landed catch of right (and other whalebone) whales in the American fishery, 1805-1909. Fish. Bull. 85(3):403-18.

Best, P.B. and Ross, G.J.B. 1986. Catches of right whales from shore-based establishments in southern Africa, 1792-1975. Rep. int. Whal. Commn (special issue) 10:275-89.

Dawbin, W.H. 1986. Right whales caught in waters around south eastern Australia and New Zealand during the nineteenth and early twentieth centuries. Rep. int. Whal. Commn (special issue) 10:261-7.

Du Pasquier, T. 1986. Catch history of French right whaling mainly in the South Atlantic. Rep. int. Whal. Commn (special issue) 10:269-74

International Whaling Commission. 1986. Report of the Workshop on the Status of Right Whales, Appendix 7. Historical catches of right whales by area. Rep. int. Whal. Commn (special issue) 10:27-30.

Kock, K.-H. 1996. Validation of catch data from German whaling in the Southern Ocean before World War II. Rep. int. Whal. Commn 46:649-51.

Palazzo, J.T., Jr. and Carter, L.A. 1983. A caça de baleias no Brasil. AGAPAN, Porto Alegre, 25pp. [In Portuguese].

Richards, R. 1993. Into the South Seas: The Southern Whale Fishery Comes of Age on the Brazil Banks 1765 to 1812. The Paramatta Press, Wellington. 128pp.

Richards, R. and du Pasquier, T. 1989. Bay whaling off southern Africa, c. 1785-1805. S. Afr. J. mar. Sci. 8:231-50.

Tønnessen, J.N. and Johnsen, A.O. 1982. The History of Modern Whaling. C. Hurst \& Co., London. i-XX+798pp.

Tormosov, D.D., Mikhalev, Y.A., Best, P.B., Zemsky, V.A., Sekiguchi, K. and Brownell Jr, R.L. 1998. Soviet catches of southern right whales, Eubalaena australis, 1951-1971; biological data and conservation implications. Biol. Conserv. 86(2):185-97. 